\title{
Quartz Dissolution and Silica Deposition in Hot-Dry-Rock Geothermal Systems
}

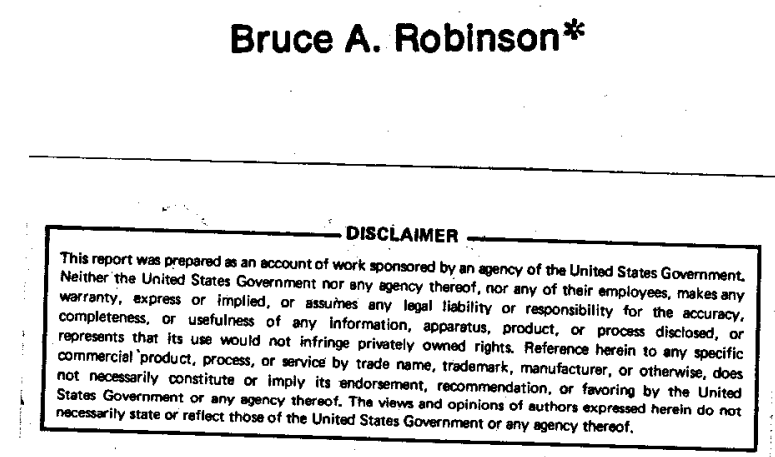

-Graduate Research Assistant. Massachusetts Institute of Technology, Department of Chemical Engineering, Cambridge, MA 02139.

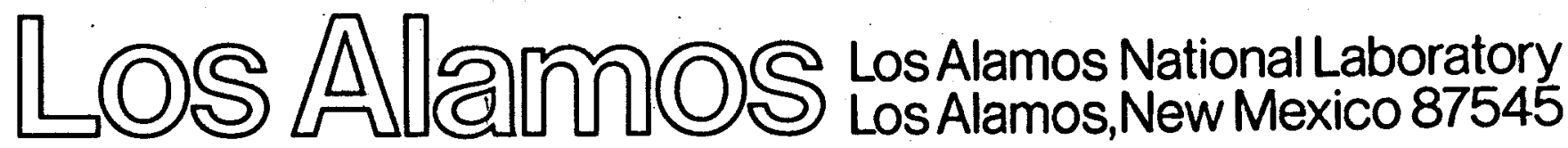




\section{DISCLAIMER}

This report was prepared as an account of work sponsored by an agency of the United States Government. Neither the United States Government nor any agency Thereof, nor any of their employees, makes any warranty, express or implied, or assumes any legal liability or responsibility for the accuracy, completeness, or usefulness of any information, apparatus, product, or process disclosed, or represents that its use would not infringe privately owned rights. Reference herein to any specific commercial product, process, or service by trade name, trademark, manufacturer, or otherwise does not necessarily constitute or imply its endorsement, recommendation, or favoring by the United States Government or any agency thereof. The views and opinions of authors expressed herein do not necessarily state or reflect those of the United States Government or any agency thereof. 


\section{DISCLAIMER}

Portions of this document may be illegible in electronic image products. Images are produced from the best available original document. 


\section{Table of Contents}

Abstract.................................................vi

Chapter 1. Introduction and Scope...............................

Chapter 2. Quartz-Water Dissolution Kinetics: A Review of Previous Work..............................................5

2.1 Introduction.............................................

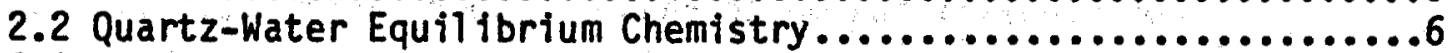

2.3 Kinetics of Quartz Dissolution in Water......................

2.4 Experimental Considerations.............................11

Chapter 3. Quartz Dissol ution Experiments..........................19

3.1 Introduction...........................................19

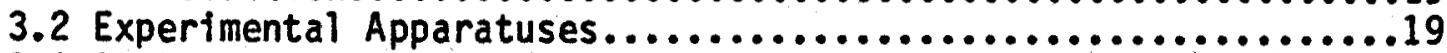

3.3 Analytical Techniques..................................22

3.4 Damaged Surface Layer Dissol ution.......................24

3.5 Experimental Results.....................................28

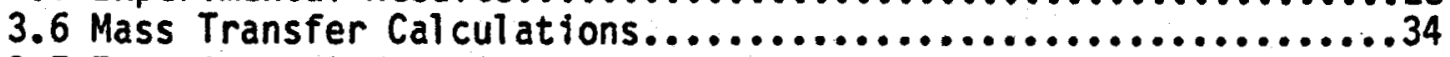

3.7 Experimental Verification of Mass Transfer Calculations.......37

3.8 Granite Dissolution Experiments.......................43

Chapter 4. Hot Dry Rock Geothermal Reservoir Computer Model ...........50

4.1 Introduction...........................................50

4.2 The Fenton Hi11 HDR Geothermal Reservoirs.................. 51

4.3 HDR Reservoir Model ...................................... 53

4.4 Phase I Computer Simul ations................................61

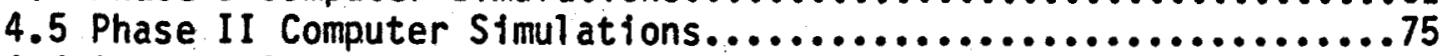

4.6 Another Application of the Model: Chemically Reactive

Tracers................................................78

Chapter 5. Silica Deposition In Geothermal Systems.................81

5.1 Introduction.......................................81

5.2 Sil tca Polymerization Laboratory Studies..................84

5.3 Experimental Heat Exchanger Studies.....................88

5.4 Sil ica Scal ing Fiel d Studies..............................90

5.5 Silica Deposition in the Fenton. Hill Phase II System.........93

5.6 Experimental Apparatus For Silica Scaling Studies............96

Appendix A. Explanation of the Calculations Required to Obtain Quartz Dissolution Rate Constants From the Literature Data......101

Appendix B. Quartz Dissol ution Concentration Versus Time Data.......104

Appendix C. Sample Calculation For Stirred Autoclave Run A14........108

Appendix 0 . Calculation of the Mass Transfer Coefficient in the Stirred Autoclave Reactor..........................113 
Appendix E. Calculation of the Minimum Rotation Speed for Complete Particle Suspension.................................115

Appendix F. Calculation of the Time Required to Dissolve the Damaged Silica in a HDR Reservoir............................117

Appendix G. Analytical Solution For Reservoir Temperature Field......119

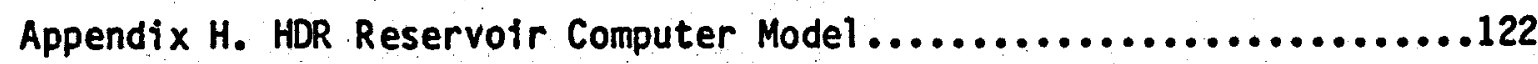

Appendix I. Calculation of the Rate of Homogeneous Nucleation of Colloidal Silica Under Phase II Conditions..............127

Appendix J. Calculation of the Mass Transfer Coefficient in the Rock Reactor.........................................130

Acknowledgements...................................... 134

Bibliography........................................ 135 


\section{Abstract}

The kinetics of quartz dissolution control the produced fluid dissolved silica concentration in geothermal systems in which the downtiole residence time is finite. The produced fluid of the Phase $I$, Run Segment 5 experimental Hot Dry Rock (HDR) geothermal system at Fenton Hill, N.M. was undersaturated with respect to quartz in one pass through the reservoir, suggesting that the rate of granite dissolution governed the outlet dissolved silica concentration in this system. . The literature data for the rate of quartz dissolution in water from $65-625^{\circ} \mathrm{C}$ is correlated using an empirical rate law which is first order in quartz surface area and degree of undersaturation of the fluid. The Arrhenius plot ( $1 n k$ vs. $T^{-1}$ ) is linear over ei ght orders of magnitude of the rate constant, verifying the validity of the proposed rate expression. Carefully performed quartz dissolution experiments in the present study duplicated the lijterature data and completed the data base in the temperature range from $150-250^{\circ} \mathrm{C}$. I dentical experiments using crushed granite indicate that the rate of quartz dissolution in the presence of granite could be as much as 1-2 orders of magnitude faster than the rates observed in the pure quartz experiments.

A temperature dependent HDR reservoir model incorporates the quartz dissolution rate law to simulate the dissolved silica behavior during the Fenton Hill Run Segment 5 experiment. For this low-permeability, fracture-dominated reservoir, the assumptions of one-dimensional plug flow through a vertically-inclined rectangular fracture and onedimensional rock heat conduction perpendicular to the direction of flow are employed. These simplifications lead to an analytical solution for the temperature field in the reservoir. A computer code couples the temperature solution to the quartz dissolution rate law to predict the 
dissolved silica concentration in the fluid as a function of position in the fracture. The computer simulations demonstrate that the rate constant for pure quartz dissolution is much too low to explain the Run Segment 5 dissolved silica field data, and that the more rapid kinetics of granite dissolution govern the produced fluid dissolved silica concentration. When applied to a commercial sized reservoir $\left(1-2 \mathrm{~km}^{2}\right.$ and initial rock temperature of $300^{\circ} \mathrm{C}$ ), the model predicts that the fluid will reach saturation with respect to quartz in less than one pass through the system. The model also suggests that a chemically reactive tracer with finite kinetics in the temperature range encountered in HDR geothermal systems could be a valuable tool for estimating the heat transfer surface areas of these systems.

Using the model prediction of dissolved silica equilibrium with respect to quartz for commercial sized systems, the extent of silica precipitation in a larger, hotter system presently being developed at Fenton Hill (Phase II) is assassed by examining the literature studies on silica deposition from supersaturated solutions. Bench scale experiments of silica scaling in heat exchangers suggest that a significant but not unmanageable amount of silica scale may be expected in the Fenton Hill system under Phase II conditions. Silica polymerization studies and geothermal field experience demonstrate that colloidal silica deposition in the injection wellbore and reservoir are also possible. An experimental apparatus designed to study these potential problems is presently being built. 


\section{Quartz Dissolution and Silfica Deposition \\ in Hot Dry Rock Geothermal Systems}

by

Bruce A. Robinson

\section{Chapter 1}

\section{Introduction and Scope}

The behavior of dissolved silica in hot dry rock (HDR) geothermal energy systems is one important geochemical consideration which must be understood more thoroughly before the HDR concept attains commerctal feasibility. Silica scaling, a well known problem in geothermal systems, comes about when the fluid reaches supersaturation with respect to amorphous silica, as it often does during heat extraction or partial flashing. In order to assess the likel ihood of stlifa scaling in a geothermal plant, nucleation and silica deposition rates must be determined. These rates in turn depend on fluid temperature, silica concentration, $\mathrm{pH}$, and the concentration of other dissolved components. While the results of the present study can be applied to the entire geothermal energy field, the goal of the research was to examine specifically the phenomena of silica dissolution and deposition in HDR geothermal energy systems.

Under normal operating conditions of an experimental HDR reservoir at Fenton Hill, New Mexico, the geochemical ffeld data exhibited dissolved silica behavior unl ike that encountered in most hydrothermal systems. For this low permeability reservoir, flow paths are created by artificial fracturing. Heat is then extracted by circulating water 
major initial component of this investigation (see Chapters 2 and 3 ).

A rate law for quartz dissolution had previously been suggested and tested experimentally by several investigators. Their work is presented in Chapter 2. Because certain experimental uncertainties in these studies were not addressed in sufficient detail, independent quartz dissolution experiments were performed to verify the accuracy of the previous work. Good agreement was found between the quartz dissolution experiments of this study and the data of other experimenters, assuring the accuracy of the first order rate law for quartz dissolution (Equation 2.3.1)). An attempt was made to prove that the kinetics of quartz dissolution in granite can be assumed to be unaffected by the presence of other solid mineral phases. However, the experimental results showed much higher rates of dissolution for granite than for quartz. Other experimental evidence suggests that these runs had exhibited anomalous behavior not encountered in the pure quartz dissolution trials. More importantly, it is shown that the rapid rates observed for granite dissolution appear to control the actual rate of dissolution in the reservoir. The kinetic rate constant found for pure quartz dissolution cannot be used to calculate quartz dissolution rates in the Fenton $\mathrm{Hill}$ reservoir.

Chapter 4 uses the experimentally determined granite dissolution rate law in a model which predicts the concentration of dissolved silica in the geothermal fluid. This model assumes one-dimensional rock heat conduction and plug flow of fluid within a rectangular fracture and allows for the superposition of mass and heat transfer effects. An analytical solution specifies the temperature field in the reservoir at a particular time during a field test as a prerequisite to the numerical calculation of the silica concentration in the fluid. An accurate representation of the temperature field is essential because of the 
strong temperature dependence of the rate constant and equilibrium solubility of quartz. The concentration is then calculated at each point in the fracture, including the outlet, which is obviously the only position for which experimental field data exists. Using the granite dissolution kinetics, the model roughly simulates the dissolved silica and thermal drawdown data observed during a 286 day heat extraction test of the Fenton Hill reservoir (Phase I, Run Segment 5). Assuming that the same dissolution rate law and heat transfer analysis are valid, the outlet silica concentration for a hotter $\left(250-325^{\circ} \mathrm{C}\right)$, larger reservoir $\left(1-2 \times 10^{6} \mathrm{~m}^{2}\right)$ planned for Fenton Hill (Phase II) is calculated. Because of the higher temperatures, the kinetics are fast enough that the fluid will reach equilibrium with respect to quartz in one pass through the reservoir system.

An added benefit of the model which goes beyond merely predicting dissolved silica concentrations is that it demonstrates that chemically reactive tracers could be used to estimate the size of a HDR reservoir. If a reaction with finite kinetics is carried out in the geothermal fluid, then the reservoir temperature field could be determined on the basis of the extent of reaction, without having to wait for the temperature of the produced fluid to decline. In the Phase I system, the quartz dissolution reaction happened to have kinetics such that a surface area determination could be made. To analyze the Phase II reservoir, a synthetic reaction must be chosen with kinetics such that the extent of reaction at those higher temperatures is sensitive to the size of the reservoir. The computer modeling in Chapter 4 demonstrates the viability of the concept of chemically reactive tracers, and will aid in the selection of a reaction with the proper kinetics.

In the short-term, however, the most important result obtained from the computer modeling is its prediction of the outlet fluid silica 
accurate surface area determination could be made. To analyze the Phase II reservoir, a synthetic reaction must be chosen with kinetics such that the extent of reaction at those higher temperatures is sensitive to the size of the reservoir. The computer modeling in Chapter 4 demonstrates the viability of the concept of chemically reactive tracers, and will aid in the selection of a reaction with the proper kinetics.

In the short-term, however, the most important result obtained from the computer model ing is its prediction of the outlet fluid silica concentration in the Phase II system. Now that it has been shown that the fluid will reach chemical equilibrium with quartz very quickly, the possible problem of silica scaling may be more efficiently addressed. No silica deposition was observed in Phase I, but the hotter reservoir expected in Phase II will result in higher dissol ved silica concentrations (600 ppm versus 250 ppm during Phase I), making silica scaling much more likely. Chapter 5 examines the literature data available on silica polymerization kinetics, the rate of silica scaling in heat exchangers, and the field experience of geothermal plant operation. These studies are used to assess the likel ihood of silica scaling in the Fenton Hill Phase II system. 


\section{Chapter 2}

Quartz-Water Dissolution Kinetics: A Review of Previous Work

\subsection{Introduction}

The dissolution of quartz in water has been studied extensively because of its importance in understanding the geochemical behavior of rock-water systems. Fournier and Rowe (1966) showed that the quartz geothermometer could be used to estimate the underground temperature of a geothermal aquifer. By measuring the concentration of dissolved silica in the groundwater above an aquifer, the underground temperature is obtained by assuming that the fluid reaches equilibrium with the quartz and that none of the dissolved silica reprecipitates during its path to the surface. This temperature is estimated from the quartz-water equilibrium solubility curve. As a result of many investigations of the silica-water system, accurate equilibrium solubil ity data exist over the temperature range of interest for geothermal systems $\left(25-325^{\circ} \mathrm{C}\right)$.

Somewhat less has been accomplished in the area of quartz dissolution kinetics. In some geochemical systems the rate of dissolution is essential in determining chemical behavior. Any system which provides an insufficient residence time for the dissolution to proceed to equilibrium falls into this category. As will be shown for the HDR case, the dynamics of flow and heat transfer within the reservoir must be considered to correctly predict the dissolved silica concentration in the fluid.

The main purpose of this chapter is to establish the validity of the most commonly suggested first order rate 1 aw for quartz dissolution and 
to obtain its kinetic parameters. A literature search was performed and the data compiled using the proposed rate law. Later, Chapter 3 will describe independent experiments which were performed to reproduce these results. Special care was taken to el iminate two possible areas of uncertainty in previous studies, namely, mass transfer limitations and the existence of a rapidly dissolving damaged surface layer on the quartz samples.

\subsection{Quartz-Water Equil ibrium Chemistry}

The dissolution of quartz and other solid silica phases $\left(\mathrm{SiO}_{2}\right)$ in water is a subject which has been studied extensively because of its importance in characterizing many geochemical systems (Kennedy, 1950, Kitahara, 1960, Morey et al., 1962, Siever, 1962, Crerar and Anderson, 1971, Mackenzie and Gees, 1971, Voloson et al., 1972). It is widely accepted that the silica-water reaction is a simple surface reaction to form silicic acid monomer:

$$
\mathrm{SiO}_{2(\mathrm{~s})}+2 \mathrm{H}_{2} \mathrm{O}=\mathrm{Si}_{(\mathrm{OH})_{4(\mathrm{aq})}} \text {. }
$$

The product, hereafter called silicic acid or dissolved silica, is a weak acid of $\mathrm{pK}_{\mathrm{A}}=9.8$ (Iler, 1979), which remains essentially undissociated in the $\mathrm{pH}$ range commonly of interest for geothermal systems.

Figure 1 is a plot of the equilibrium solubility of different solid silica phases as a function of temperature, taken from the data compiled by Rimstidt (1979). Table 1 shows his best fits of the solubility literature data obtained from the investigations cited above. 
Table 1. Equilibrium Solubility of Solid Silica in Water Correlations obtained from the thesis of Rimstidt (1979).

\begin{tabular}{l|c|c|c}
\multicolumn{5}{c}{$\mathrm{SiO}_{2(\mathrm{~s})}+2 \mathrm{H}_{2} \mathrm{O}=\mathrm{Si}(\mathrm{OH})_{4(\mathrm{aq})}$} \\
\multicolumn{1}{c|}{$\log _{10} \mathrm{~K}=\mathrm{a}+\mathrm{bT}+\mathrm{c} / \mathrm{T}(\mathrm{T}$ in $\mathrm{K})$} \\
\hline Quartica Phase & $\mathrm{a}$ & $\mathrm{b}$ & $\mathrm{c}$ \\
\hline Q-Cristobalite & 1.881 & $2.028 \times 10^{-3}$ & -1560.0 \\
B-Cristobalite & -0.032 & - & -988.2 \\
Amorphous Silica & -0.256 & - & -793.6 \\
& 0.338 & $-7.889 \times 10^{-4}$ & -840.1
\end{tabular}

The form of the equation used is justified on the basis of elementary thermodynamic considerations. To convert from an equilibrium constant to solubility, the assumption of ideal solution behavior is employed. Since quartz is thermodynamically the most stable phase, its solubility at any given temperature is lower than that of the other solid phases. When the subject of silica scaling in heat exchangers is discussed in Chapter 5 , the amorphous silica solubility curve will also be important, since it has been observed empirically that supersaturated silicic acid deposits on surfaces as amorphous silica.

The equilibrium solubility curves shown in Figure 1 are for the dissolution to silicic acid monomer, $\mathrm{Si}(\mathrm{OH})_{4}$. However, under certain conditions of concentration, temperature, and $\mathrm{pH}$, polymerization reactions take place which yield the silicic acid dimer, trimer, and longer chained polymers. This polymerization reaction is important in the silica scaling process described more fully in Chapter 5 .

\subsection{Kinetics of Quartz Dissolution in Water}

The kinetics of quartz dissolution in water has been studied by 


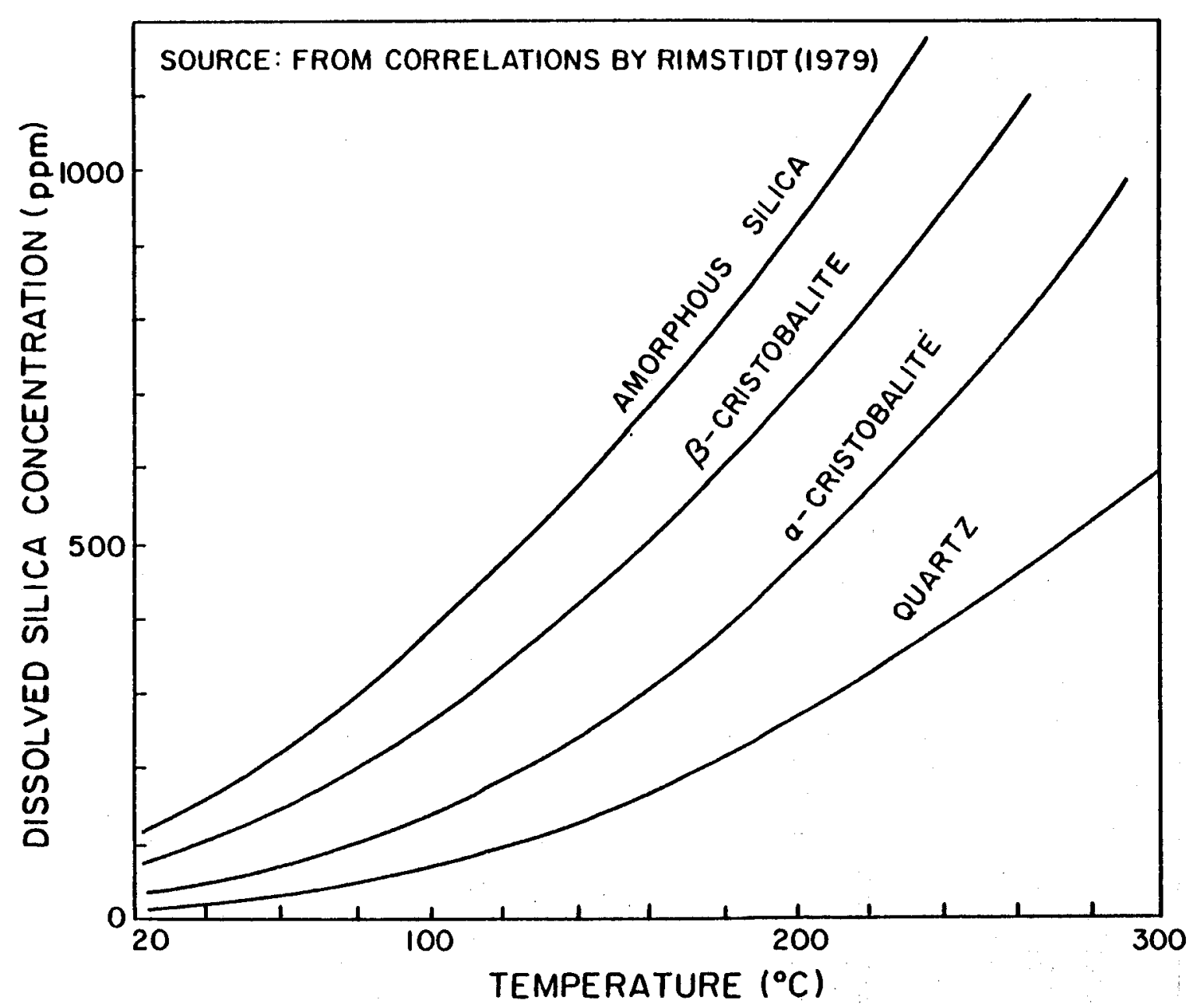

Finure 1. Eauilibrium Solubilities of Solid Silica (see Table 1 for Empirical Correlations) 
several investigators (Briscoe et al., 1937, Kitahara, 1960, Van Lier et al., 1960, Siebert et al., 1962, Weill and Fyfe, 1964, Stober, 1966, and Rimstidt, 1979). It is generally accepted that in a closed vessel the rate obeys the following relation:

$$
\frac{d C}{d t}=k a^{*}\left(C^{\infty}-C\right) \text {. }
$$

where

$\mathrm{C}=$ concentration of silicic acid (ppm)

$\mathrm{t}=$ time (sec)

$k=k$ inetic rate constant for dissolution $(\mathrm{m} / \mathrm{sec})$

$a^{*}=S / V=$ ratio of quartz surface area to fluid voume $\left(\mathrm{m}^{-1}\right)$

$\mathrm{C}^{\infty}=$ equil ibrium concentration of dissol ved silica (ppm).

This rate law is empirical, but the assumption of a first order dependence of rate on surface area and degree of undersaturation of the fluid are reasonable. Rimstidt (1979) attempts to derive this equation from absolute rate theory, which uses the law of microreversibility as its basis. However, since it is questionable whether the law of microreversibility applies to this solid-fluid reaction, it is best to consider the rate law to be at least semi-empirical.

Figure 2 is a diagram of the concentration butldup in a closed system governed by Equation (2.3.1). For a constant temperature, constant volume experiment, integration of Equation (2.3.1) yields

$$
\ln \phi=-k a^{*} t \text {, }
$$

where

$$
\begin{aligned}
& \Phi=\left(C^{\infty}-C\right) /\left(C^{\infty}-C_{0}\right) \\
& C_{0}=\text { initial concentration of silica (ppm). }
\end{aligned}
$$

Equation 2.3.2 suggests that a plot of $\ln _{\Phi}$ vs. $t$ will result in a straight line of slope $-k^{*}$, from which the rate constant may be evaluated (see Figure 3).

Alternatively, Equation (2.3.1) may be used directly by considering only the initial rate data. At $t=0$, 


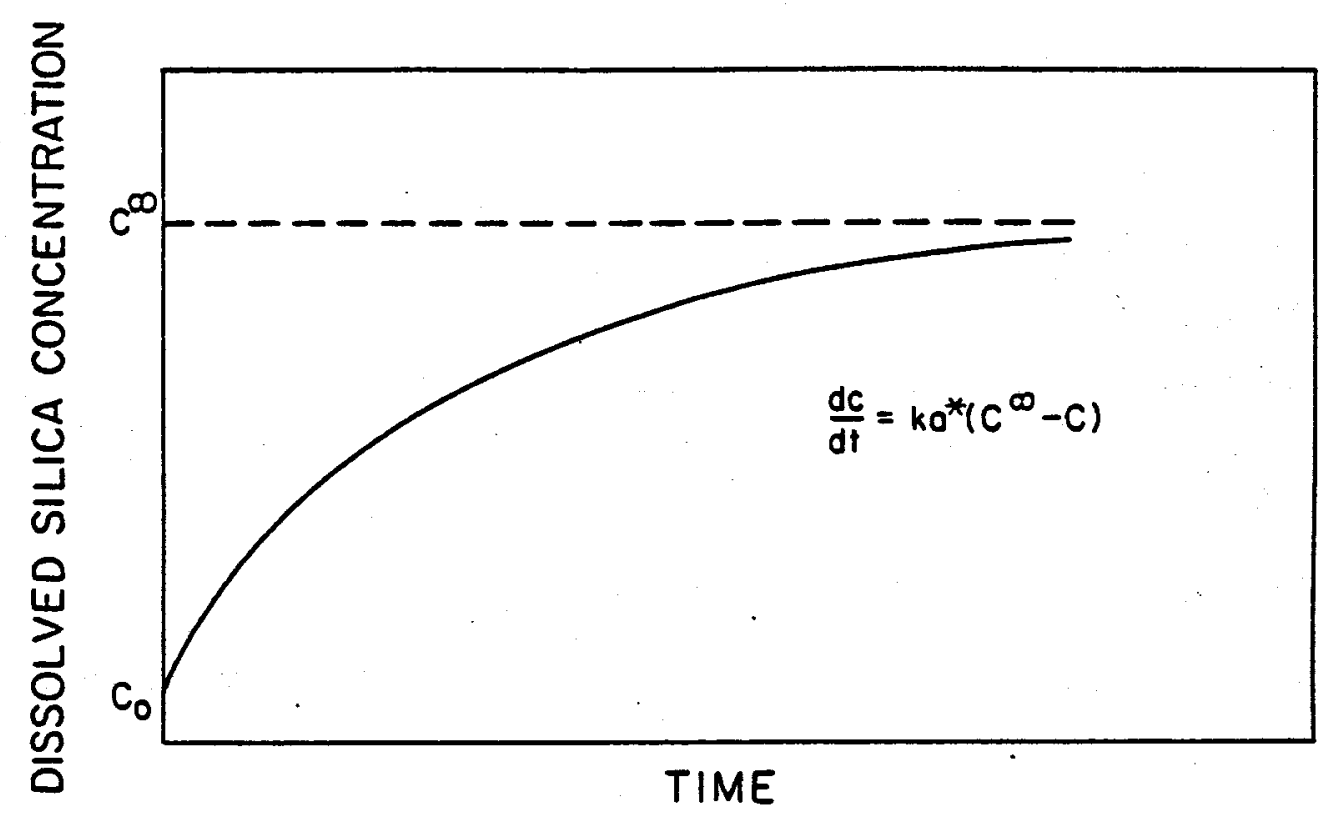

Finure 2. nuartz Dissolution Concentration vs. Time Response

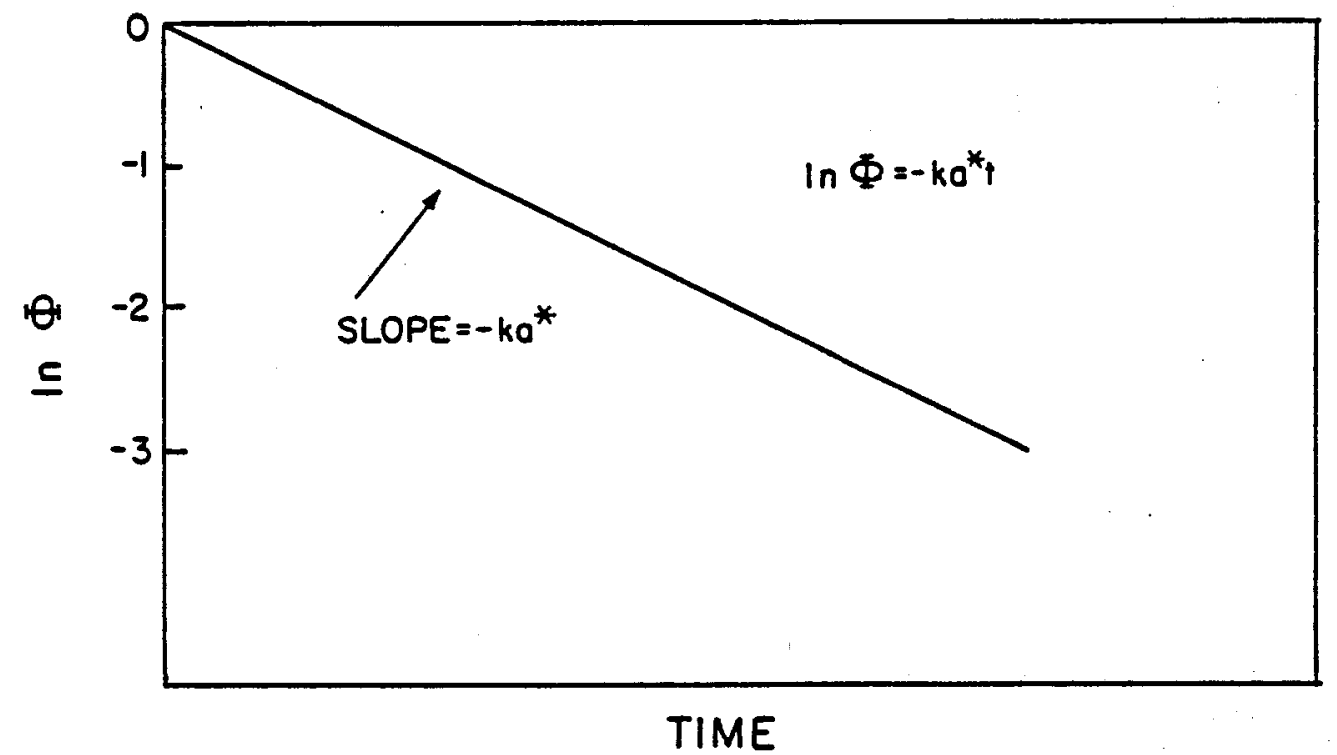

Fiqure 3. nuartz Dissolution In $\Phi$ vs. Time Response 


$$
\left.\frac{d C}{d t}\right)_{t=0}=k a^{*}\left(C^{\infty}-C_{0}\right)
$$

Thus, the initial slope of a concentration versus time plot may be used to evaluate the rate constant, as shown in Figure 4.

The literature data for the dissolution of quartz in water are compiled using the rate 1 aw of Equation (2.3.1) and tabulated in Table 2. An Arrhenius plot $\left(1 n k\right.$ vs. $\left.T^{-1}\right)$ for this data is shown in Figure 5 . Appendix $A$ outlines the method used to obtain the rate constants for each set of literature data. The observed linear behavior over eight orders of magnitude of variation in $k$ unequivocally supports the emptrical form of the rate law. One surprising feature of this plot is that it retains its linearity up to $650^{\circ} \mathrm{C}$, well above the critical point of water $\left(374^{\circ} \mathrm{C}\right)$. Since the equilibrium solubility of quartz at the vapor pressure of water levels off and declines with increasing temperature near the critical point (Kennedy, 1950), it might have been suspected that the rate 1 aw would no longer be appropriate in this temperature range.

\subsection{Experimental Considerations}

There are several experimental factors to consider when performing quartz dissolution experiments. Among these are the measurement of dissolved silica concentrations, estimation of the active quartz surface area, rapid dissolution of the damaged surface layer normally found on crushed quartz samples, and the possibtlity of mass transfer 1 imitations.

The method most often used for determining the concentration of silicic acid in solution is the molybdate yellow colorimetric technique described by Alexander et al. (1954). Siltcic acid monomer and dimer 


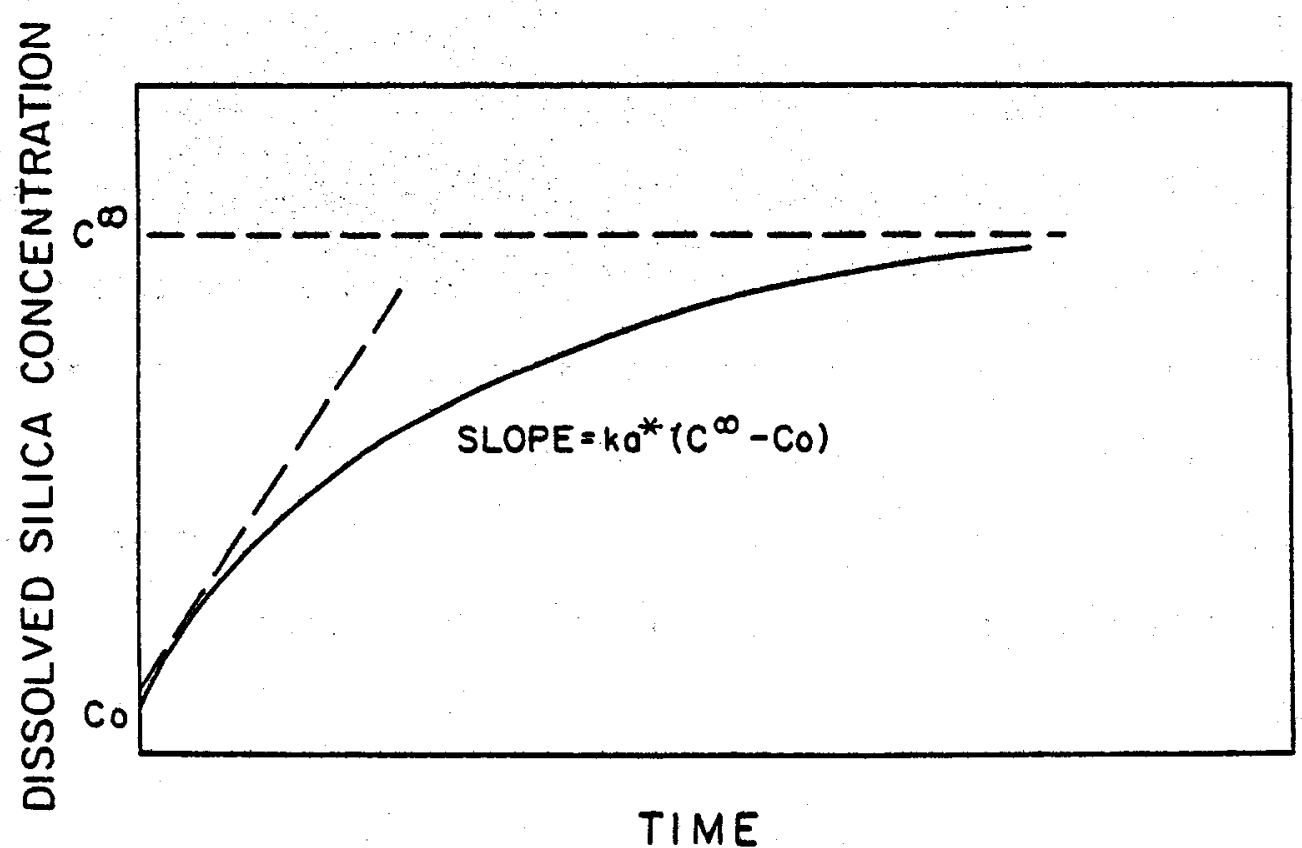

Figure 4. Ouartz Dissolution Initial Rate Response 
Table 2. Dissolution Rate Constant Literature Data

\begin{tabular}{|c|c|c|c|}
\hline $\mathrm{T}\left({ }^{\circ} \mathrm{C}\right)$ & $T^{-1} \times 10^{3}\left(K^{-1}\right)$ & $k(\mathrm{~m} / \mathrm{sec})$ & Source \\
\hline 65 & 2.956 & $4.877 \times 10^{-11}$ & 1 \\
\hline 70 & 2.914 & $1.030 \times 10^{-12}$ & 2 \\
\hline 80 & 2.831 & $4.131 \times 10^{-12}$ & 2 \\
\hline 90 & 2.753 & $6.706 \times 10^{-12}$ & 2 \\
\hline 90 & 2.753 & $2.235 \times 10^{-12}$ & 2 \\
\hline 90 & 2.753 & $9.314 \times 10^{-12}$ & 2 \\
\hline 90 & 2.753 & $6.148 \times 10^{-12}$ & 2 \\
\hline 105 & 2.644 & $5.696 \times 10^{-10}$ & 1 \\
\hline 105 & 2.644 & $1.043 \times 10^{-10}$ & 1 \\
\hline 105 & 2.644 & $4.634 \times 10^{-11}$ & 1 \\
\hline 105 & 2.644 & $5.197 \times 10^{-11}$ & 1 \\
\hline 145 & 2.391 & $1.741 \times 10^{-9}$ & 1 \\
\hline 145 & 2.391 & $3.738 \times 10^{-10}$ & 1 \\
\hline 170 & 2.256 & $9.830 \times 10^{-10}$ & 1 \\
\hline 173 & 2.241 & $1.476 \times 10^{-9}$ & 1 \\
\hline 173 & 2.241 & $1.301 \times 10^{-9}$ & 1 \\
\hline 173 & 2.241 & $2.057 \times 10^{-9}$ & 1 \\
\hline 173 & 2.241 & $1.528 \times 10^{-9}$ & 1 \\
\hline 173 & 2.241 & $1.374 \times 10^{-9}$ & 1 \\
\hline 187 & 2.173 & $1.626 \times 10^{-9}$ & 1 \\
\hline 202 & 2.104 & $3.916 \times 10^{-9}$ & 1 \\
\hline 202 & 2.104 & $3.589 \times 10^{-9}$ & 1 \\
\hline 202 & .2 .104 & $3.587 \times 10^{-9}$ & -1 \\
\hline 202 & 2.104 & $3.008 \times 10^{-9}$ & 1 \\
\hline 202 & 2.104 & $2.141 \times 10^{-9}$ & 1 \\
\hline 213 & 2.057 & $1.344 \times 10^{-8}$ & 1 \\
\hline 223 & 2.015 & $9.699 \times 10^{-9}$ & 1 \\
\hline 223 & 2.015 & $9.567 \times 10^{-9}$ & 1 \\
\hline
\end{tabular}


Table 2. (cont.)

\begin{tabular}{|c|c|c|c|}
\hline$T\left({ }^{\circ} \mathrm{C}\right)$ & $T^{-1} \times 10^{3}\left(K^{-1}\right)$ & $k(\mathrm{~m} / \mathrm{sec})$ & Source \\
\hline 223 & 2.015 & $7.276 \times 10^{-9}$ & 1 \\
\hline 223 & 2.015 & $4.883 \times 10^{-9}$ & 1 \\
\hline 223 & 2.015 & $4.816 \times 10^{-9}$ & 1 \\
\hline 248 & 1.918 & $5.524 \times 10^{-8}$ & 3 \\
\hline 250 & 1.911 & $1.676 \times 10^{-7}$ & 3 \\
\hline 265 & 1.858 & $2.368 \times 10^{-8}$ & 1 \\
\hline 269. & 1.844 & $2.009 \times 10^{-7}$ & 3 \\
\hline 291 & 1.722 & $3.402 \times 10^{-7}$ & 3 \\
\hline 305 & 1.729 & $4.723 \times 10^{-8}$ & 1 \\
\hline 315 & 1.700 & $6.683 \times 10^{-7}$ & 3 \\
\hline 332 & 1.652 & $9.238 \times 10^{-7}$ & 3 \\
\hline 400 & 1.485 & $4.290 \times 10^{-6}$ & 4 \\
\hline 400 & 1.485 & $1.162 \times 10^{-5}$ & $\dot{\mathbf{5}}$ \\
\hline 400 & 1.485 & $6.492 \times 10^{-6}$ & 5 \\
\hline 440 & 1.402 & $6.833 \times 10^{-6}$ & 5 \\
\hline 440 & 1.402 & $4.783 \times 10^{-6}$ & 5 \\
\hline 440 & 1.402 & $4.442 \times 10^{-6}$ & 5 \\
\hline 480 & 1.328 & $6.150 \times 10^{-6}$ & 5 \\
\hline 480 & 1.328 & $4.783 \times 10^{-6}$ & 5 \\
\hline 625 & 1.113 & $4.000 \times 10^{-5}$ & 4 \\
\hline
\end{tabular}

Sources

1. Rimstidt (1979)

2. Van Lier et al. (1960)

3. Siebert et a1. (1962)

4. Weill and Fyfe (1964)

5. Kitahara (1960) 


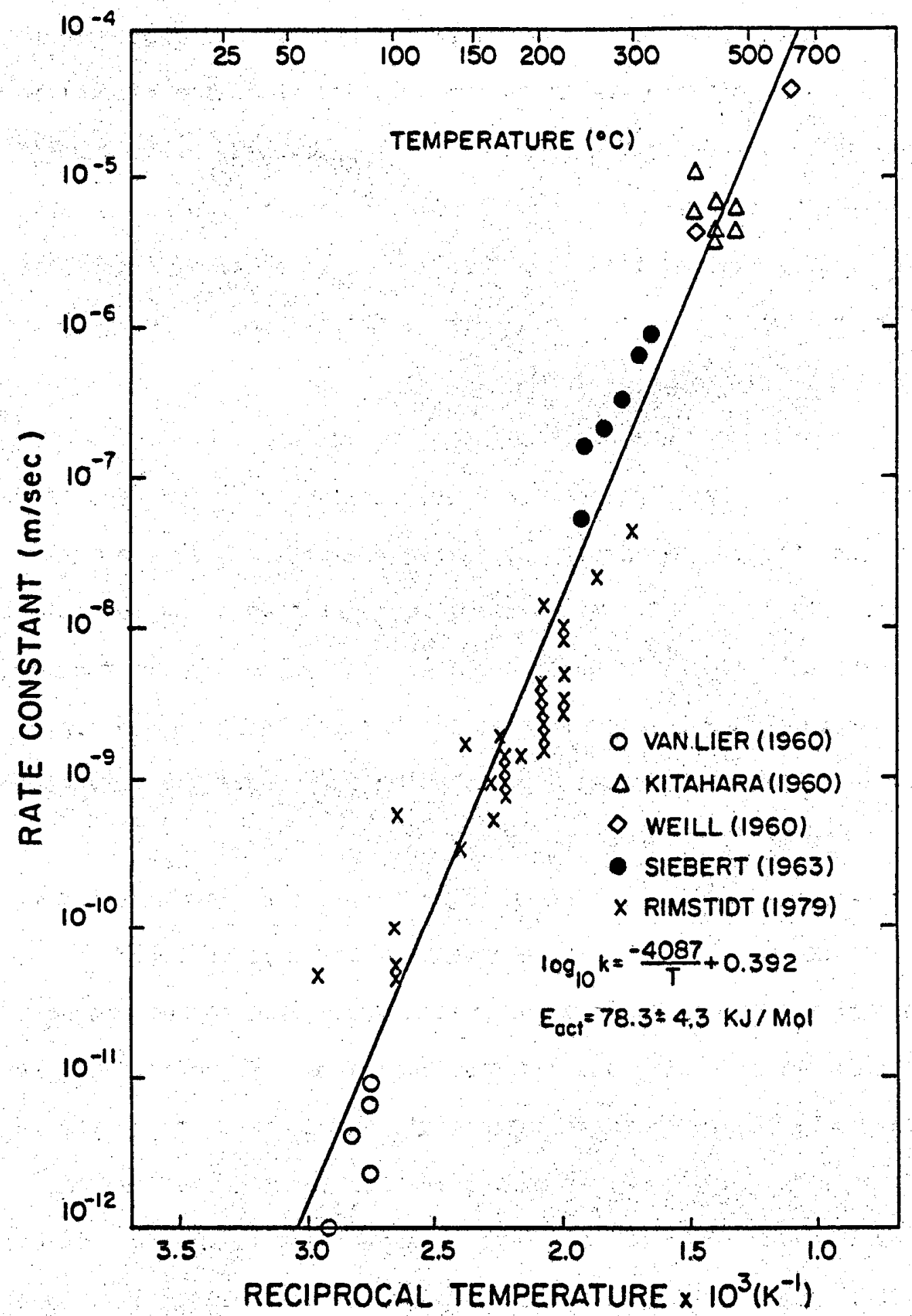

Figure 5. Arrhenius Plot for Quartz Dissolution Obtained from Literature Data 
react with ammonium molybdate to yield a yellow silicomolybdate complex whose color intensity follows Beer's law quite closely. Thus, a measurement of the low molecular weight (monomer and dimer) silicic acid concentration may be obtained colorimetrically. If the silicomolybdate complex becomes unstable due to the dissolution of higher molecular weight species during the colorimetric analysis, then Mullin and Riley (1955) suggest using an acidic-metol-sulfite solution to reduce the silicomolybdate complex to a more stable blue complex. The molybdate yellow technique used in this study is described more fully in Section 3.3.

An independent method sometimes used to measure silicic acid concentration is atomic absorption spectrophotometry. However, it must be realized that the AA spectrophotometer measures all Si atoms in solution. If there is significant polymerization in a sample, then this measurement will result in an erroneously high value for the monomer concentration. Atomic absorption is an appropriate technique for measuring the total dissolved silica, which may or may not be equivalent to the low molecular welght silica.

The second experimental factor to consider, the determination of the active quartz surface area, is dependent on the type of solid configuration chosen. One type of system often used to measure solid dissolution rates is the rotating disc apparatus. By polishing a solid disc to remove the rough edges which might add uncertainty to the surface area determination, an accurate value for the area may be obtained. The drawback of this type of experiment is that for quartz dissolution the disc configuration does not afford a sufficient amount of surface area relative to the fluid volume to complete the experiment in a short period of time.

An experiment which alleviates the problem of insufficient surface 
area is the stirred autoclave experiment, in which finely crushed quartz is mixed in a reactor vessel using a rotating impeller. Large surface area to fluid volume ratios are possible, decreasing drastically the time required to complete an experiment. However, the determination of the total surface area is difficult because of the irregular shape of the particles. The technique of estimating area assumes spherical particles of one characteristic diameter determined from the steve tray mesh size. This is certainly a crude approximation because of surface roughness and shape irregularities.

The crushed particle experiment al so leads to uncertainty due to the existence of a damaged surface layer. The very act of crushing the quartz into particles creates a coating of very small fines which adhere to the surface of the particles. These high surface energy fines dissolve much more rapidly than pure quartz. The result is an experiment clouded by this rapid dissolution.

The kinetic data of Siebert (1963) were the only data of Table 2 derived from rotating disc experiments. Figure 5 demonstrates the advantage of the rotating disc setup. Siebert's study, which el iminated the uncertainties of estimating the active quartz surface area of crushed particles, is much less scattered than the rest of the literature data or the data obtained in this investigation (see Chapter 3). The lack of scatter of the rotating disc data relative to that for the crushed quartz experiments suggests that the greatest experimental uncertainty in these studies lies in the determination of the active quartz surface area.

The fourth important experimental consideration is the possible existence of mass transfer limitations. The dissolution of quartz in water is a two step process in which the chemical/physical reaction at the solid surface is followed by the bulk diffusion of $\mathrm{Si}(\mathrm{OH})_{4}$ molecules 
from the interface into the fluid. Since these two processes occur in series, it must be shown that the bulk mass transfer coefficient for the particular system being studied is much larger than the intrinsic chemical rate constant for the reaction. If these two coefficients are of comparable magnitude, then the concentration versus time data of the experiment cannot be used directly to obtain the rate constant.

of the two types of experimental configurations normally used, the rotating disc is the easier to analyze because of the simple geometry involved. Levich (1962) solved the Navier-Stokes equations exactly for low rotation speeds in which the fluid is in laminar motion, proving for this case that the mass transfer coefficient is uniform over the entire disc. Sherwood et al. (1975) showed how to determine theoretically the mass transfer coefficient for this system. The stirred autoclave is a much more complex system to analyze, but a semiempirical method exists which allows for an estimation of the mass transfer coefficient (Sherwood et al., 1975). Of course, in both cases it can be determined experimentally whether mass transfer is important. If upon varying the rotation speed or agitation rate, no change in the observed concentration versus time data occurs, then the experiment is in the kineticaliy controlled regime. 


\section{Chapter 3}

Quartz Dissol ution Experiments

\subsection{Introduction}

The quartz dissolution kinetic data examined in Chapter 2 were obtained from a number of different sources. As a result, experimental apparatuses and techniques differed greatly from one study to the next. Futhermore, in several cases, the possibility of mass transfer limitations and the existence of small silica fines were not examined fully, casting doubt on the validity of these data. Thus, an experimental program was developed as part of this study to verify the literature data, paying special attention to the considerations mentioned above. Possible effects of other mineral phases on the dissolution of quartz were al so explored by performing dissolution experiments using a well characterized polycrystall ine granite. The theoretical and experimental results of this research are presented in this chapter.

\subsection{Experimental Apparatuses}

The experimental apparatus used to perform most of the quartz dissolution experiments was a stirred autoclave, shown schematically in Figure 6. The reactor vessel is a Pressure Products Industries 3165S Magnetic Drive Reactor, with a total usable volume of 1 liter. The variable speed D.C. motor drives a rotating magnet to which the agitation propeller/shaft assembly is attached, allowing the rotation speed to be adjusted from approximately 200-900 rpm. The sampling val ve 


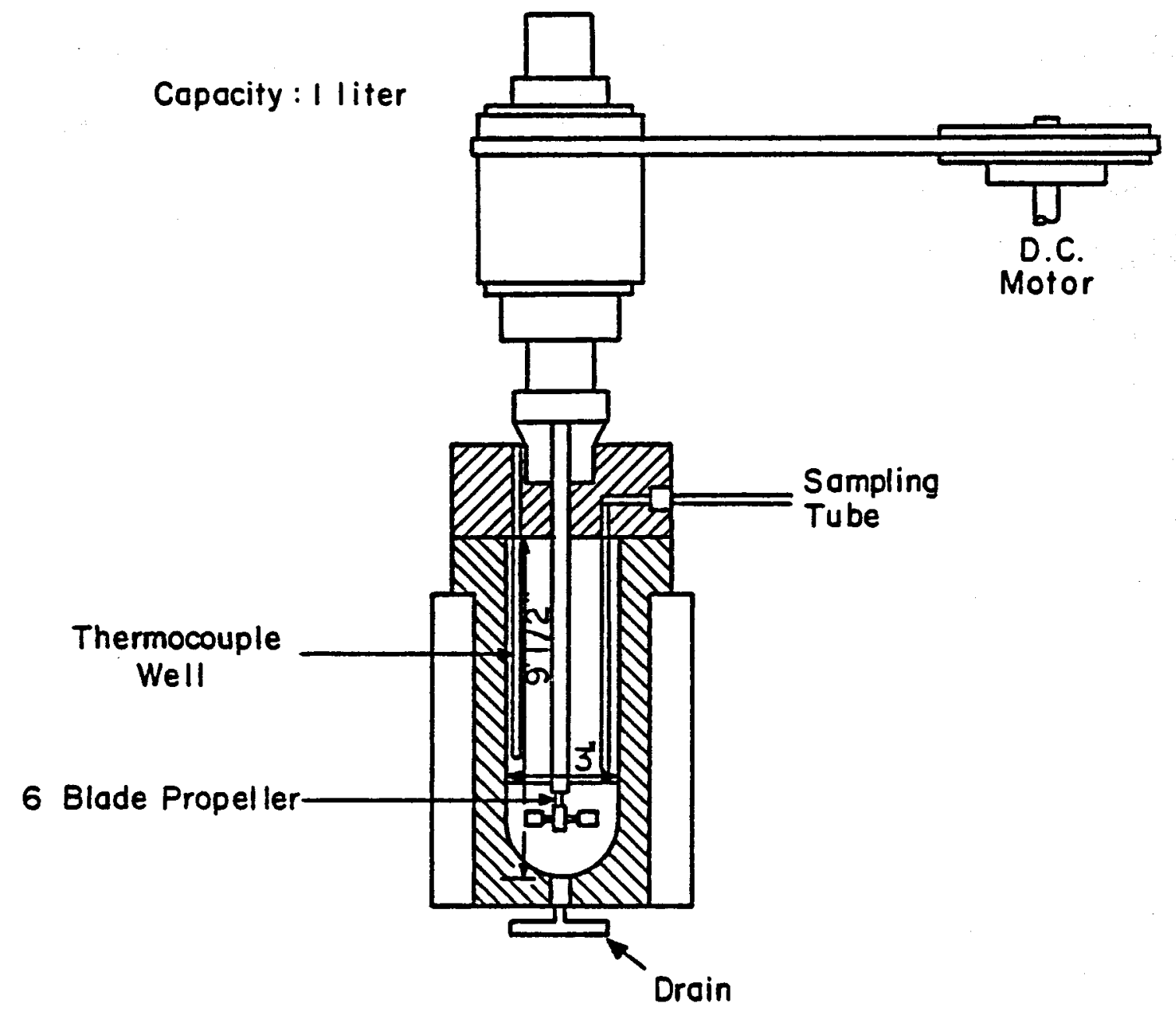

Figure 6. Schematic Diagram of the Stirred Autoclave Reactor 
is connected to a small diameter tube which is immersed in a cold water bath to cool the liquid sample to well below its boiling point. The electrical resistance heating jacket is controlled by an Athena temperature controller, which receives its temperature signal from a thermocouple placed in the immersed thermocouple well. The system was controlled to within $1^{\circ} \mathrm{C}$ using this setup.

To perform an experiment, a sample of crushed quartz or granite of known weight and size fraction was charged through the top of the reaction vessel. A known amount of preheated water (usually $500 \mathrm{ml}$ ) was then added and the system closed to begin heatup. The water was preheated to cut down on the time required for the system to reach the desired temperature. The reactor and contents were allowed to heat up without turning on the stirrer: this procedure minimized the dissolution rate during the heatup period. Once the desired temperature was reached, samples were taken at regular intervals as follows: the stirrer, which was operating constantly during the experiment, was shut off for about one minute before a sample was taken to allow the solid particles to settle to the bottom of the autoclave. Then approximately $4 \mathrm{ml}$ of liquid were expelled to displace the stagnant fluid in the sampling tube. Then roughly $3 \mathrm{ml}$ of sample were taken and the stirrer turned back on. At the end of an experiment, the stirrer and controller were turned off and the system allowed to cool to below the boiling point of water (approximately $92^{\circ} \mathrm{C}$ at the $7000 \mathrm{ft}$ altitude of the experiments). This temperature is high enough that none of the dissolved silica would reprecipitate on the quartz particles upon cooling. The entire contents were then drained and the quartz or granite particles rinsed thoroughly before being used in the next experiment.

A few experiments were al so performed in small, closed reactor 
vessels which were agitated using a rocking arm (see figure 7). The reactor bombs are heated using band heaters or were placed in an oven. Temperature was controlled using an Athena controller in the same way as the stirred autoclave. The rocking action of the arm agitates the liquid and crushed quartz. To determine the amount of dissolution at a given time, the system was shut down and the bomb rapidly quenched in liquid nitrogen to a temperature where the fluid may be analyzed. The disadvantage of this type of experiment is that for each data point of concentration versus time, the entire sample volume of 1 iquid is used. Thus, to obtain, say, six data points, the whole procedure must be repeated six times.

\subsection{Analytical Techniques}

As mentioned in Chapter 2, the method used in this study for analyzing for dissolved silica in the samples was the molybdate yellow technique. The color reagent was prepared by mixing $50 \mathrm{ml}$ of $1.0 \mathrm{~N}$ sulfuric acid with $20 \mathrm{ml}$ of a premixed 10 wt\% ammonium molybdate solution and diluting to $500 \mathrm{ml}$ with deionized water. The ammonium molybdate solution was prepared by dissolving an appropriate amount of reagent grade ammonium molybdate pellets in deionized water to obtain a $10 \%$ solution. The concentrated sulfuric acid used to prepare the $1.0 \mathrm{~N}$ $\mathrm{H}_{2} \mathrm{SO}_{4}$ solution was also of reagent grade purity.

Fresh quantities of color reagent were prepared every day during an experiment since it was observed that the transmittance of light in the reagent declines noticeably after a few days. To perform an analysis, $1.0 \mathrm{ml}$ of sample was pipetted and diluted to $50.0 \mathrm{ml}$ in a volumetric f1ask. Transmittance readings at 6,9 , and 12 minutes after the start of the reaction were taken at a wavelength of $440 \mathrm{~nm}$ and $0.098 \mu \mathrm{m}$ slit 22 


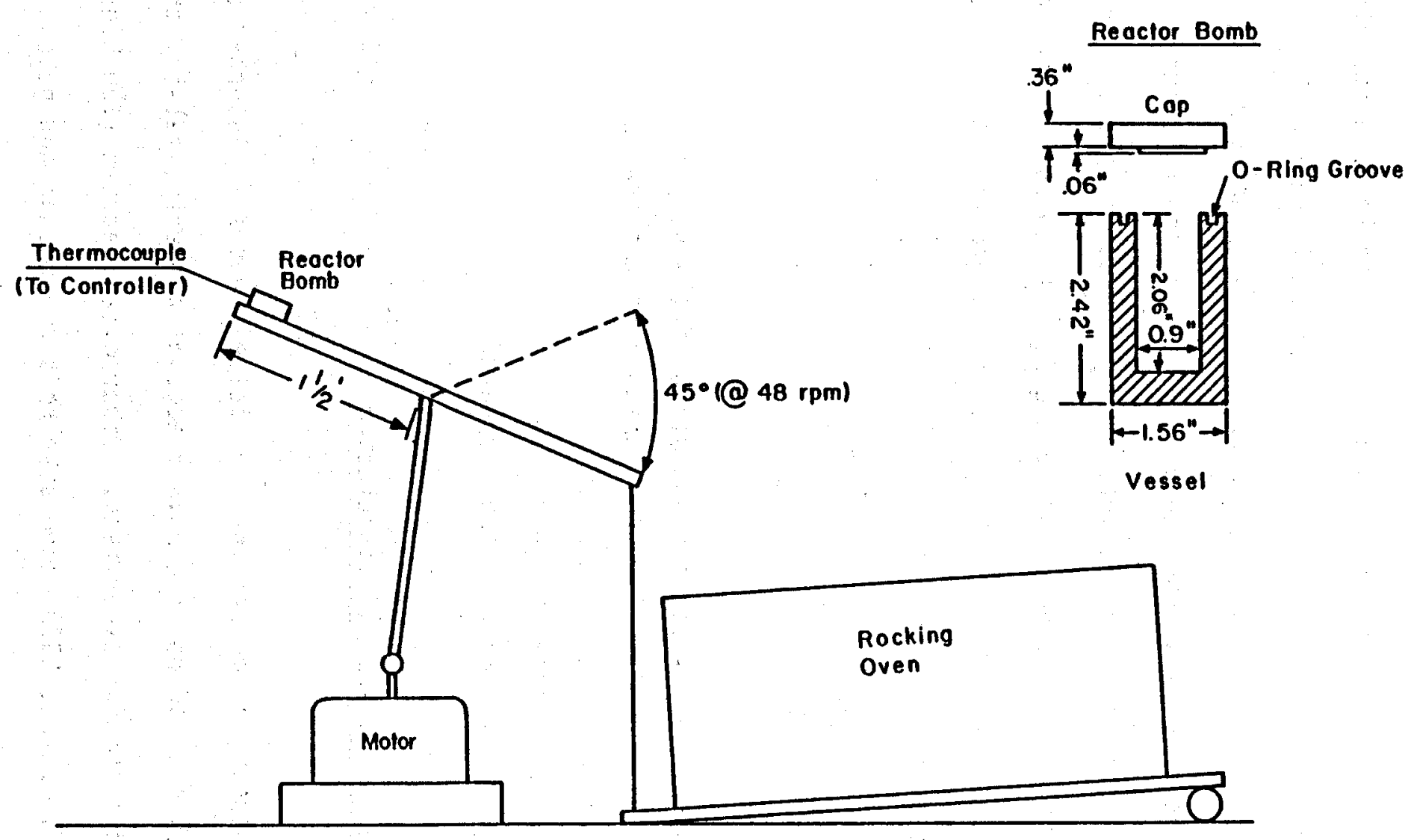

Figure 7. Schematic Diagram of the Rocking Arm Apparatus 
width using a Beckman DU-2 spectrophotometer. For almost all samples, two agreeing transmittance readings (to the third decimal place) were obtained in these three readings.

The transmittance readings were converted to concentrations assuming Beer's 1aw, which, as noted in Chapter 2, is followed quite closely for the molybdate yellow colorimetric technique. To verify this fact, a $1000 \mathrm{ppm}$ sodium silicate standard was diluted to 50,100 , and $200 \mathrm{ppm}$ and the absorbance was found to vary linearly with concentration in this concentration range. The formula used to calculate the concentration in the dissolution experiments, using the Beer's law assumption that the absorbance is directly proportional to the concentration of the solution (Fritz and Schenk, 1974), is

$$
c_{s}=\frac{C_{s t d}\left(\log T_{b}-\log T_{s}\right)}{\left(\log T_{b}-\log T_{s t d}\right)},
$$

where

$C_{s}=$ dissol ved silica concentration of the sample

$C_{\text {std }}=$ dissol ved silica concentration of the standard

$T_{b}=$ transmittance of the blank

$T_{s}=$ transmittance of the sample

$T_{\text {std }}=$ transmittance of the standard.

\subsection{Damaged Surface Layer Dissolution}

The crushing of quartz into particles creates a disturbed surface layer which can, if not taken into account properly, falsify the data of a quartz dissolution experiment. Other experimenters (Van Lier et al., 1960, and Rimstidt, 1979) have seen this phenomenon and have hypothesized on the form of the disturbed layer. Rimstidt showed that a plot of $\ln \Phi$ vs. $t$, as suggested by Equation (2.3.2) and Figure 3 , results in an initial steep slope region followed by a more gradually 24 
sloped straight line. He assumed that this behavior is due to a thin layer of amorphous silica and proceeds to obtain kinetic data for amorphous silica using the initial steep slope.

The fact that crushed quartz exhibits this fast initial dissolution rate indicates that some sort of damaged solid silica phase exists. Therefore, scanning electron microscope (SEM) photographs were used in the present study to verify the existence of the damaged layer. Figure 8 is a SEM photograph of an unwashed particle of quartz taken using an ISI Model DS-130 scanning el ectron microscope. Clearly, the damaged layer exists as a discontinuous collection of fines adhering to the surface of the particle. Even if the small fines are pure amorphous silica, obtaining an accurate value for the surface area is not feasible. Thus, extracting meaningful amorphous silica kinetic data from a quartz dissolution experiment using the initial rate data is impossible. Futhermore, some of the fines may have small enough radii of curvature that surface energy effects could raise their equilibrium solubility in water (see, for example, Modell and Reid, 1974).

The initial rapid dissolution of these small particles suggests an effective method to get around the problem of fines adhering to the quartz surface. If the quartz particles are brought to a high temperature in water $\left(200^{\circ} \mathrm{C}\right.$ or greater) for several hours, then the fines will dissolve preferentially until they have been totally el iminated. In practice, the method used in this study was simply to reuse the same quartz particles in each experiment. The first experiment using "new" quartz particles always exhibited the rapid intial rate of dissolution. Subsequent experiments did not, suggesting that the small fines had been dissol ved completely in the first experiment. Figure 9 is a SEM photograph of a typical quartz particle after several runs at high temperature. The fines have been virtually 


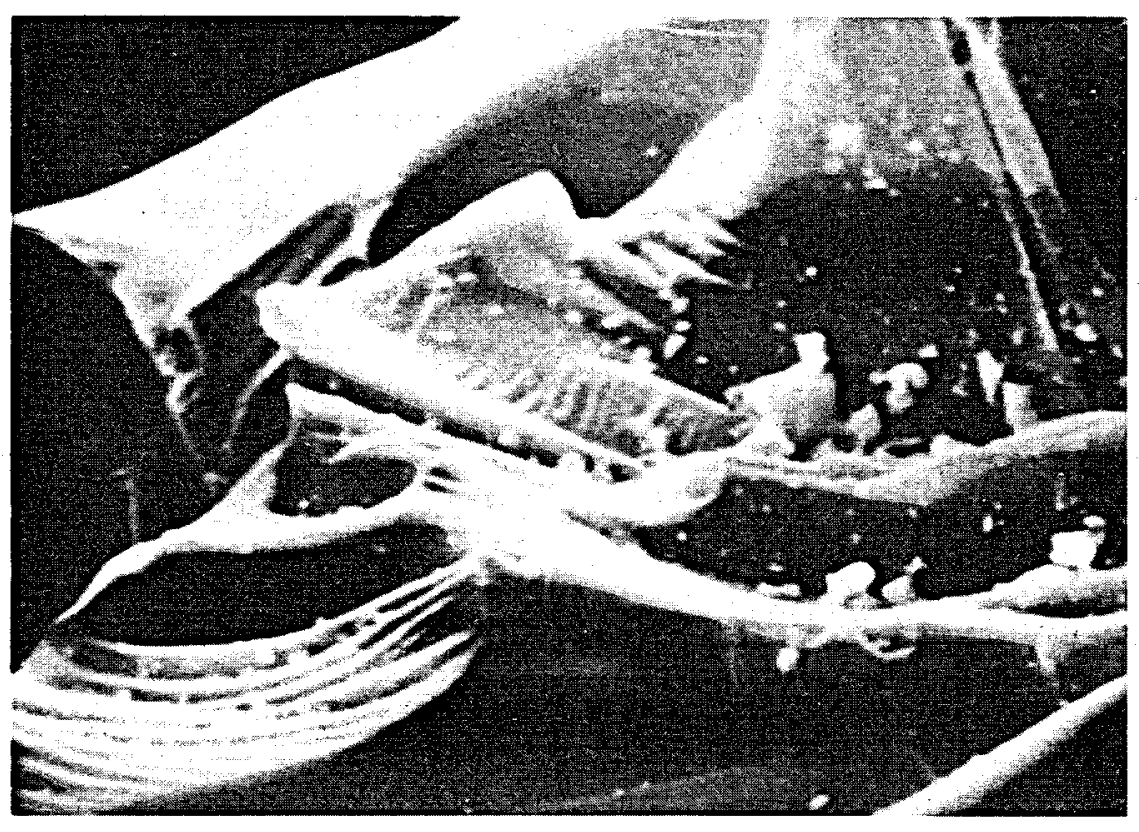

\section{$5 \mu \mathrm{m}$}

Figure 8. SEM Photograph of a Crushed Ouartz Particle Before Dissolution Experiments

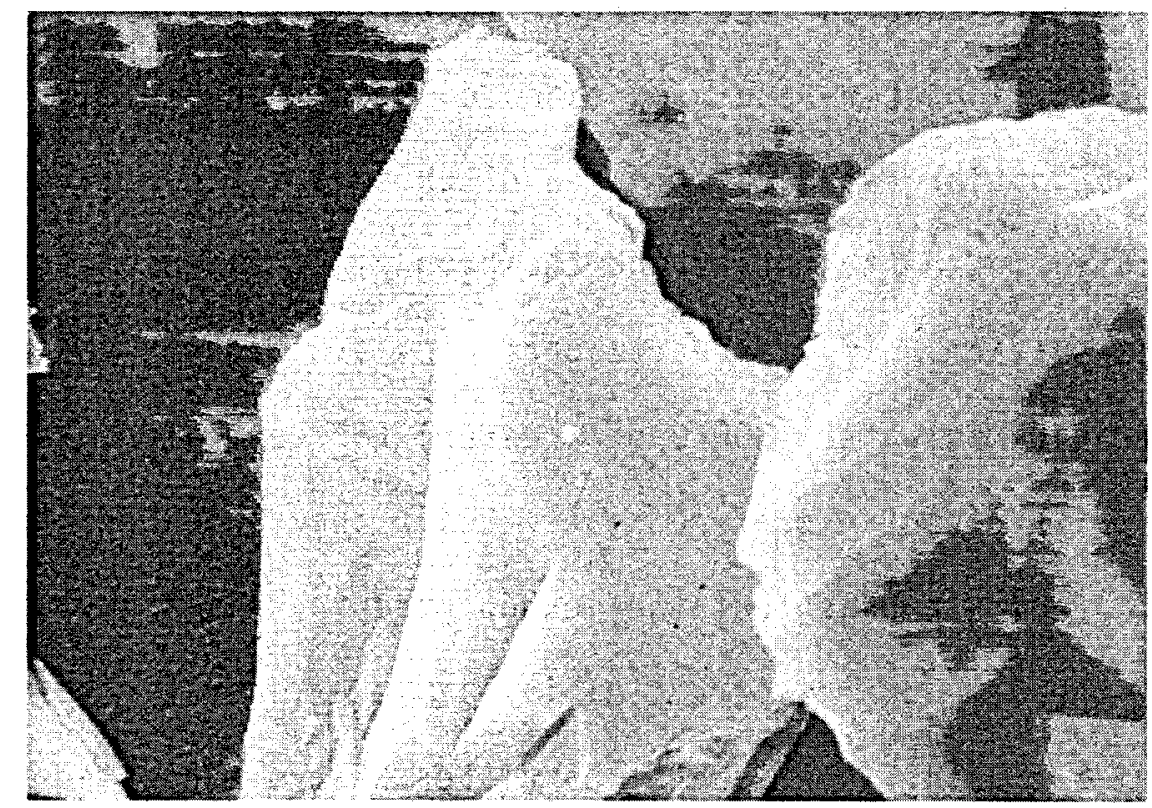

$5 \mu \mathrm{m}$

Figure 9. SEM Photograph of a Crushed Quartz Particle After Several Dissolution Experiments 
el iminated, ensuring that the subsequent dissolution experiments are those of the large quartz particles with no interference from the small fines.

Van Lier (1960) showed that treatment with HF will dissolve the fines very rapidly. However, since HF has an enormous accelerating effect on the dissolution of quartz, an el aborate washing procedure is necessary to ensure that none of the HF is left in the microfractures of the quartz particles. The procedure suggested in the present study is much easier to carry out experimentally, and avoids the problem of HF adsorption into the microfractures.

One other piece of empirical evidence obtained from these experiments suggests that the small fines are responsible for the rapid initial rate of dissolution. During the time required to heat the stirred autoclave reactor up to temperature $(1-2 \mathrm{hr})$, the amount of: dissolution predicted from the rate expression of Equation (2.3.2) is so small that the initial concentration of dissolved silica (the. concentration after the system has reached its ultimate temperature) should still be approximately 0 ppm. Experimentally, this calculation is borne out in the runs performed using "clean" quartz, but the first experiment using unwashed quartz shows that the concentration reaches at least $40 \mathrm{ppm}$ during the heatup period. Presumably this initial concentration is due to rapid dissolution of the small fines. If Figure 8 is taken as a typical example of the size and quantity of the fines, then it can be calculated that complete dissolution of these small particles during heatup would result in an initial concentration within a factor of 2 of the observed $40 \mathrm{ppm}$. Given the 1 imited accuracy of such a calculation, the fact that it resul ts in a concentration in the neighborhood of the observed result suggests that rapid dissolution of the small fines is the correct explanation of the initial behavior. 


\subsection{Experimental Results}

The experimental systems described in the preceding section were used to carry out quartz dissolution experiments in the temperature range from $150-250^{\circ} \mathrm{C}$. The results of the stirred autoclave experimental study are tabulated in Table 3, while the rocking arm data are summarized in Table 4.

Table 4. Summary of Rocking Arm Dissolution Experiments

\begin{tabular}{l|l|l|l|l|c}
$T\left({ }^{\circ} \mathrm{C}\right)$ & Mesh Size & Weight $(\mathrm{g})$ & $\mathrm{S}\left(\mathrm{cm}^{2}\right)$ & $\mathrm{k}(\mathrm{m} / \mathrm{sec})$ & $\begin{array}{c}\text { Number of } \\
\text { Data Poi nts }\end{array}$ \\
\hline 200 & $200-270$ & 0.0955 & 33.61 & $1.601 \times 10^{-8}$ & 4 \\
250 & $16-24$ & 1.283 & 33.61 & $2.881 \times 10^{-8}$ & 4 \\
200 & $16-24$ & 1.283 & 33.61 & $1.164 \times 10^{-8}$ & 4 \\
200 & $65-100$ & 2.698 & 33.61 & $9.440 \times 10^{-8}$ & 4
\end{tabular}

The results obtained from both of these systems are correlated in the form of an Arrhenius plot in Figure 10. The tables summarize the important experimental parameters for each run, along with the number of data points used in the analysis. Appendix $B$ gives the actual concentration versus time output for each of the successful experiments. In the temperature range of this study, the best fit to the data yields an activation energy of $79.2 \pm 18.5 \mathrm{~kJ} / \mathrm{mol}$ ( $90 \%$ confidence level).

Figure 11 is an Arrhenius plot ( $1 n k$ vs. $T^{-1}$ ) combining the data of the present study with that of the previous investigations. The close agreement suggests that the quartz dissolution rate law represented by Equation (2.3.1) is a reliable empirical correlation which can be used with confidence to predict the rate of quartz dissolution as a function of temperature and surface area. The best straight line fit to this 
Table 3. Summary of the Stirred Autoclave Dissolution Experiments

\begin{tabular}{|c|c|c|c|c|c|c|c|c|}
\hline Run & $T\left({ }^{\circ} \mathrm{C}\right)$ & Rock Type & Mesh Size & Weight $(g)$ & $s\left(\mathrm{~cm}^{2}\right)$ & $k(m / s e c)$ & $\begin{array}{c}\text { A verage } \\
\text { RPM }\end{array}$ & $\begin{array}{l}\text { Number of } \\
\text { Data Points }\end{array}$ \\
\hline$A 3^{\star \star}$ & 200 & quartz & $200-270$ & 5.00 & 1760 & $5.178 \times 10^{-8}$ & - & $4^{\star}$ \\
\hline$A 4^{\star \star \star}$ & 200 & quartz & $200-270$ & 5.00 & 1760 & $1.664 \times 10^{-8}$ & 658 & 3 \\
\hline$A 5^{\star \star}$ & 201.8 & quartz & $200-270$ & 5.00 & 1760 & $2.468 \times 10^{-8}$ & 433 & $3 *$ \\
\hline$A 6^{\star \star}$ & 150 & quartz & $24-42$ & 27.789 & 1349 & $1.477 \times 10^{-9}$ & 533 & 5 \\
\hline A 10 & 184 & quartz(a) & $65-100$ & 28.682 & 3611 & $3.139 \times 10^{-9}$ & 423 & 5 \\
\hline A11 & 184.5 & quartz(a) & $65-100$ & 28.36 & 3571 & $1.462 \times 10^{-9}$ & 414 & 5 \\
\hline A 12 & 184 & quartz(a) & $65-100$ & 27.902 & 3513 & $2.214 \times 10^{-9}$ & 637 & 5 \\
\hline$A 13^{\star \star}$ & 203 & quartz & $100-200$ & 100.00 & 21190 & $3.569 \times 10^{-8}$ & 469 & 4 \\
\hline A 14 & 202 & quartz(a) & $100-200$ & 99.00 & 20980 & $1.193 \times 10^{-8}$ & 453 & 6 \\
\hline A 15 & 202.5 & quartz(a) & $100-200$ & 97.90 & 20750 & $7.502 \times 10^{-9}$ & 447 & 5 \\
\hline A 16 & 203 & quartz(a) & $100-200$ & 85.44 & 18100 & $1.348 \times 10^{-8}$ & 635 & 5 \\
\hline$A 17 * \star$ & 201 & quartz(a) & $100-200$ & 85.25 & 18060 & $1.707 \times 10^{-8}$ & 635 & 4 \\
\hline A 18 & 221 & quartz(a) & $100-200$ & 85.25 & 18060 & $3.140 \times 10^{-8}$ & 608 & 5 \\
\hline A 19 & 221 & quartz(a) & $100-200$ & 84.65 & 17940 & $2.103 \times 10^{-8}$ & 714 & 6 \\
\hline A 20 & 221 & quartz(a) & $100-200$ & 83.75 & 17750 & $1.454 \times 10^{-8}$ & 698 & 8 \\
\hline A22 & 253 & quartz(a) & $100-200$ & 53.31 & 11300 & $6.037 \times 10^{-8}$ & 695 & 5 \\
\hline A23 & 255 & quartz(a) & $100-200$ & 51.55 & 10920 & $4.656 \times 10^{-8}$ & 691 & 7 \\
\hline A24 & 215 & quartz(a) & $100-200$ & 30.69 & 6503 & $1.608 \times 10^{-8}$ & 679 & $8 *$ \\
\hline$A 25$ *t & 201 & granite & $16-24$ & 73.25 & $581.2(b)$ & $1.950 \times 10^{-7}$ & 683 & 4 \\
\hline A26 t* & 208 & granite(a) & $16-24$ & 70.96 & $563.1(b)$ & $2.629 \times 10^{-7}$ & 704 & 5 \\
\hline$A 27 * *$ & 205 & granite(a) & $16-24$ & 70.71 & $561.0(b)$ & $3.052 \times 10^{-7}$ & 689 & 6 \\
\hline$A 28^{* *}$ & 180 & granite(a) & $16-24$ & 70.32 & $558.0(\mathrm{~b})$ & $3.052 \times 10^{-8}$ & 655 & 5 \\
\hline$A 29$ * & 194 & granite(a) & $16-24$ & 65.30 & $518.2(b)$ & $2.238 \times 10^{-7}$ & 634 & 6 \\
\hline$A 30 * *$ & 195 & granite & $100-140$ & 10.01 & $529.4(b)$ & $3.579 \times 10^{-7}$ & 645 & 5 \\
\hline$A 31$ * & 186 & granite(a) & $100-140$ & 22.05 & $1166(b)$ & $2.645 \times 10^{-7}$ & 646 & 6 \\
\hline
\end{tabular}

* Rate constant calculated using initial rate data

** Data point not used in least squares fit

(a) Crushed particles were used in the preceding experiment.

(b) Quartz surface area was calculated assuming $30 \%$ quartz. 


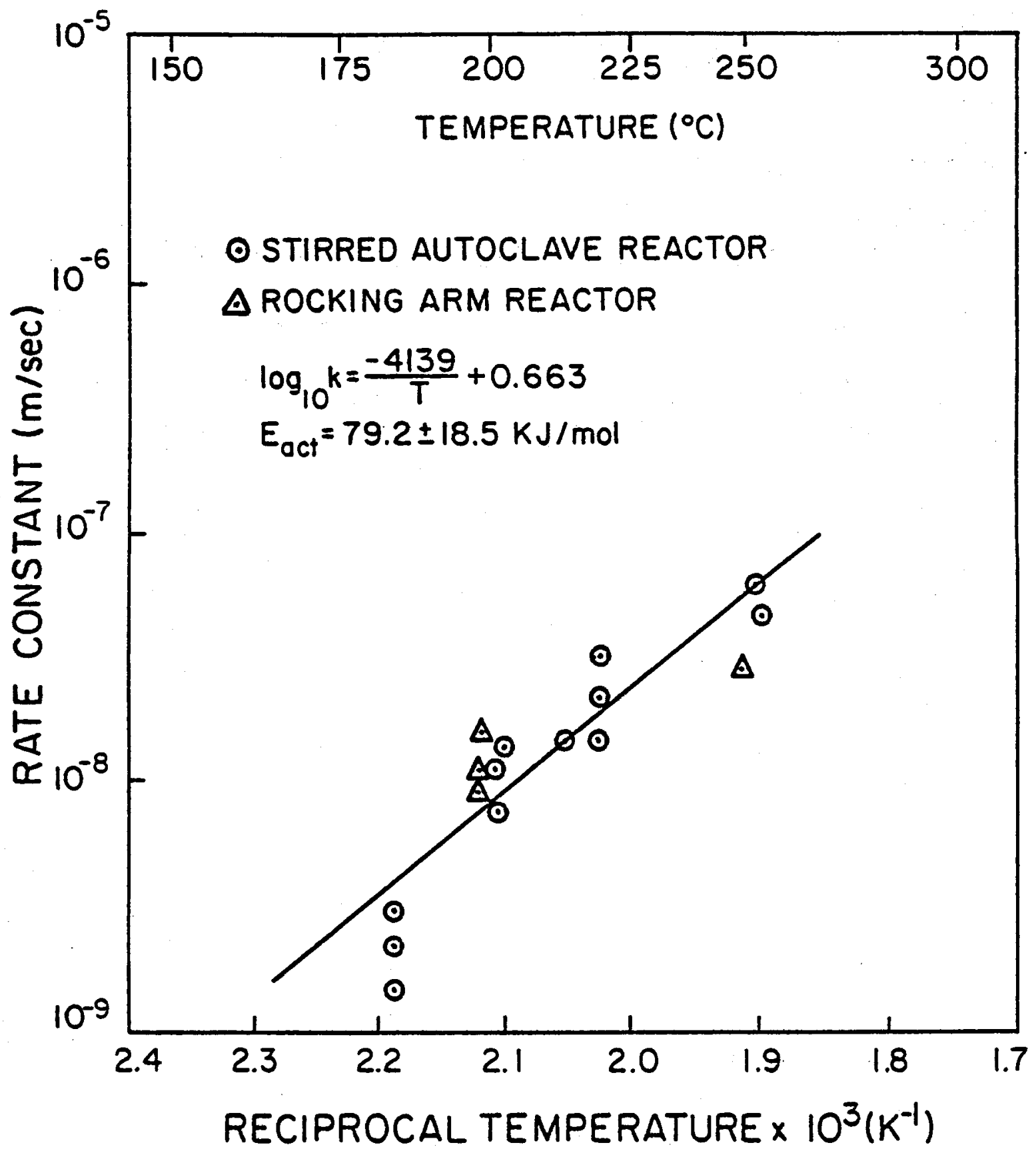

Figure 10. Arrhenius Plot for Ouartz Dissolution Obtained from Data of the Present Study. 


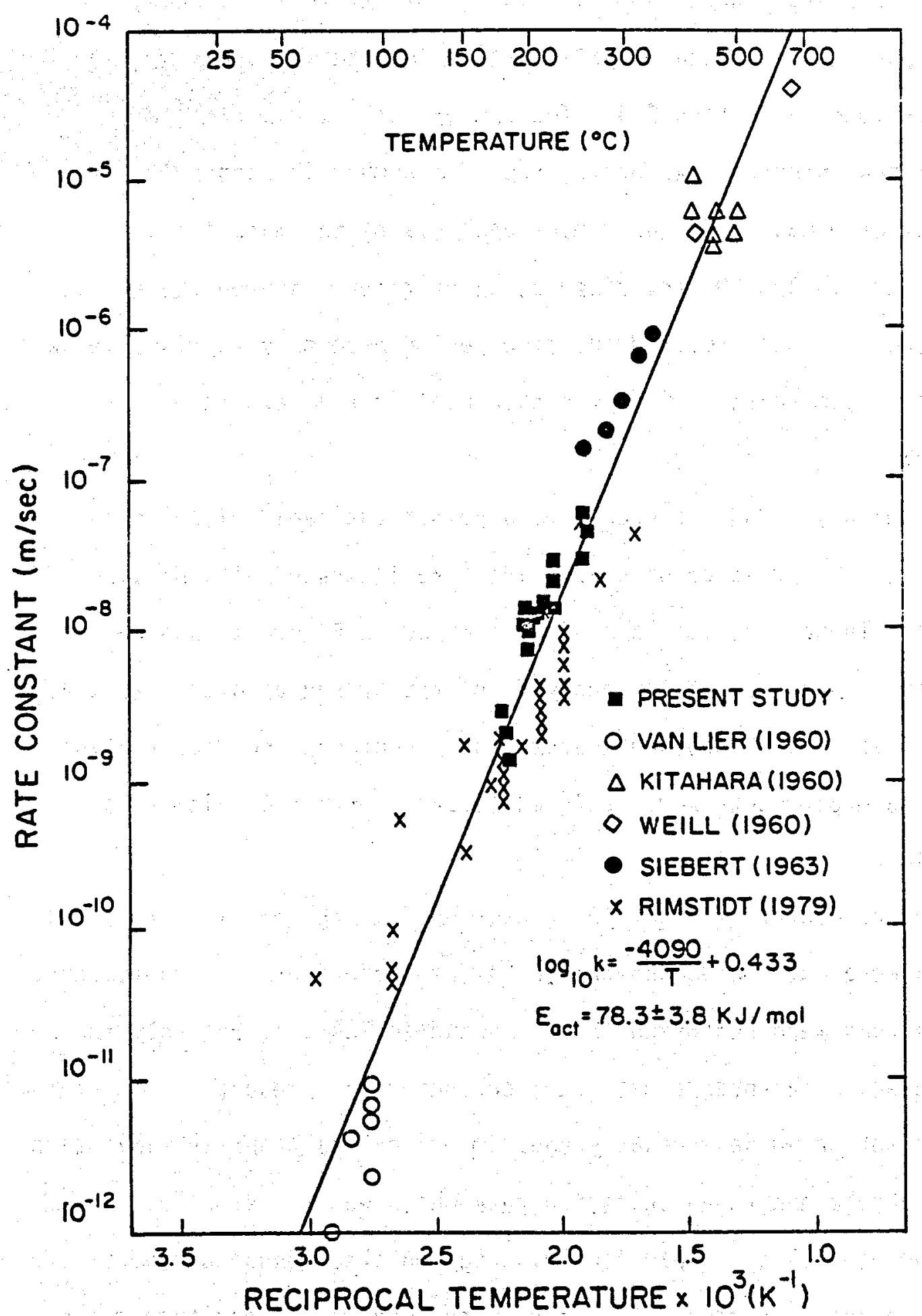

Figure 11. Arrhenius Plot for nuartz Dissolution Comparing Literature Data to Data Obtained in the Present Study 
data is given by $\log _{10} k=-4240 / T+0.781$ ( $E_{\text {act }}=81.2 \pm 4.0 \mathrm{~kJ} / \mathrm{mol}$ ).

As indicated in Table 3, most of the stirred autoclave experiments in the present study were run using quartz of mesh size 100-200, reusing the same particles in each experiment to eliminate the problem of small fines described in Section 3.4. The numbers of the experiments indicates the chronological order, but if a number is missing it means that an experimental difficulty made analysis of the data impossible. For instance, in Run A9, the dissolution of fines obscured the quartz dissolution data but provided the time period necessary to dissol ve away the fines on the quartz, which was then used in the next three experiments.

Runs which yielded calculable data points but rapid dissolution rates due to the presence of small fines are indicated with double asterisks. These experiments are not plotted in figure 10 and were not used in the linear regression analys is of the Arrhenius plot. Runs A3 through A6 also used unwashed quartz, which confused the data analysis since these experiments were designed to study only the initial rate of dissolution.

The experimental difficulties encountered in the rocking arm studies were much more extreme due to the cumbersome nature of the experiments. Many more runs were performed than is shown in Table 4 , but only the trials in which acceptable data were collected are presented. The runs which are not shown were usually ones in which mass transfer limitations exist, probably due to an agitation rate which was too slow to suspend all of the particles. Rapid fine dissolution also rendered several of these experiments unacceptable. A rocking speed of $48 \mathrm{rpm}$ through an angle of roughly $45^{\circ}$ was necessary to el iminate mass transfer effects due to incomplete particle suspension.

The analysis of the data to obtain a kinetic rate constant followed 
the treatment described in Section 2.3 with a few minor revisions. The kinetic rate law described by Equation (2.3.1) was used along with Rimstidt's quartz equilibrfum solubllity correlation (Table 1) to obtain the rate constant at a given temperature. In many cases the initial rate of an experiment was too rapid compared to the later data points to be able to fit the data with one straight 1 ine of $\log \Phi$ vs. $t$. In such. cases it was assumed that the initial rate was enhanced by the dissolution of small fines. The kinetic rate constant was then obtained by considering only the later data points in the analysis.

The nature of the stirred autoclave experiments al so required that a few other minor revisions be made in the data analysis in order to describe the liquid volume accurately. First, the calculation of the volume of liquid charged to the reactor was corrected to account for thermal expansion and a small amount of vaporization into the empty. region above the 1 iquid level. More importantly, the decrease in liquid volume due to repeated sampling must be taken into account. For a system of changing volume, Equation (2.3.1) must be integrated with $V$ no longer assumed constant. The result is

$$
\ln \Phi=-k s \int_{0}^{t} \frac{d t}{V}
$$

Since the volume decreases in a known fashion, the integral term $\int_{0}^{t} d t / V$ is calculable at the point when each sample was taken. Thus, a plot of In $\Phi$ vs. $\int_{0}^{t} d t / v$ may be made to obtain the rate constant. The liquid volume correction due to vaporization was approximately $1 \%$ of the total volume, while the volume decrease due to repeated sampling was a correction of roughly $10 \%$ at the end of an experiment. A sample calculation in which all of these considerations are taken into account is shown in Appendix $C$. 
Mass transfer 1 imitations may exist in any experimental system which attempts to measure the rate of a chemical reaction. In the case of quartz dissolution in water, the rate of reaction is governed by a two step process. The chemical/physical reaction of quartz with water at the liquid-solid interface is coupled to the bulk mass transfer of $\mathrm{Si}(\mathrm{OH})_{4}$ molecules from the surface to the fluid. In order to use the concentration versus time data directly to obtain a kinetic rate constant, the surface reaction must be the rate limiting step.

The complex nature of the stirred autoclave experiment prohibits the derivation of an exact correlation for the mass transfer coefficient. Instead, semiempirical methods such as the one developed by Harriot (1962) are used to calculate an average mass transfer coefficient for a stirred suspension of sol id particles in a liquid. The method assumes that for a suspended particle, the appropriate velocity to use in a calculation of the mass transfer coefficient is the Stokes' law terminal velocity, as given by the following equation (Sherwood et al., 1975):

$$
U_{T S}=\frac{d_{p}^{2}\left|\rho_{s}-\rho_{1}\right| g}{18 \mu_{1}} \text {, }
$$

where

$$
\begin{aligned}
& U_{\text {TS }}=\text { Stokes ' law terminal velocity }(\mathrm{m} / \mathrm{sec}) \\
& d_{p}=\text { average diameter of particles }(\mathrm{m}) \\
& p_{s}=\text { density of solid particles }\left(\mathrm{kg} / \mathrm{m}^{3}\right) \\
& p_{1}=\text { density of liquid }\left(\mathrm{kg} / \mathrm{m}^{3}\right) \\
& g=9.81 \mathrm{~m} / \mathrm{sec}^{2} \\
& \mu_{1}=1 \text { iquid viscosity }(\mathrm{kg} / \mathrm{m}-\mathrm{sec}) .
\end{aligned}
$$

This velocity is used to calculate a Reynolds number based on Stokes' Taw:

$$
R e_{T S}=\frac{d_{p}^{3} \rho_{1}\left|\rho_{s}-\rho_{1}\right| g}{18 \mu_{1}^{2}}
$$


At this point the Reynolds number is recalculated on the basis of an empirical correction factor. The reason for this correction is that experimentally it is found that using the Stokes' law velocity, the calculated mass transfer coefficient is too high. The correction factor is the ratio of the empirically "correct" velocity to the Stokes! law velocity, which is tabulated for different Stokes' law Reynolds numbers in Sherwood et al. (1975). This new velocity, $U_{T}$, is then used to recalculate the Reynolds number, which is then used in a Frossling-type correlation to estimate the mass transfer Sherwood number:

$$
\mathrm{Sh}=2+0.6 \mathrm{Re}^{1 / 2} \mathrm{Sc}^{1 / 3} \text {, }
$$

where

$$
\begin{aligned}
& \text { Sh=Sherwood number }=k_{m} d_{p} / D_{A B} \\
& k_{m}=\text { mass transfer coefficient }(\mathrm{m} / \mathrm{sec}) \\
& D_{A B}=\text { diffusivity of } \mathrm{Si}(\mathrm{OH})_{4} \text { in water }\left(\mathrm{m}^{2} / \mathrm{sec}\right) \\
& S C=S c h m i d t \text { number }=v / D_{A B} \\
& v=k i \text { nematic viscosity of water }\left(\mathrm{m}^{2} / \mathrm{sec}\right) .
\end{aligned}
$$

Using this method, the mass transfer coefficient may be calculated and compared to the kinetic rate constant. Appendix $D$ demonstrates a sample calculation and Table 5 shows the results of calculations done at a variety of different experimental conditions. In all cases the calculated mass transfer coefficient is several orders of magnitude larger than the kinetic rate constant. Thus, if quartz particles are suspended in the water, then mass transfer limitations will be negligible for this system for any temperature below the critical point of water $\left(374^{\circ} \mathrm{C}\right)$.

The question of whether or not the particles are suspended in water is crucial since the preceding mass transfer coefficient calculations are dependent on the fact that each particle is floating freely in the liquid. If a large number of particles remain at the bottom of the 
Table 5. Mass Transfer Coefficient in the Stirred Autoclave Reactor

\begin{tabular}{l|l|l|c|c}
$T\left({ }^{\circ} \mathrm{C}\right)$ & $\begin{array}{c}\text { Mesh } \\
\text { Size }\end{array}$ & $d_{p}(\mathrm{~mm})$ & $\begin{array}{c}\text { Calculated Mass } \\
\text { Transfer Cofficient } \\
k_{\mathrm{m}}(\mathrm{m} / \mathrm{sec})\end{array}$ & $\begin{array}{c}\text { Measured Rate } \\
\text { Constant } \\
k(\mathrm{~m} / \mathrm{sec})\end{array}$ \\
\hline 150 & $16-24$ & 0.841 & $3.76 \times 10^{-4}$ & $5.56 \times 10^{-10}$ \\
150 & $100-200$ & 0.105 & $5.63 \times 10^{-4}$ & $5.56 \times 10^{-10}$ \\
150 & $200-270$ & 0.0313 & $5.85 \times 10^{-4}$ & $5.56 \times 10^{-10}$ \\
200 & $16-24$ & 0.841 & $4.83 \times 10^{-4}$ & $6.39 \times 10^{-9}$ \\
200 & $100-200$ & 0.105 & $6.67 \times 10^{-4}$ & $6.39 \times 10^{-9}$ \\
200 & $200-270$ & 0.0313 & $8.77 \times 10^{-4}$ & $6.39 \times 10^{-9}$ \\
250 & $16-24$ & 0.841 & $6.90 \times 10^{-4}$ & $4.60 \times 10^{-8}$ \\
250 & $100-200$ & 0.105 & $9.60 \times 10^{-4}$ & $4.60 \times 10^{-8}$ \\
250 & $200-270$ & 0.0313 & $1.22 \times 10^{-4}$ & $4.60 \times 10^{-8}$
\end{tabular}


reactor due to insufficient stirring, then the particles on the bottom are not being exposed to water and the observed reaction rates will be artificially low. An empirical correlation has been developed by Zwietering (1958) to predict the mi nimum stirrer speed necessary to keep the particles suspended. The correlation, presented in Appendix E, takes into account the type of stirrer and its dimensions, the reactor dimensions, fluid properties, particle size, and the amount of solid charged to the reactor. Table 6 shows the results of calculations made for the different conditions encountered in the actual experiments and demonstrates that in each experiment the rotation speed used was greater than the minimum speed recommended by Zwietering's correlation.

\subsection{Experimental Verification of Mass Transfer Calculations}

In some cases, it is possible to verify experimentally that the mass transfer limitations discussed theoretically in the preceding section are negligible for the specific conditions of the experiment. The suspension of the particles was verified experimentally in this study by using a plexiglas vessel to observe the motion of the quartz particles. The size and geometry of the system were identical to the actual reactor, and the conditions were set up to duplicate as closely as possible the actual experimental system. Since the plexiglas system could only operate at room temperature, the liquid conditions, particularly viscosity, were somewhat different than the actual water properties at elevated temperature. However, since Zwietering's empirical correlation (Equation (E-1)) suggests only a weak dependence on liquid viscosity, these experiments should be sufficient to approximate actual stirred autoclave conditions.

Observations were made to estimate the minimum revolution speed 
Table 6. Minimum Rotation Speeds For Stirred Autoclave Experiments

\begin{tabular}{l|l|l|l|l|l} 
Run & $T\left({ }^{\circ} \mathrm{C}\right)$ & $d_{p}(\mathrm{~mm})$ & Weight (g) & $\begin{array}{c}\text { Cal cul ated } \\
\text { Minimum } \\
\text { RPM }\end{array}$ & $\begin{array}{c}\text { Actual } \\
\text { RPM }\end{array}$ \\
\hline A10 & 184 & 0.177 & 28.682 & 358 & 423 \\
A11 & 184.5 & 0.177 & 28.36 & 357 & 414 \\
A12 & 184 & 0.177 & 27.902 & 357 & 637 \\
A13 & 203 & 0.105 & 100.00 & 377 & 469 \\
A14 & 202 & 0.105 & 99.00 & 376 & 453 \\
A15 & 202.5 & 0.105 & 97.90 & 376 & 447 \\
A16 & 203 & 0.105 & 85.44 & 370 & 635 \\
A18 & 221 & 0.105 & 85.25 & 374 & 608 \\
A19 & 221 & 0.105 & 84.65 & 374 & 714 \\
A20 & 221 & 0.105 & 83.75 & 374 & 698 \\
A22 & 253 & 0.105 & 53.31 & 367 & 695 \\
A23 & 255 & 0.105 & 51.55 & 364 & 691 \\
A24 & 215 & 0.105 & 30.69 & 331 & 679 \\
A25 & 201 & 0.841 & 73.25 & 550 & 683 \\
A26 & 208 & 0.841 & 70.96 & 551 & 704 \\
A27 & 205 & 0.841 & 70.71 & 550 & 689 \\
A28 & 180 & 0.841 & 70.32 & 543 & 655 \\
A29 & 194 & 0.841 & 65.30 & 542 & 634 \\
A30 & 195 & 0.125 & 10.01 & 294 & 645 \\
A31 & 186 & 0.125 & 22.05 & 324 & 646 \\
& & & & &
\end{tabular}


required to suspend the particles. For the range of quartz weights of interest, the amount of quartz charged has little bearing on the minimum stirrer speed. This observation agrees qualitatively with Zwietering's correlation, which shows a weak dependence on the amount of quartz. Figure 12 is a plot of the minimum rotation speed versus particle size for the stirred autoclave reactor used in this study. While the curve is not a best fit based on a theoretical or empirical model, it certainly can be used as a guide to determine the appropriate rotation speed for this system. All experimental runs in this study were performed at a higher rotation speed than is suggested by Figure 12, assuring the suspension of the particles in each case.

Variation of rotation speed while leaving all other conditions constant is another experimental technique for determining the existence of mass transfer 1 imitations. If an increase in stirring rate results in no observable change in concentration response, then the system is in a regime where mass transfer effects are negligible. If, however, the rate of reaction increases with increased stirring rate, then the most probable explanation is that mass transfer effects are important, and that the increased mixing increased the mass transfer coefficient of the system. Ideally, to measure quartz dissolution reaction rates it is desirable to operate in a kinetically controlled regime. Otherwise, a mass transfer correlation must be used to subtract out the mass transfer effect from the observed data. Since this is a calculated rather than measured effect, the certainty of the kinetic results decreases.

Changing the stirring rate could affect the data in two ways: an increase could either increase the amount of quartz which is suspended in water or increase the mass transfer coefficient for the particles. The former may be ruled out on the basis of the experimental arguments presented above. Thus, this test is examining the possibility that an 


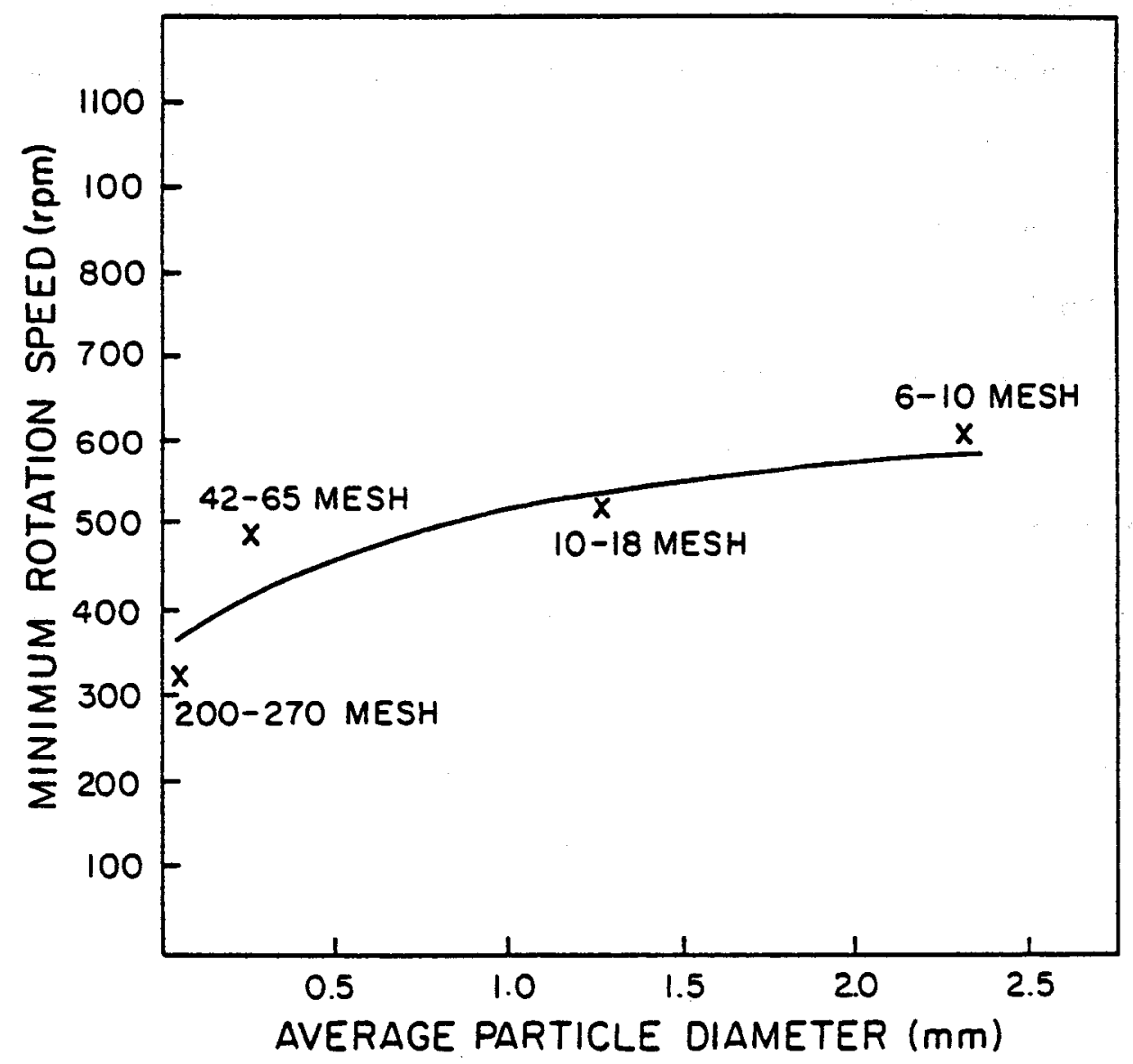

Figure 12. Experimentally Determined Minimum Stirrer Rotation Speed as a Function of Particle Size 
increase in mixing will el iminate mass transfer resistances which might occur at the lower rotation speeds. Figure 13 shows the response of two dissolution experiments carried out at approximately the same temperature and quartz surface area, the only variable being the rotation speed. Due to operating differences in the beginning of the experiment the curves are somewhat displaced from each other vertically, but their slopes, and hence their reaction rates, are comparable despite the difference in mixing rates. Indeed, Runs A14 and A16 resul ted in congruent values of the rate constant $k$ despite the difference in stirring rate.

Because the variation of $k$ was observed to be small with stirring rate, we are beyond the mass transfer controlled region. Ideally, an experimental study of mixing rate effects should be carried out at conditions where mass transfer limitations are most likely to occur. Since the mass transfer coefficient is coupled in series to the kinetic rate constant to yield the overall rate coefficient, high temperatures, which result in high chemical reaction rates, are most likely to exhibit rate behavior which is dependent on mass transfer. Due to the difficulty of maintaining the stirred autoclave at the highest temperatures for more than a few runs, it was not possible to carry out a varying rotation experiment at the highest temperature. However, the experimental evidence at lower temperatures, along with the theoretical calculation of the mass transfer coefficient, makes the assumption of no mass transfer 1 imitations a reasonable one for this system.

Estimating a mass transfer coefficient for the rocking arm experiments is more difficult since less work has been done to characterize mixing in this type of system. As before, the reaction rate is based on a particle fully suspended in water. Therefore, the mass transfer coefficient is probably not much different for the rocking 


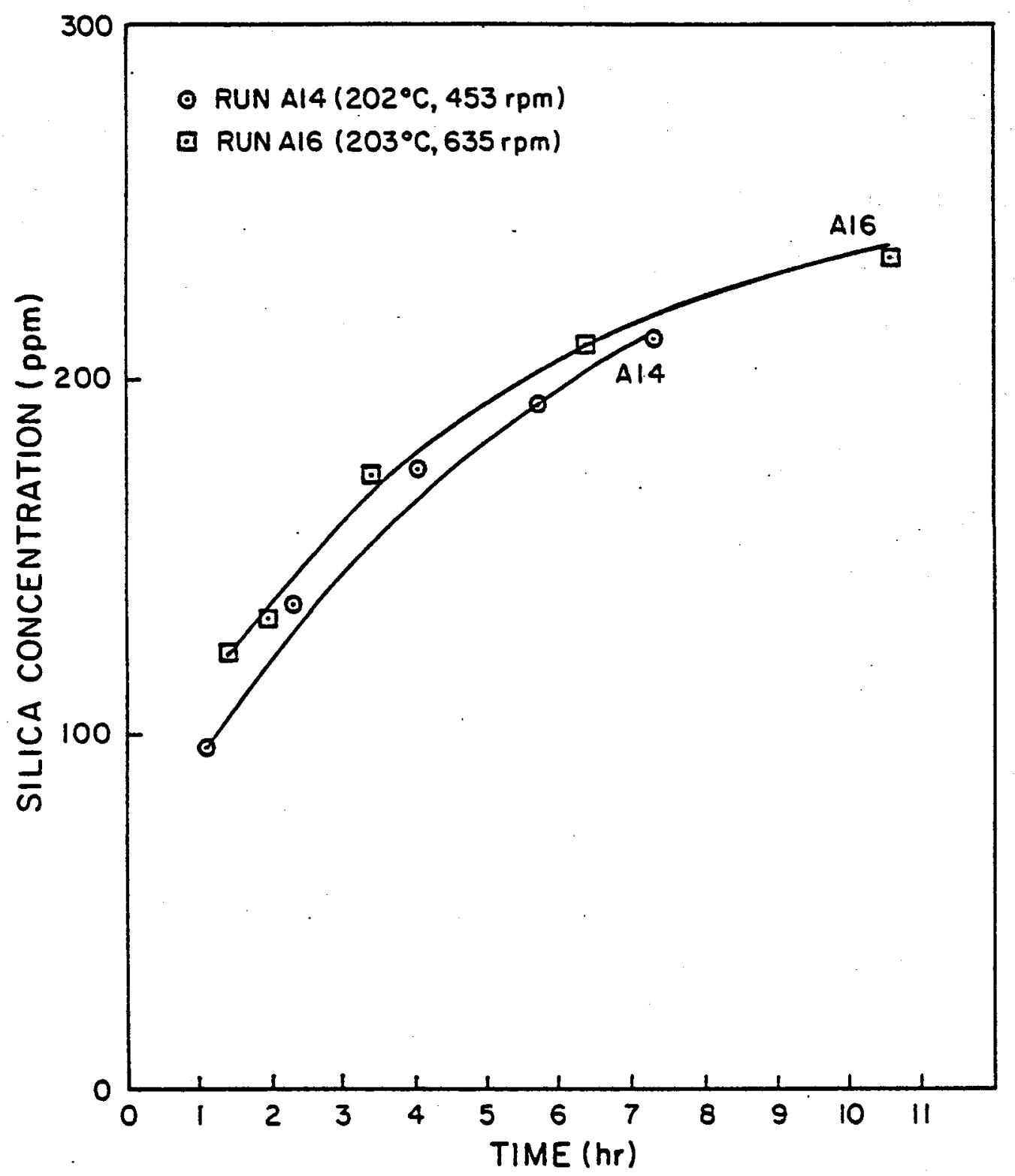

Figure 13. Comparison of Concentration vs. Time Responses of Two Experiments at Different Rotation Speeds. Vertical Displacement Between Curves Represents Differences in the Initial Operation of the Experiments 
arm reactor However, determining theoretically the arm speed necessary for complete suspension of the particles was not possible, and the simulation of flow in a plexiglas reactor seemed unjustified given the limited number of experiments performed using this system. However, there is evidence which suggests that the rocking arm experiments were completely in the kinetically controlled regime. By comparing the data of the rocking arm experiments to those for the stirred autoclave system, where the possibility of mass transfer limitations has been eliminated, one can assess whether mass transfer was important. The rate constant data obtained from these experiments scattered both above and below the data from the stirred autoclave. If mass transfer limitations had existed, the rocking arm data would have been consistently lower because of the slower solution rates which would have been measured.

\subsection{Granite Dissolution Experiments}

One other factor to consider is that the presence of other mineral phases in the reservoir appears to affect the kinetics of quartz dissolution. The biotite granodiorite found in the Fenton $\mathrm{Hill}$ reservoir is a mixture of four major and nine minor mineral phases, as is shown by the modal analysis in Table 7 (Charles et al., 1979). However, Charles (1979) showed that the quartz-water reaction is by far the dominant source of dissolved sllica in the geothermal fluid in the temperature range from $100-300^{\circ} \mathrm{C}$. Secondary zeolite phases precipitate in measureable amounts on the rock after exposure to high temperature (approximately $300^{\circ} \mathrm{C}$ ) circulating fluids for periods of 100 days or more (Charles, 1978). However, these phases do not affect the equilibrium of quartz dissolution in 
Table 7. Fenton Hill Biotite Granodiorite Modal Analysis

Sources: Charles et al. (1979) and Laughl in and Eddy (1977)

\begin{tabular}{|c|c|c|}
\hline Phase & Chemical Formul a* & $\begin{array}{c}\text { Vol ume } \\
\%\end{array}$ \\
\hline Microcl ine & $\mathrm{KAISI}_{3} \mathrm{O}_{8}$ & 15 \\
\hline Plagioclase & $\mathrm{NaAlSi}_{3} \mathrm{O}_{8}-\mathrm{CaAl}_{2} \mathrm{Si}_{2} \mathrm{O}_{8}$ & 40 \\
\hline Quartz & $\mathrm{SiO}_{2}$ & 30 \\
\hline $\begin{array}{l}\text { Biotite } \\
\text { and Chlorite }\end{array}$ & $\star *$ & 7 \\
\hline Magnetite & $\mathrm{Fe}^{2+} \mathrm{Fe}_{2}^{3+}{ }_{2}{ }_{4}$ & 1 \\
\hline Epidote & $\mathrm{Ca}_{2} \mathrm{Fe}^{3+} \mathrm{Al}_{2} \mathrm{O}^{\cdot} \mathrm{OH}^{\cdot} \mathrm{Si}_{2} \mathrm{O}_{7} \cdot \mathrm{SiO}_{4}$ & 1 \\
\hline Sphene & $\mathrm{CaTi}\left(\mathrm{SiO}_{4}\right) \mathrm{O}$ & 2 \\
\hline Calcite & $\mathrm{CaCO}_{3}$ & 2 \\
\hline Apatite & $\mathrm{Ca}_{5}\left(\mathrm{PO}_{4}\right)_{3} \mathrm{OH}$ & 2 \\
\hline Zircon & $\mathrm{Zr}\left(\mathrm{SiO}_{4}\right)$ & $\operatorname{tr}$ \\
\hline Sericite & $\mathrm{K}_{2} \mathrm{Al}_{4}\left(\mathrm{Si}_{6} \mathrm{Al}_{2} \mathrm{O}_{20}\right)(\mathrm{OH})_{4}$ & $\operatorname{tr}$ \\
\hline Sul fide & $\mathrm{FeS}_{2}$ & $\operatorname{tr}$ \\
\hline Prehnite & $\mathrm{CaAl}\left(\mathrm{AlSi}_{3}{ }^{\cdot} \mathrm{O}_{10}\right)(\mathrm{OH})_{2}$ & $\operatorname{tr}$ \\
\hline
\end{tabular}

* For actual modal analyses, see Laughl in and Eddy (1977)

** Biotite $=\mathrm{K}_{2}\left(\mathrm{Mg}, \mathrm{Fe}^{2+}\right)_{6-4}\left(\mathrm{Fe}^{3+}, \mathrm{Al}, \mathrm{Ti}\right)_{0-2}\left(\mathrm{Si}_{6-5^{\mathrm{Al}}}{ }_{2-3^{\mathrm{O}} \mathrm{O}_{2}}\right)(\mathrm{OH})_{4}$

Chl orite $=(\mathrm{Mg}, \mathrm{Al}, \mathrm{Fe})_{12}\left((\mathrm{Si}, \mathrm{Al})_{8} \mathrm{O}_{20}\right)(\mathrm{OH})_{16}$ 
granite to any great extent.

For all practical cases of interest studied so far, the equilibrium solubility of quartz certainly controls the dissolved silica concentration in geothermal fluids in which the contact time is long, but the question of dissolution kinetics for quartz in granite has still not been explored sufficiently. Therefore, stirred autoclave experiments using crushed granite were performed in this study. By assuming a quartz surface area of $30 \%$ of the total, a rate constant for quartz dissolution in granite may be obtained. The results of these experiments are shown in Table 3 and the rate constant values plotted alongside those for pure quartz dissolution in Figure 14. For a given temperature, the rate constants fall an average of 1.5 orders of magnitude higher than those for pure quartz dissolution. Blatz et al. (1977) performed similar experiments using the same granite and found dissolution rate constants which agreed roughly with the findings of the present study.

There are several experimental observations which may be used to account for the discrepancy between the rates of granite (quartz) and pure quartz dissolution in these crushed particle experiments. First, colloidal silica formed in the samples of the granite dissolution experiments at silica concentrations that were no higher than those in the pure quartz experiments, where no polymerization was observed. To analyze these samples, the colloids were dissolved using a method suggested by Holley (Sept. 1981). The $3 \mathrm{ml}$ samples were treated with $160 \mu \mathrm{l}$ of concentrated $\mathrm{HF}$ and heated to $90^{\circ} \mathrm{C}$ for approximately one hour. The silicon fluoride complexes formed in this process were then converted back to sillicic acid monomers using $5 \mathrm{ml}$ of $23.2 \mathrm{~g} / 1$ (based on $\left.\mathrm{Al}^{3+}\right) \mathrm{Al}_{2}\left(\mathrm{SO}_{4}\right)_{3}$ solution per milliliter of $\mathrm{HF}$ treated sample. The molybdate yellow technique was then used to complete the analyses. 


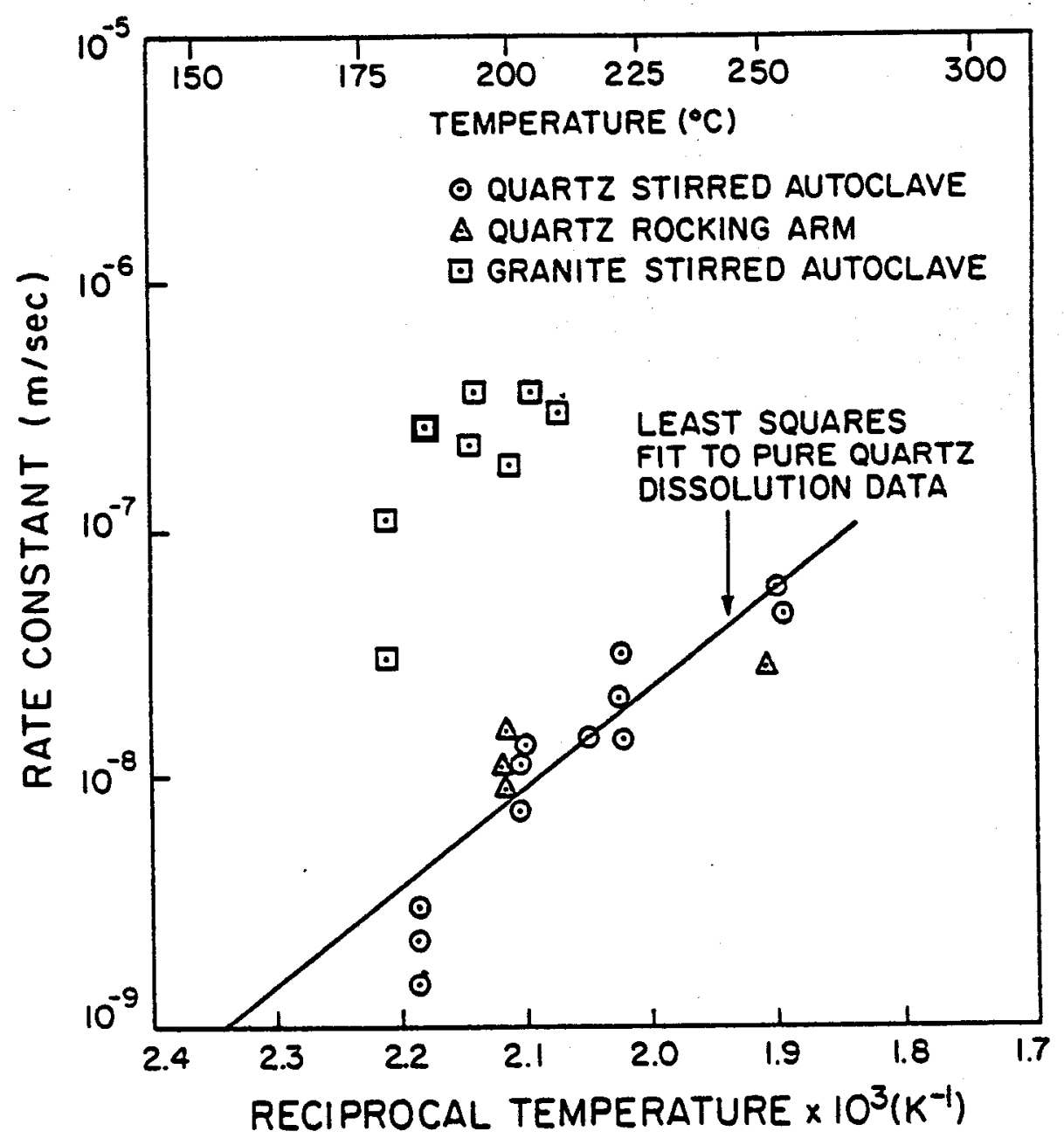

Figure 14. Comparison of Rate Constants Obtained from Pure Ouartz and Granite Dissolution Experiments 
The fact that colloidal silica was found in these experiments suggests that the monomer concentration, which controls the rate of quartz dissolution, could have been much lower than the values found in these runs. For this to be a valid explanation, the colloids would al so have to exist at the temperature of the experiment, and not have been formed subsequently during the sample cooling and preparation steps. There is no experimental evidence in this study which can prove or disprove this hypothesis, but in Chapter 5 it is shown that the solubility of amorphous silica must be exceeded before polymerization can occur. At the temperature of these experiments, it is unl ikely that any colloidal silica would exist. It should be pointed out that this problem was not encountered in the chemical analyses of the geothermal fluid at Fenton $\mathrm{Hill}$, which these experiments are meant to simulate.

A more likely explanation is that small fines of sllica exist on the particles as in the pure quartz experiments, but in much greater quantities. The experimental technique of reusing the same granite in successive experiments did not solve the problem. The data in Appendix $B$ show that the initial concentration of dissolved silica remained high even after five experiments using the same granite. Two independent experiments were performed using the rocking arm apparatus in which the surface area to fluid volume ratio was made very large to ensure that the damaged layer would not be completely dissolved. At $215^{\circ} \mathrm{C}$, the silica concentration rose rapidiy to over $400 \mathrm{ppm}$, much higher than the equilibrium solubility of quartz at that temperature (298 ppm).

The SEM photographs shown in Figures 15 and 16 substantiate this explanation for the rapid apparent rate of quartz dissolution in the stirred autoclave granite dissolution experiments. Figure 15 is a photograph of a typical 100-140 mesh erushed granite particle before being used in a dissolution experiment. The small fines adhering to the 


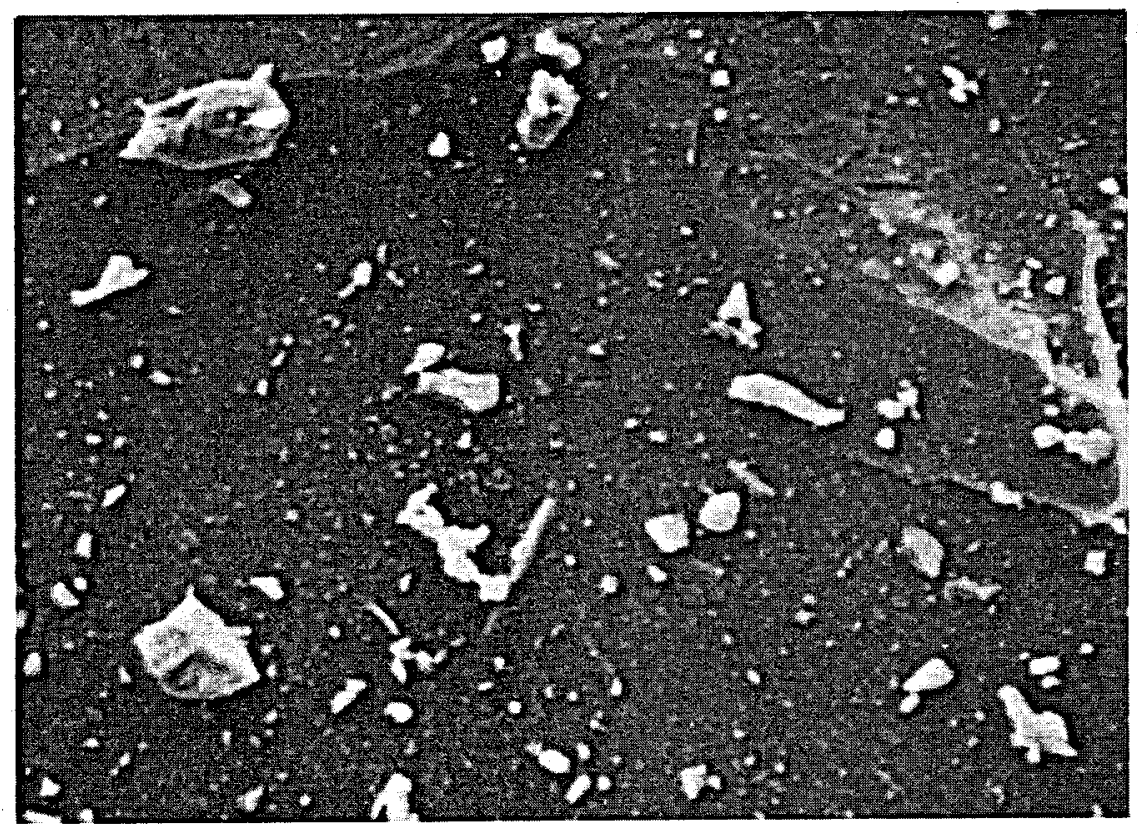

$5 \mu \mathrm{m}$

Figure 15. SEM Photograph of a Crushed Granite Particle Before Runs A30 and A31
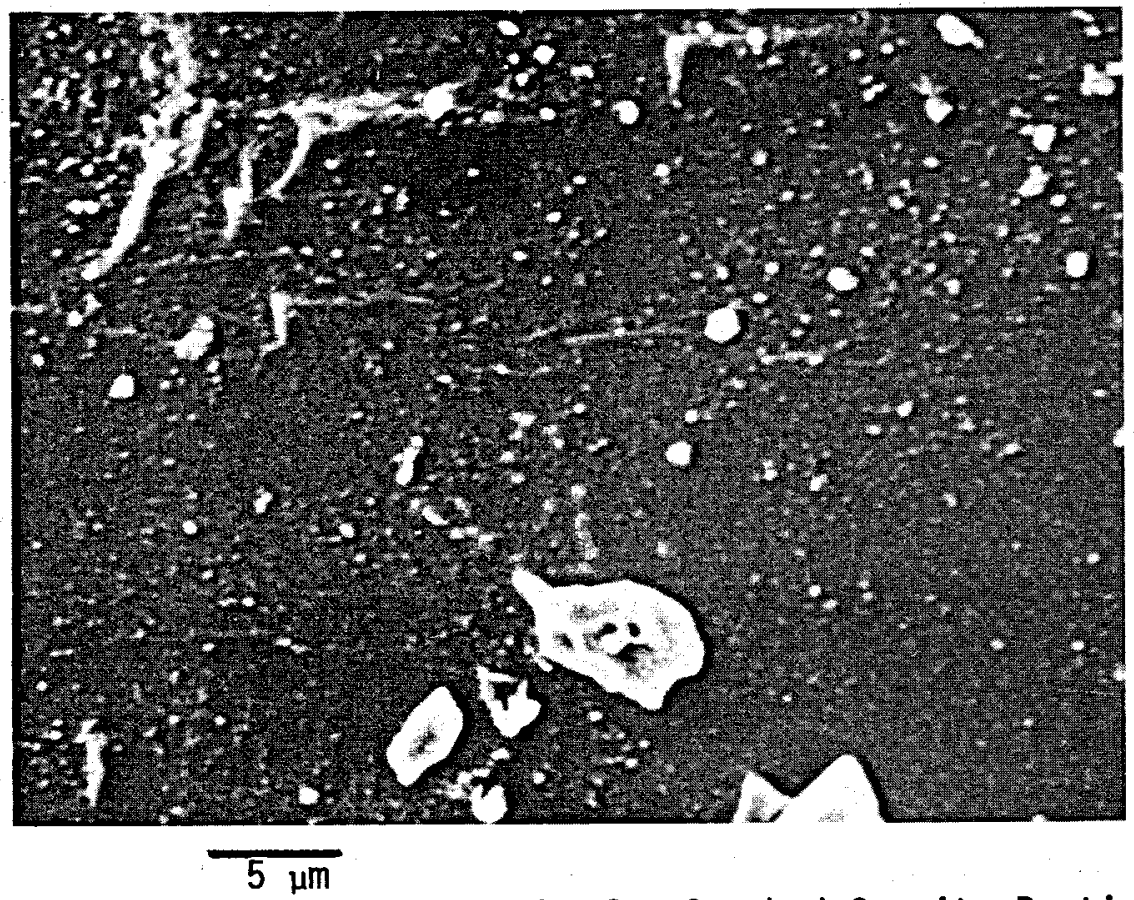

Figure 16. SEM Photograph of a Crushed Granite Particle After Runs A30 and A31 
surface were presumably formed during the crushing process. As shown in Figure 16, these fines are still present in large quantities after two runs in the stirred autoclave (Runs $A 30$ and 31 ) at elevated temperature. Thus, it is quite possible that in these experiments the rapid dissolution of small fines falsified the entire experiment, rather than just the initial rate data, as in the pure quartz experiments.

In Chapter 4, it will be shown that the rapid granite (quartz) dissolution kinetics found in the present study and in the work of Blatz et al. (1977) must be used to describe the dissolved silica behavior observed in the Fenton Hill reservoir. The pure quartz dissolution rate constant expression predicts rates which are too low to provide a reasonable fit to the field data. Although the high rates of dissolution for granite observed in the stirred autoclave experiments should be expected to exist in actual reservoir systems, the mechanism under which this rapid dissolution occurs is unclear at the present time. If the amount of in situ damaged material in a HDR geothermal reservoir is of the same magnitude as the amount on the crushed granite particles used in the stirred autoclave experiments, then a simple calculation (see Appendix $F$ ) reveals that these particles would be dissolved completely in the first few days of operation of the reservoir. Therefore, the rapid fine dissolution explanation does not appear to be adequate to explain the dissolution rates in the Phase I system. Rotating disc granite dissolution experiments are currently being planned to explore this phenomenon. 
Hot Dry Rock Geothermal Reservoir Computer Model

\subsection{Introduction}

Under certian operating conditions in HDR systems the geothermal water is in contact with hot reservoir rock for an insufficient amount of time for the fluid to come to equilibrium with respect to quartz. This departure from saturation can be used to estimate the effective heat transfer area of the reservoir. In order to predict the outlet concentration of dissolved silica for such a case, a model of the geothermal system must be constructed which approximates the actual conditions of reservoir geometry, temperature, and fluid flow rate. Then the simple granite dissolution rate law may be coupled to this model to predict the concentration of dissolved silica.

The purpose of this chapter is to demonstrate how granite dissolution kinetics can be used to explain much of the dissolved silica data from field tests of the HDR geothermal reservoir at Fenton $\mathrm{Hill}$, New Mexico. After demonstrating that the computer model provides a reasonable fit to existing field data, the model is used to predict the sillica concentration in a larger, hotter Phase II reservoir which is presently being developed at Fenton Hill. This predictive capability is helpful in evaluating the possibility of silica deposition in the above-ground heat exchange equipment and in the cold portion of the wellbores and reservoir itself. Finally, modeling results will be used to show that other chemically reactive tracers may provide an excellent method for estimating the effective heat transfer area of a HDR geothermal reservoir. 
As the HDR reservoir model is developed, it will become evident that silica concentration data alone will not explain the complex geothermal system at Fenton Hill. Additional information from independent experiments are utilized to estimate important system parameters needed for this new model. Therefore, the model presented in this study should not be considered as an independent calculation, but rather as one piece of information which adds insight to the overall understanding of the Fenton Hill reservoir.

\subsection{The Fenton Hill HDR Geothermal Reservoirs}

The information contained in this section is obtained from Los Alamos Scientific Laboratory reports by Zyvoloski et al . (1981), Dash et a1. (1981), Tester and Albright. (1979), and Murphy et al. (1980) on the Fenton Hill, N.M. reservoir system and field test results. One concept for HDR geothermal exploitation involves increasing the effective permeability of inherently low permeability rock contained in deep, hot crystalline basement formation. More or less conventional drilling techniques are used to gain access to depths where the rock is hot enough to be of commercial interest for energy extraction. Rock permeability is enhanced by hydraulic fracturing to create a network of high fluid conductivity paths. Energy is removed by pumping cold water down one wellbore to the fracture system, forcing it to sweep across a large surface area of hot rock, and recovering the hot fluid in a second well bore (Smith et al., 1975).

Theoretically, due to the nature of the earth stresses encountered in fracturing, fractures formed by hydraul ic pressure are vertically incl ined. In reality, many fractures may be opened along existing natural fractures to form the final geothermal reservoir. To realize 
efficient, long-term energy extraction (20 years or more) from a HDR reservoir, the effective heat transfer area must be on the order of $1-2 \times 10^{6} \mathrm{~m}^{2}$. This could be achieved by creating one large fracture of at least $1000 \mathrm{~m}$ radius, a number of smaller, discrete fractures, or a highly permeable volumetric zone through which the fluid sweeps. Of course, for efficient heat removal the fluid must sweep across the entire surface area of fractures and not short-circuit from inlet to outlet, or else the smaller area of rock involved will be cooled down very quickly. The active surface area might be increased during operation by the mechanism of thermal stress cracking (Demuth and Harlow, 1980), in which the rock adjacent to the fracture cracks due to the large temperature gradient in the rock perpendicular to the fracture.

The HDR reservoirs being studied in this paper are located at Fenton Hill, in the Jemez Mountains of New Mexico. The first experimental reservoir was formed by drilling a borehole (GT-2) to a depth of 2.929 $\mathrm{km}$ and temperature of $197^{\circ} \mathrm{C}$ and performing several fracture experiments. The EE-1 wellbore was drilled in an unsuccessful attempt to intersect a fracture initiated near the bottom of GT-2. Because of a failure in the wellbore surveying instruments, a direct connection into the GT-2 fracture system was not achieved. Later, after a year or so of testing and attempting various methods to improve the connection between EE-1 and GT-2, a connection was made by redirecting the bottom of the GT-2 wellbore toward a large fracture initiated near $2.8 \mathrm{~km}$ in EE-1. A low impedance connection was made with a vertical separation of $100 \mathrm{~m}$ between the redrilled section of $G T-2 B$ and the injection zone in EE-1. A 75 day, closed-1 oop energy extraction experiment was then performed, producing a fluid which was initially at $175^{\circ} \mathrm{C}$, but rapidly declined to $85^{\circ} \mathrm{C}$ by the end of the experiment. The effective heat transfer area, 52 
estimated using a heat transfer model similar to the one presented in Section 4.3, was $8000 \mathrm{~m}^{2}$ for this reservoir (one side of the fracture). The EE-1 wellbore was then recemented to seal off the injection zone at $2.9 \mathrm{~km}$ in an effort to create a larger reservoir connected vertically between EE-1 at $2.9 \mathrm{~km}$ and $\mathrm{GT}-2 \mathrm{~B}$ at $2.7 \mathrm{~km}$. Hydraulic fracturing in EE-1 was again used to produce a low impedance connection over the $300 \mathrm{~m}$ of vertical wellbore separation. A 286 day experiment was performed to examine the heat transfer, flow impedance, and water loss characteristics of the reservoir. The entire history of experiments to this point is known as Phase I, but in this study only the 286 day experiment (Segment 5 of Phase I) is considered for comparing the model predictions.

Phase II is an ambitious new initiative designed to demonstrate the feasibility of the HDR geothermal concept with a commercial-sized reservoir. Two new wells, EE-2 (3.977 km and $\left.302^{\circ} \mathrm{C}\right)$ and EE-3 (4.398 km and $327^{\circ} \mathrm{C}$ ), with a vertical separation distance of $300 \mathrm{~m}$, were completed in August, 1981. Fracturing is scheduled to start before the summer of 1982. A larger surface area (eventually $1-2 \times 10^{6} \mathrm{~m}^{2}$ ) is to be produced by forming multiple fractures spaced at approximately 50 meter intervals along a $35^{\circ}$ inclined wellbore pair. The hotter rock exposed in this reservoir will pose new geochemical problems not encountered in the Phase I system. The most troublesome problem is the increased likelihood of silica scaling due to the higher concentration of dissolved silica which will be found in the produced and recirculated fluid.

\subsection{HDR Reservoir Model}

Any attempt to model the silica behavior in a HDR reservoir must simulate the temperature field and flow geometry of the system. Predicting the correct temperature field is essential because of the 
strong temperature dependence of the dissolution rate constant and equilibrium solubility of quartz in granite. Assuming a reservoir geometry will allow for the estimation of $\mathrm{a}^{*}$, the rock surface area to fluid volume ratio. If a realistic set of specified and adjustable parameters is chosen, then a model which incorporates a granite dissolution rate law should accurately predict the dissolved silica behavior.

For this analysis, the model chosen to represent the HDR reservoir is a simple one-dimensional plug flow model in which the fluid flows vertically up a rectangular fracture (see Figure 17 ). This crude geometry of a flat crack with smooth walls results in a lower bound of $a^{*}$. However, if the fluid follows tortuous paths through the reservoir. the active surface area for dissolution could be much larger than the effective heat transfer surface area. Heat is transferred to the fluid by conduction perpendicular to the flow direction. To solve for the temperature field analytically, several simplifying assumptions must be made. The initial temperature of the rock, $T_{r}$, is assumed to be independent of depth. In reality, the natural thermal gradient in the vertical direction at Fenton $\mathrm{Hill}$ is approximately $60^{\circ} \mathrm{C} / \mathrm{km}$, so for typical values of $L$ ( $300 \mathrm{~m}$ in the present case), the gradient is not really. negligible. Also, the heat transfer coefficient for the flowing water is assumed to be large enough that the fluid reaches thermal equilibrium with the rock at all points in the fracture. Finally, for heat transfer in the rock, one-dimensional conduction in the $x$ direction is assumed. These two heat transfer assumptions can be justified using an order of magnitude analysis (Murphy et al., $\cdot 1981$ ).

Employing these simplifications. Arpaci (1966) solved a similar heat transfer problem analytically by equating the heat conduction in the rock to vertical convective heat transfer in the fluid (see Appendix $G$ ):

$$
\theta=\operatorname{erf}\left[\frac{\lambda_{r} A z}{\overline{\rho C}_{p} L Q(\alpha t)^{1 / 2}}\right]
$$




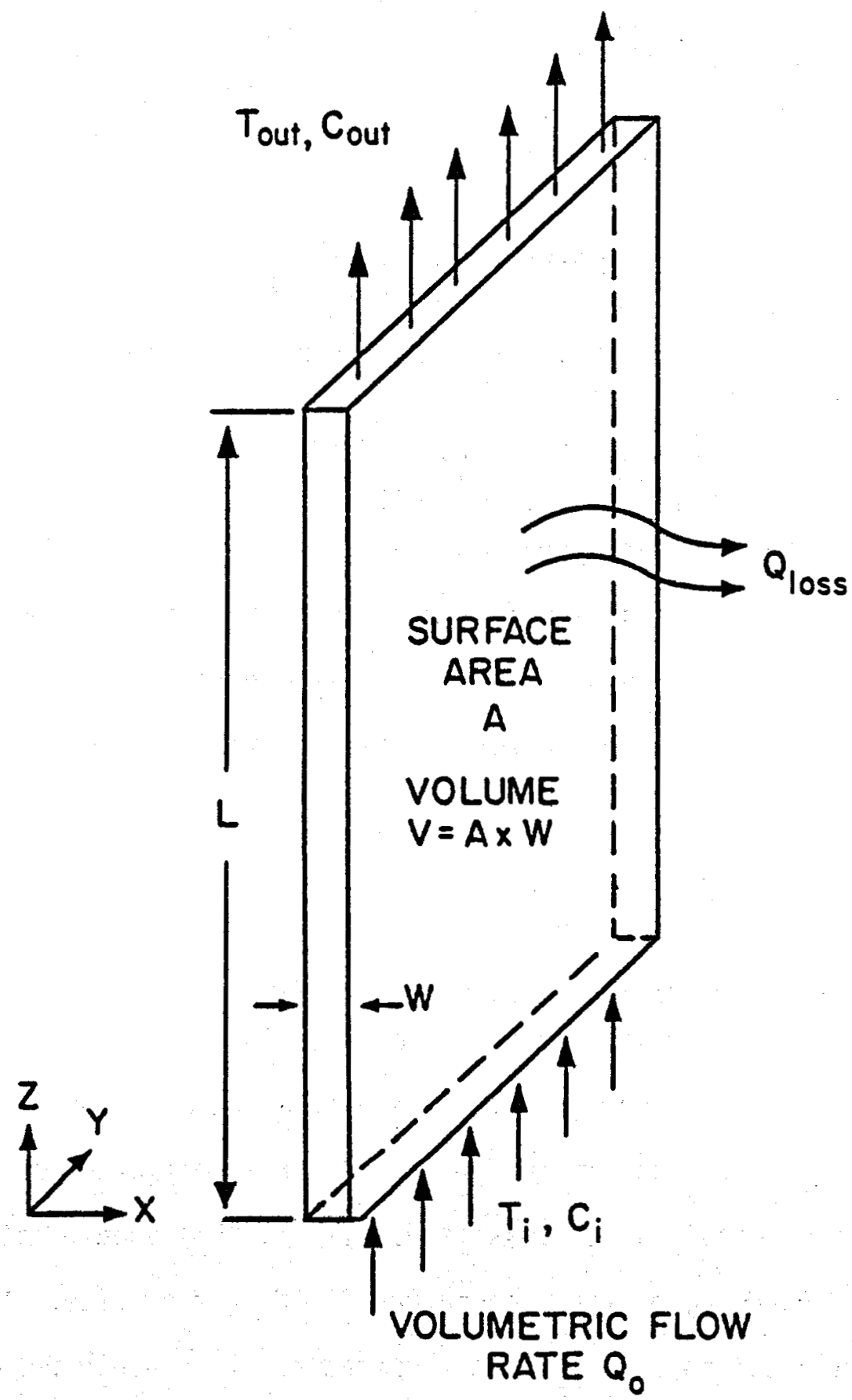

Fiaure 17. Diagram of the PHR Reservoir Model 
where

$\theta=$ dimensionless rock temperature $=\left(T-T_{i}\right) /\left(T_{r}-T_{i}\right)$

$T=$ local fluid temperature $(K)$

$T_{i}=$ inlet fluid temperature $(K)$

$T_{r}=$ initial rock temperature $(K)$

$\lambda_{r}=$ rock thermal conductivity ( $\left.W / m-s e c-K\right)$

$A=$ surface area of one face of fracture $\left(\mathrm{m}^{2}\right)$

$\overline{P C}_{p}=$ average fluiddensity-heat capacity product $\left(\mathrm{W} / \mathrm{m}^{3}-\mathrm{K}\right)$

$L=$ height of fracture $(m)$

$Q=$ volumetric flow rate of fluid $\left(\mathrm{m}^{3} / \mathrm{sec}\right)$

$\alpha=$ rock thermal diffusivity $\left(\mathrm{m}^{2} / \mathrm{sec}\right)$

$t=t$ ime from start of operation ( $\mathrm{sec})$.

Fluid loss in the fracture system is neglected in this derivation, but for the purposes of this model, it is assumed that a linear flow. rate loss in the vertical direction may be used to describe the flow rate in Equation (4.3.1). Thus,

$$
Q=Q_{0}\left(1-Q_{1} \stackrel{z}{L}\right) \text {, }
$$

where

$Q_{0}=$ inlet fluid volumetric flow rate $\left(\mathrm{m}^{3} / \mathrm{sec}\right)$

$Q_{1}=$ total fractional volumetric flow rate loss.

The validity of using a variable flow rate in Equation (4.3.1) despite the constant flow rate assumption in the original derivation seems justified since a small water loss (typically 10-15\%) should not change the overall dependence of the temperature field on flow rate. A more rigorous analytical solution of the temperature field would require a non-linear superposition to account for the flow rate decline due to water loss.

It is instructive to look at the behavior of the temperature field as predicted by this model for a typical set of operating conditions. Figure 18 shows the temperature of the fluid (and, hence the rock temperature at the rock-fluid interface) as a function of vertical 


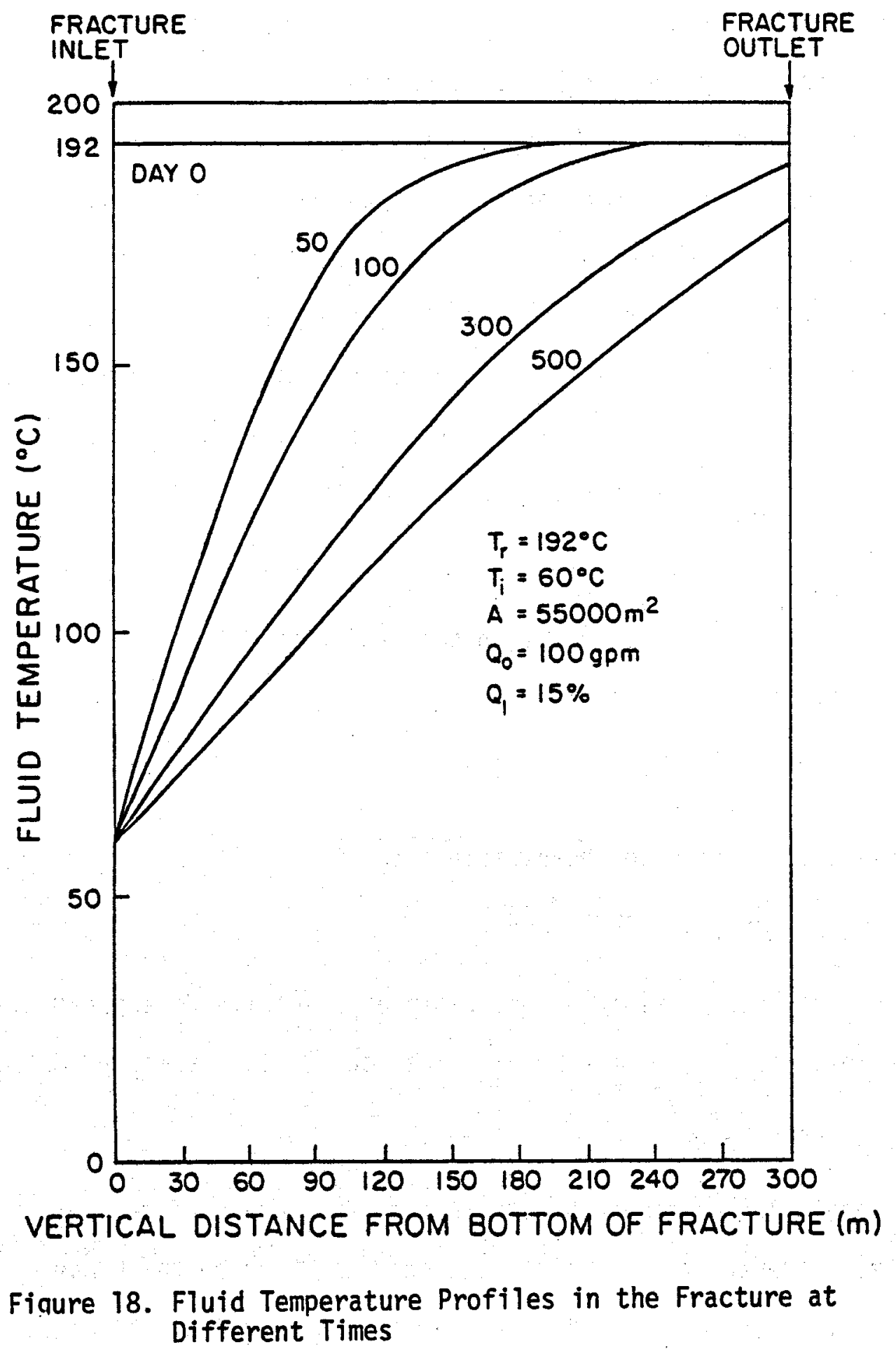


distance $z$ at different times. Upon extracting heat from the initially constant temperature reservoir, the rock in the injection zone in the lower section of the fracture cools off rapidly. As more heat is extracted, the cold temperature wave moves further up the fracture, but the observed outlet temperature remains constant. Finally, the temperature wave reaches the top of the reservoir, after which thermal drawdown in the produced fluid is observed.

The next step in the model is to couple the error function temperature solution (Equation (4.3.1)) to the granite dissolution rate law. If a volume element of fluid is followed as it travels up the fracture, the one-dimensional plug flow assumption (no dispersion or velocity gradients in the $z$ or $y$ direction) makes it possible to use Equation (2.3.1) directly. The substitution necessary to convert from the independent variable $t$ to $z$ is

$$
d z=\bar{u} d t
$$

where $\bar{u}=$ average fluid velocity in the $z$-direction $(\mathrm{m} / \mathrm{sec})$.

Then Equation (2.3.1) becomes

$$
\frac{d C}{d t}=\frac{k a^{\star}}{\bar{u}}\left(C^{\infty}-C\right) \text {. }
$$

Expressing $\bar{u}$ in terms of measurable parameters,

$$
\bar{u}=\frac{Q L}{V} .
$$

The surface area to fluid volume ratio $a^{*}$ is easily determined due to the simple geometry of the model. The rectangular geometry implies that

$$
a^{*}=\frac{2 A}{V} \text {. }
$$

Equation (4.3.6) assumes that the entire fracture surface area is quartz. However, this model is designed to describe the behavior of the Fenton Hill system, in which the granite has been found to contain approximately $30 \%$ quartz (Charles et al., 1979). Thus, for this model, 


$$
a *=\frac{0.6 \mathrm{~A}}{V}
$$

Substituting Equations (4.3.7) and (4.3.5) into Equation (4.3.4) and simpli fying,

$$
\frac{d C}{d z}=\frac{0.6 \mathrm{kA}\left(C^{\infty}-C\right)}{Q L} \text {. }
$$

A computer code was then developed (see Appendix $H$ ) to numerically integrate Equation (4.3.8) using the trapezoid rule. The rate constant expression for quartz dissolution in granite was assumed to have the same activation energy as was found for pure quartz, but the pre-exponential factor was chosen to be 100 times larger to account for the more rapid dissolution rates for granite. This factor should be considered an adjustable parameter which results from uncertainties in the granite dissolution kinetics and the actual value of $a^{*}$ in the reservoir. For a given inlet concentration, the computer program calculates the concentration profile in the fracture, from which the dissolved silica concentration in the produced fluid may be obtained.

The mode of operation of the HDR geothermal system plays an important role in the outlet silica concentration in the produced fluid. In the Phase I system, to conserve water the fluid was recirculated in a closed loop mode. The only fresh water added was to make up for the small amount of water loss experienced in the fracture system. While the temperature field is unaffected by recirculation, the outlet silica concentration should reach its equilibrium value since the fluid has a much longer average residence time in the fracture. The fluid is diluted slightly by make-up water before being pumped downhole, but usually it will approach the equilibrium quartz solubllity concentration before it reaches the surface again. The computer model just developed handles the recirculation problem by calculating the outlet concentration for a single pass through the system, diluting with 
make-up fluid, and using that concentration as the inlet concentration for the next pass through the reservoir.

For experimental purposes, the Fenton Hill system may also be run without recirculation in the so-called fresh water flush mode: the inlet fluid is $100 \%$ make-up water, and the outlet fluid is discarded after extracting the heat. In this case, the fluid may not be in the fracture system long enough for the dissolved silica concentration to come to equilibrium with respect to quartz. Data from an open-loop test of this type can be used to verify the model results for the dissolved silica concentration. For the cases considered in this study, the field data is simulated by adjusting the effective heat transfer surface area, which may be estimated from the temperature drawdown in the outlet fluid (Murphy et al., 1981). The initial rock temperature is adjustable to a certain extent, the range of reasonable values bounded by temperature logs in the wellbore (Murphy et al., 1980) and initial produced fluid temperatures. The other parameters, such as flow rate, water loss, and inlet temperature and silica concentration are directly measurable.

A revision of the model is necessary in order to describe more accurately the actual chemical behavior of the Phase I system at Fenton Hill. As cited in previous field investigations conducted at Fenton Hill (Tester and Albright, 1979, Murphy et al., 1980, and Zyvoloski et al., 1981), granite dissolution cannot account for the presence of chloride ions observed in the recirculated fluids. One possible explanation is that the $\mathrm{Cl}^{-}$ions exist as "pore fluid" trapped in grain boundaries and microfractures or as fluid inclusions contained within the solid matrix. These pore fluids may have been initially deposited during the mineral formation process and can undergo slow but conti nuous geochemical change over the existence of the formation. For practical purposes, the $\mathrm{Cl}^{-}$pore fluid composition is assumed to be equivalent to 
the stagnant concentration observed in the wellbore (approximately 1750 $\mathrm{ppm})$. The actual system showed a steady, nonzero concentration of $\mathrm{Cl}^{-}$ Ions even after continuous dilution with make-up water, indicating that the produced fluid contains a measurable amount of pore fluid as it circulates through the reservoir.

The model proposed to account for the pore fluid contribution is shown diagramatically in Figure 19 (see also Zyvoloski et al., 1981). The pore fluid contributes to the overall outlet fluid composition in an analogous fashion to two reactors operating in parallel: the main fracture flow path and a secondary flow path. A mass balance on the $\mathrm{Cl}^{-}$ ions indicates that, given this model, the pore fluid contributed approximately $5 \%$ of the total flow for the phase I system. The dissolved silica in the outlet fluid was also affected by the pore fluid contribution. The concentration of dissolved silica immediately after startup (260 ppm) is presumed to be the silica concentration in the pore fluid. This contribution is added to the silica source from the main fracture to obtain the observed outlet silica concentration, To make the model applicable to both the Phase I and Phase II systems, it is assumed that the pore fluid has a silica concentration equal to the equilibrium concentration with respect to quartz at the initial rock temperature.

\subsection{Phase I Computer Simulations}

The model developed in the preceding section can be used either to fit the dissolved sillica data In the Phase I system or to simulate the behavior of the proposed Phase II system. In order to test the validity of the many simplifying assumptions of the model, the Phase I data must 


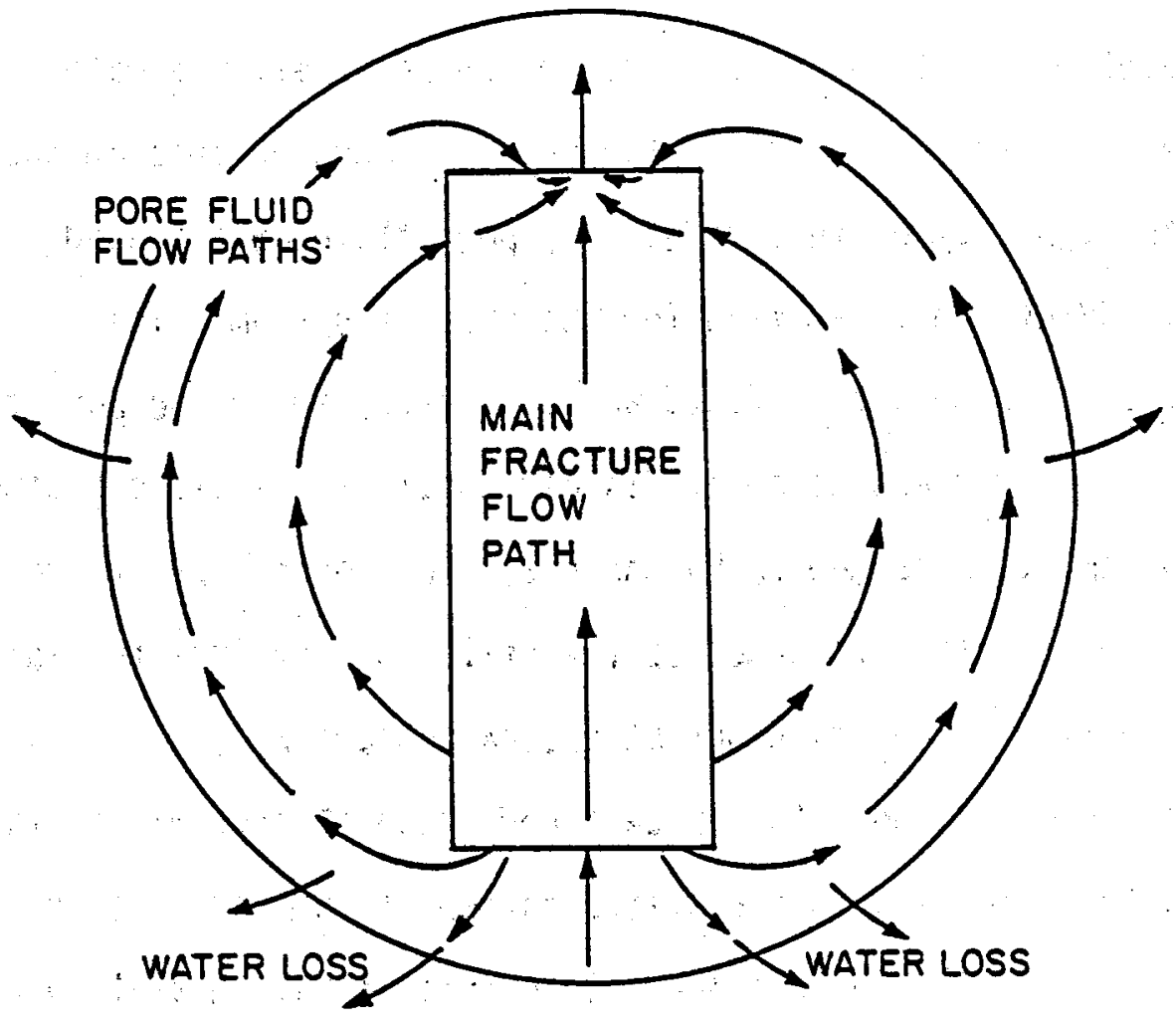

Figure 19. Schematic Diagram of the Pore Fluid Model 
first be examined.

Fresh water flush experiments, where water low in total dissolved solids is injected into the system, offer much more sensitive data for this type of analysis than do long-term recirculation experiments because the recirculating system will approach the equilibrium quartz solubility no matter what the size of the reservoir. Unfortunately, only one fresh water flush experiment was performed in the Phase I reservolr, on day 230 of the 286 day experiment. Even this experiment was not allowed to run to completion before the recirculation mode was resumed becalase of the large fresh water requirements. The dispersive effects of the reservoir are such that the fresh water flush would have required several days to reach its ultimate steady state. Because of water supply limitations the experiment was terminated before reaching a steady state concentration of dissolved silica. Using independent geochemical and reservoir modeling information, Grigsby (1981) estimated that had the experiment been allowed to continue in the non-recirculating mode, the silica concentration would have declined to a steady value of $151 \pm 4 \mathrm{ppm}$, after accounting for the effect of the pore fluid on silica concentration. The actual field data, reproduced in figure 20. shows the decrease in dissolved silica concentration at day 230 due to the fresh water flush.

The model presented in the preceding section may now be used to calculate, for a given heat transfer surface area, the initial rock temperature necessary to reproduce the estimated value of the dissolved sillica concentration for the fresh water flush conducted on day 230. Figure 21 represents the results of a calculation assuming a surface area of $55000 \mathrm{~m}^{2}$, which is consistent with values obtained by modeling the thermal drawdown (Zyvoloski et al., 1981). The curves are representations of the dissolved silica concentration in the fluid in 


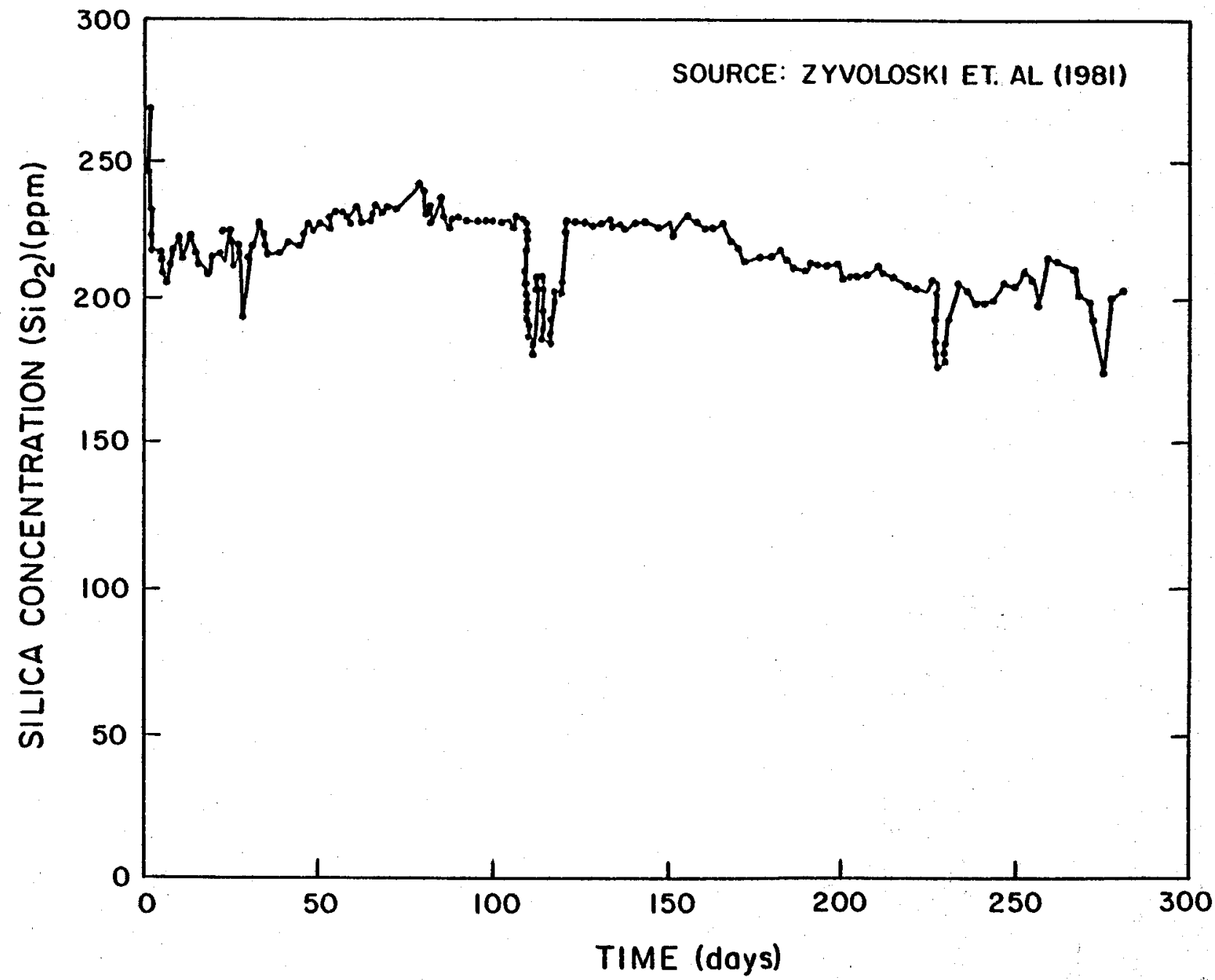

Figure 20. Phase I Run Segment 5 Produced Fluid Dissolved Silica Concentration 


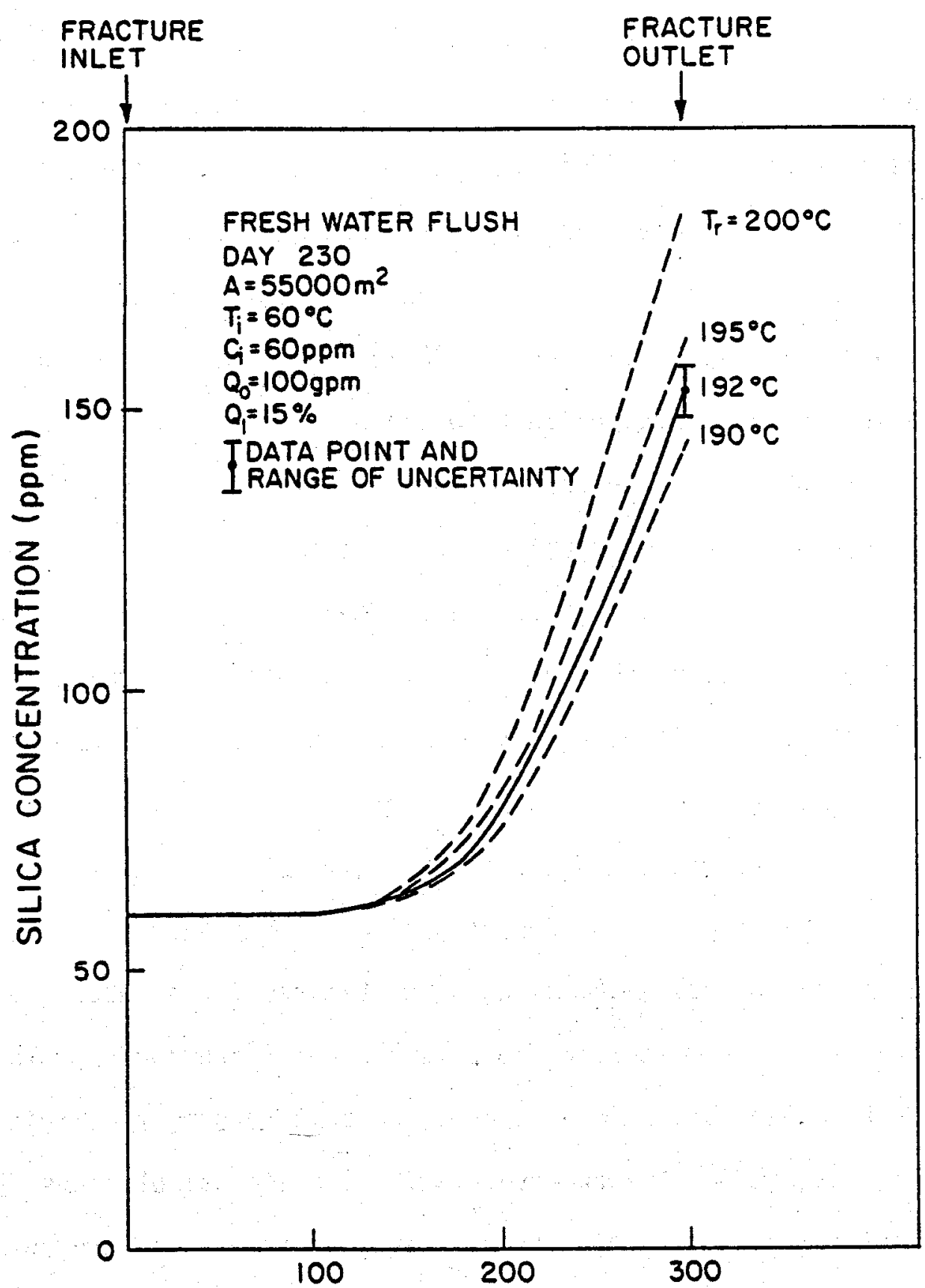

VERTICAL DISTANCE FROM BOTTOM OF FRACTURE $(\mathrm{m})$

Figure 21. Computer Simulation of the Day 230 Fresh Water Flush Data for $A=55000 \mathrm{~m}^{2}$ for Different Assumed Initial Rock Temperatures 
the fracture as a function of vertical distance from the inlet.

The shape of these curves is largely controlled by the temperature profile within the fracture and the corresponding equilibrium concentration profile for silica. Figure 22 shows that in the first 65 meters of the fracture, dissolution is impossible because the inlet concentration (60 ppm) is greater than the equilibrium value for quartz at that temperature. From 65 to 120 meters, a concentration driving force exists but the temperature is still too low for any appreciable dissolution to occur--the kinetics of quartz dissolution are too slow in this region of the reservoir. Above 120 meters, the slope of the concentration curve is proportional to the product of the concentration driving force (which remains relatively constant) and the kinetic rate constant (which increases dramatically with temperature).

Figure 21 demonstrates that for an assumed fracture surface area of $55000 \mathrm{~m}^{2}$, the best. fit to the outlet silica concentration during the fresh water flush experiment occurs when the initial rock temperature is $192 \pm 2^{\circ} \mathrm{C}$. This is obviously not a unique fit of the data, since other combinations of area and temperature would give similar results. Figures 23 and 24 show that different yet reasonable values of the surface area may be chosen which match the 1 imited fresh water flush data available, if other initial rock temperatures are chosen. The problem is that variations in both area and temperature are within experimental bounds for the reservoir. The computer simulations represented in Figures 21,23 , and 24 show that the 1 arger the surface area, the lower the initial rock temperature required to achieve the observed silica concentration. This result is logical since hotter temperatures increase the kinetics of quartz dissolution. This rapid rate of reaction must be counterbalanced by a smaller quartz surface area in order to achieve the same outlet concentration. 


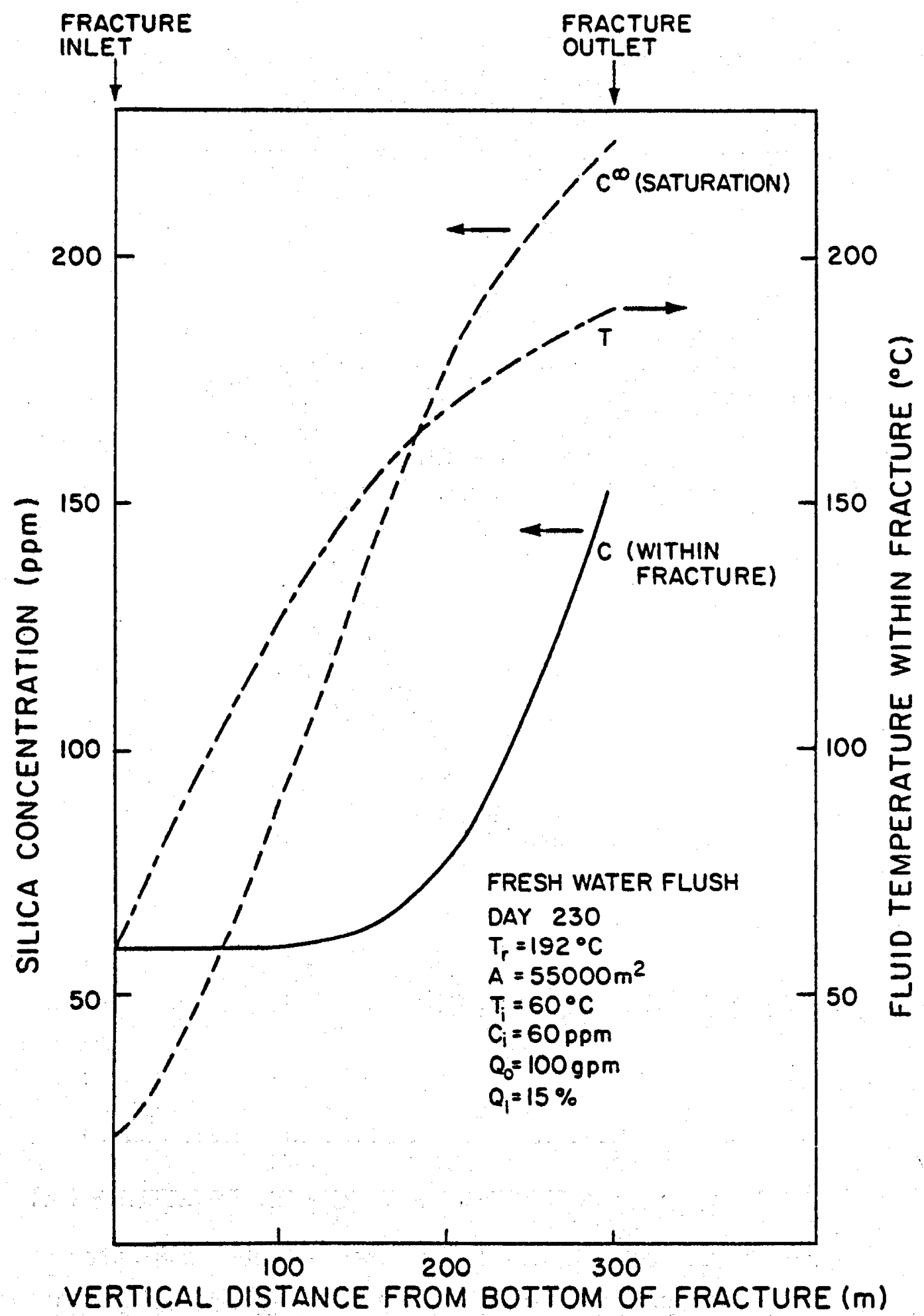

Figure 22. Computer Simulated Concentration and Temperature Profiles for a Fresh Water Flush 


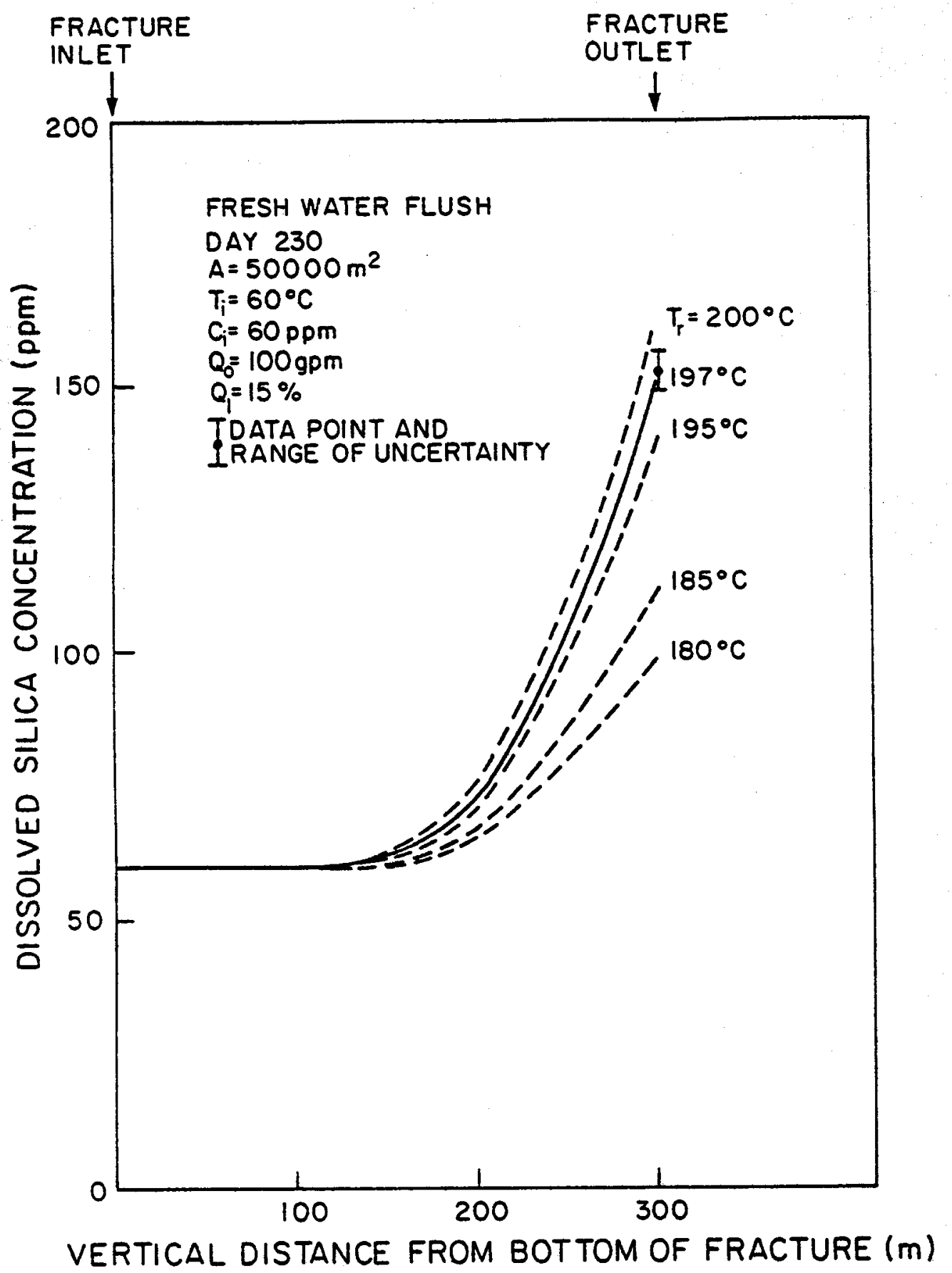

Figure 23. Computer Simulation of the Day 230 Fresh Water Flush Data for $A=50000 \mathrm{~m}^{2}$ for Different Assumed Initial Rock Temperatures 


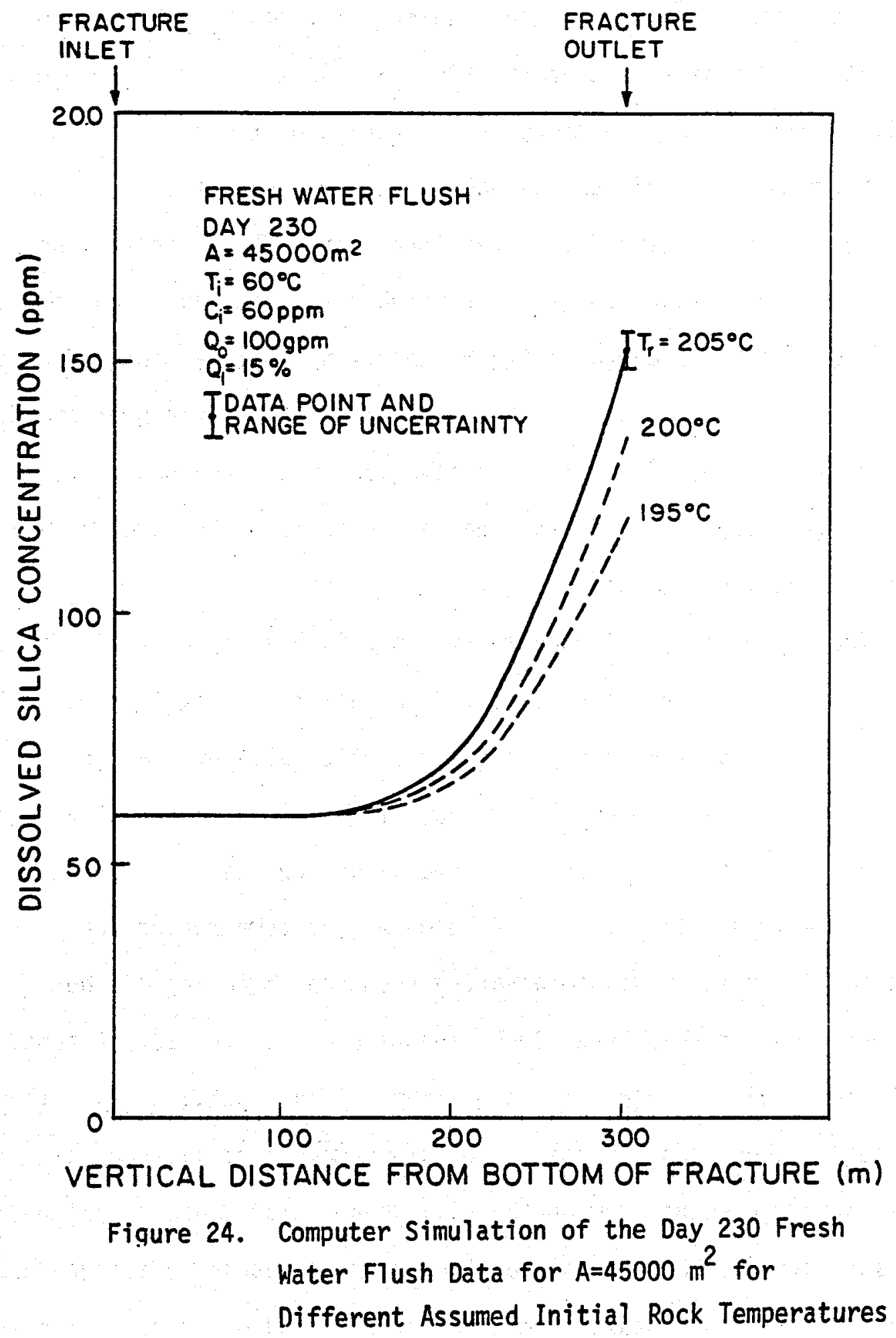


Other dissolved silica concentration data must now be used in order to refine the analysis to provide a better value for area and temperature. The final silica concentration observed after recirculation is another piece of data not yet used. From Figure 20, it is estimated that this concentration is approximately $205 \pm 5 \mathrm{ppm}$ on day 230. Figure 25 shows a computer simulation of the approach to equilibrium of the silica concentration for recirculating systems whose parameters were obtained from the fresh water flush simulations. The initial time is taken to be the time when the recirculation mode is resumed after a fresh water flush experiment. Since a plug flow model is assumed for flow through the fracture, the computer program actually generates the outlet silica concentration after each pass through the reservoir. The time axis is then fabricated from the average residence time of the fluid in the system.

The importance of Figure 25 lies not in the concentration versus time behavior, which is complicated in reality by significant deviations from ideal plug flow, but in the asymptotic value of the concentration. Both the 50000 and $55000 \mathrm{~m}^{2}$ numerical fits to the data fall within the range of uncertainty of the measured value for the silica concentration in the recirculating mode. Furthermore, the temperature drawdown, the decline in outlet fluid temperature from the beginning of the experiment, for these two simulations agree with the actual temperature data to within experimental uncertainty (Dash et al., 1981). Thus, either of these two computer simulations may be considered as a realistic representation of the silica and temperature behavior of the Phase I system. Further pinpointing the parameters of surface area and initial rock temperature seemed pointless because of the uncertainty of the data and simplicity of the model.

One other set of data that can be examined using this model is the 


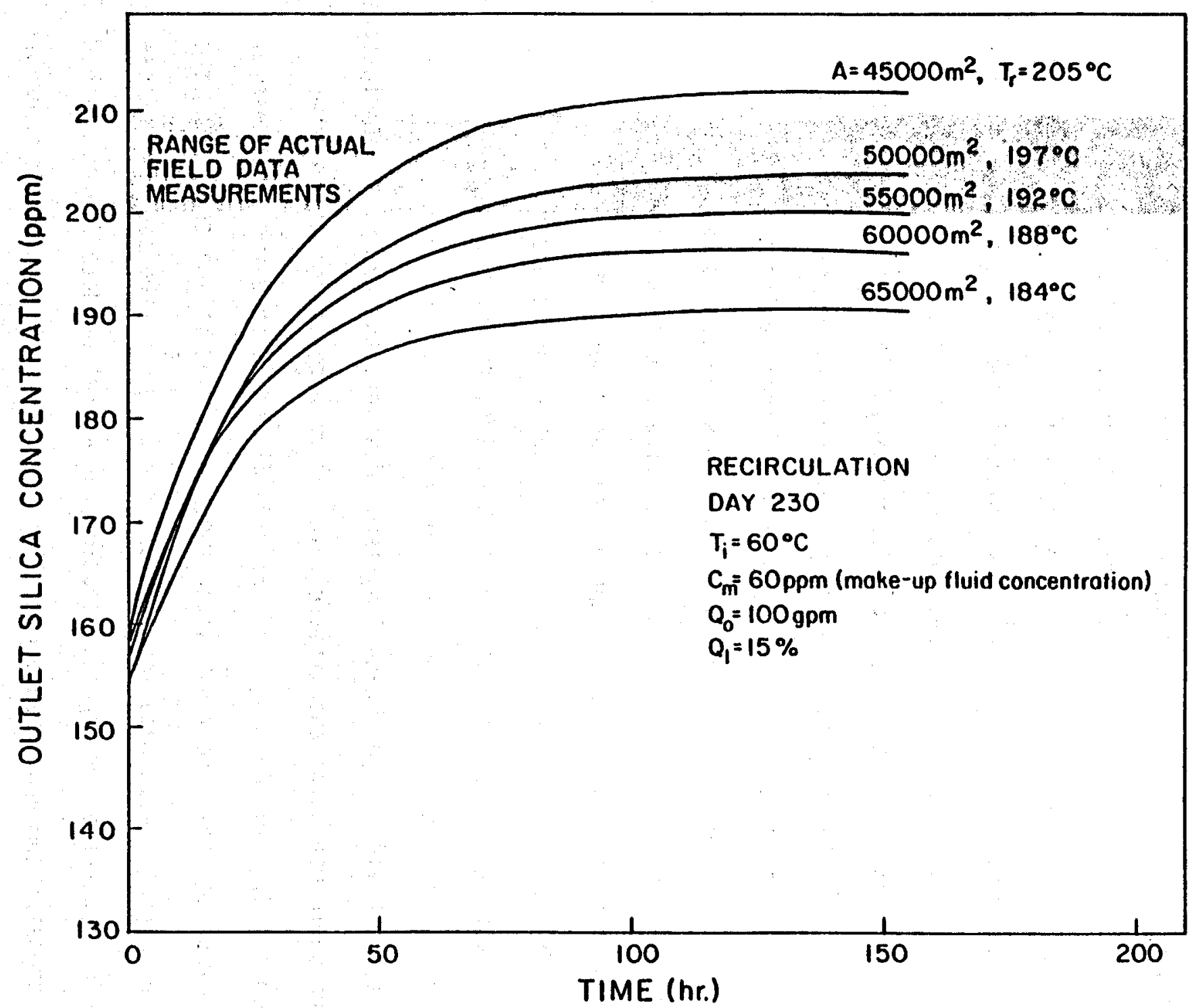

Fiqure 25. Dissolved Silica Recirculation Responses for Different Combinations of Fracture Area and Initial Rock Temperature. Produced Fluid Concentration at $t=0$ is Initialized After Closed Loop Recirculation Was Resumed 
overall decline in the dissolved silica concentration from day 150 to the end of the experiment (see Figure 20). Excessive fluid loss in the earlier days of the experiment make the analysis of this silica data difficult. Using a surface area of $55000 \mathrm{~m}^{2}$ and initial rock temperature of $192^{\circ} \mathrm{C}$, the computer program was used to calculate the behavior of the outlet silica concentration over the time period from day 150 to 275 . The results of this computer simulation are shown in Figure 26. The fit of the model to the data is very close, indicating that the decline in dissolved silica concentration in this time period can be explained by the gradual cooling of the reservoir and the ramifications that has on the equilibrium solubility and kinetics of granite dissolution. Unfortunately, this data is complicated by an increased water loss rate caused by a fluid leak behind the injection wellbore casing. Thus, thermal drawdown must be considered as only a possible explanation for the gradual decline in outlet dissolved silica concentration from day $\mathbf{1 5 0}$ to the end of the experiment.

With reasonable values for the adjustable parameters of area, temperature, and granite dissolution kinetics, the proposed model for granite dissolution in a HDR reservoir accurately describes the dissolved silica behavior in the Phase I system. However, the numerical simulations were performed using the kinetic data for granite dissolution rather than the data for pure quartz. Figures 27 and 28 show two unsuccessful attempts to model the fresh water flush dissolved silica data using the pure quartz kinetic data found in Chapter 3. As can be seen from these figures, the fresh water flush outlet concentration data can be matched by choosing the appropriate conditions, but in either case the reservoir properties necessary to simulate the data are unreasonable. The experimentally determined kinetics of pure quartz dissolution are much too slow to explain the dissolved silica behavior in the Phase I system, 


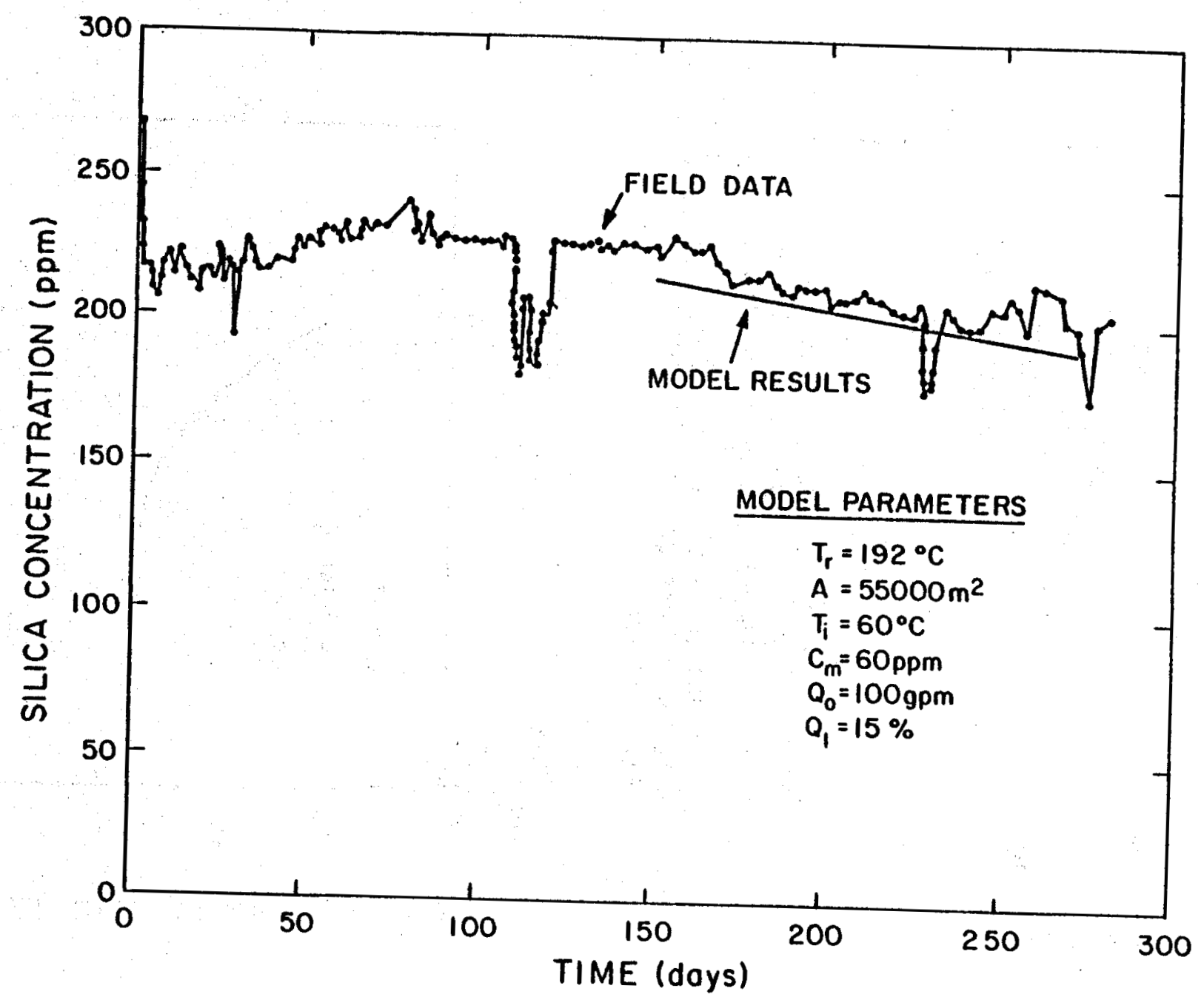

Figure 26. Comparison of the Model Prediction to the Phase I Run Segment 5
Dissolved Silica Field Data 


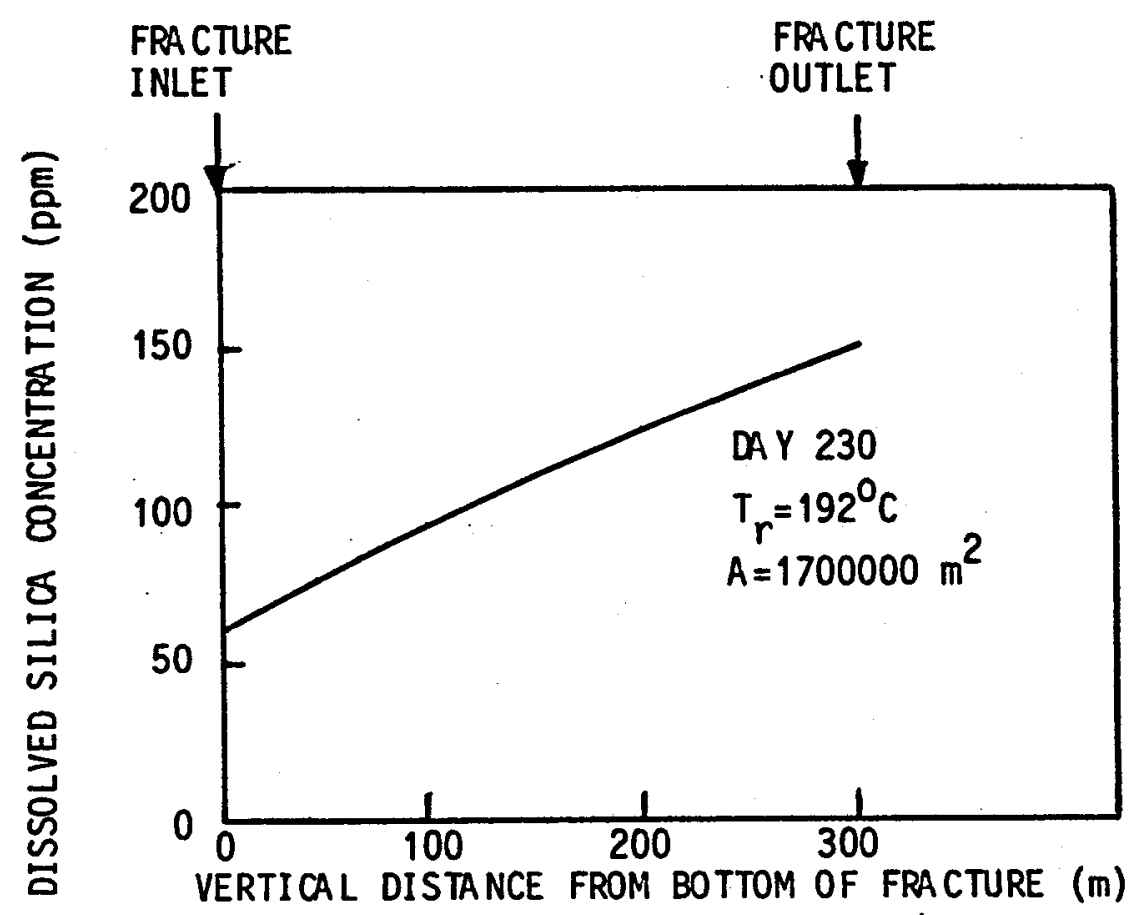

Figure 27. An Unsuccessful Attempt to Model the Fresh Water Flush Data Using Pure Quartz Dissolution Kinetics-- $T_{r}$ Chosen, Area Varied

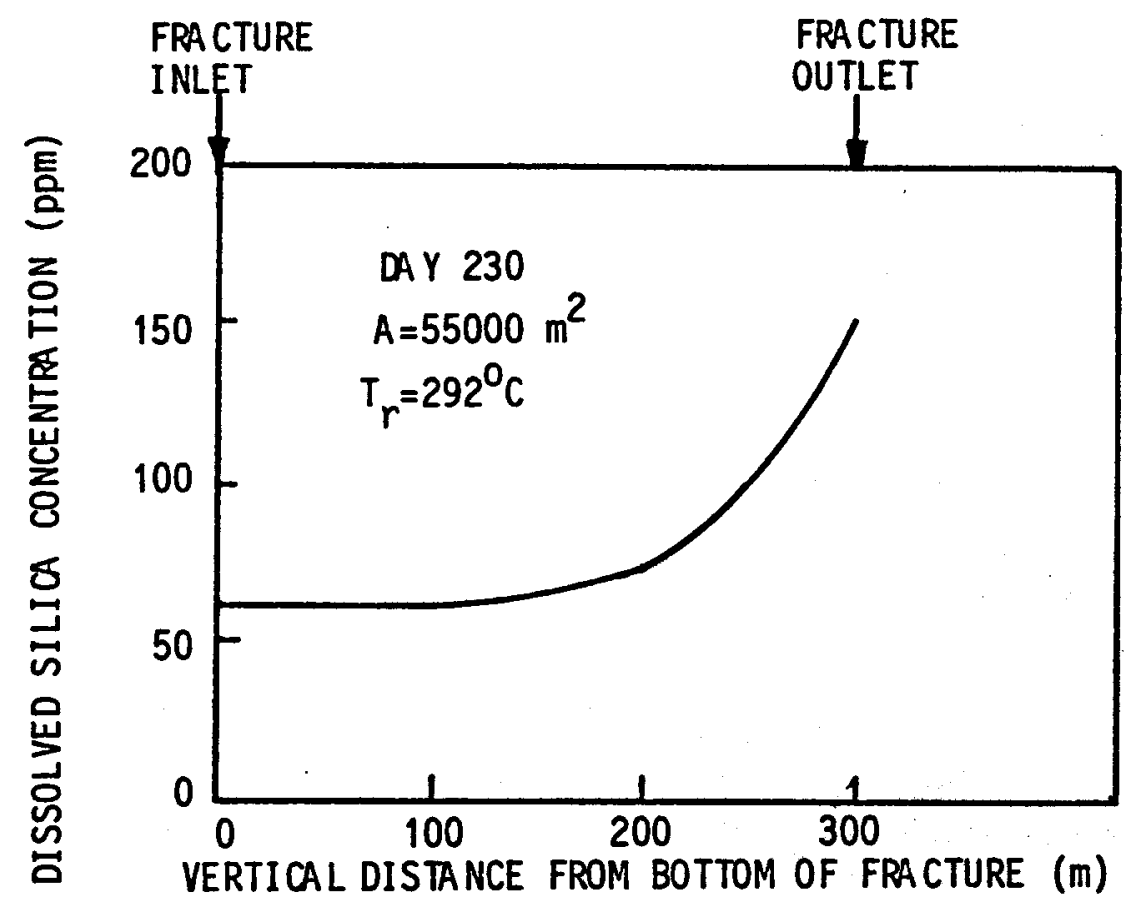

Figure 28. An Unsuccessful Attempt to Model the Fresh Water Flush Data Using Pure Quartz Dissolution Kinetics-- Area Chosen, $T_{r}$ Varied 
implying that the dissolution in the reservoir is governed by the more rapid kinetics observed for granite dissolution.

Possible reasons for the discrepancy between the pure quartz and granite dissolution data were discussed in Chapter 3. The calculation in Appendix $F$ demonstrated that the length of time necessary for the small fines to be dissolved away in the reservoir (assuming the same "surface concentration" of fines as on the crushed granite) is very short because of the large water flow rates involved. Thus, some other explanation must be found to explain the rapid rate of quartz dissolution in the presence of granite.

In summary, the model correctly predicts the Phase I fresh water flush/recirculation data, along with the long term decline in steady state levels caused by thermal drawdown. The thermal drawdown itself is also correctly predicted. Unfortunately, uncertainties in the kinetic rate constant and active dissolution surface area probably limit the usefulness of dissolved silica data as a diagnostic tool for estimating the effective heat transfer surface area. For instance, a system which consists of many closely-spaced parallel fractures will exhibit thermal behavior comparable to the error function solution for a single fracture, but the active surface area for dissolution in this reservoir will be much larger than the effective heat transfer area. Despite this problem, the fact that the dissolved silica data was modeled using the computer code just developed suggests that the model may be used to simulate the dissolved silica behavior anticipated for the Phase II system.

\subsection{Phase II Computer Simulations}

For this computer simulation, it will be assumed that the Phase II 
reservoir will be a combination of 8-10 identical fractures, each the same size as the Phase I reservoir (approximately $300 \mathrm{~m}$ diameter). Each fracture will receive $100 \mathrm{gpm}$ flow, as in the Phase I system. Since the behavior of one these theoretical fractures is the same as any other, the analysis of the dissolved silica behavior of one fracture may be assumed to describe the response of the entire reservoir. In fact, for the purposes of this calculation, the only difference between the Phase I reservoir and a fracture in the proposed Phase II system is the initial rock temperature, assumed to be $300^{\circ} \mathrm{C}$ for the new system.

The results of a fresh water flush simulation are depicted in Figure 29. The silica concentration profiles (concentration versus vertical distance from the bottom of the fracture) are shown for different times. Initially, for average rock temperatures of $300^{\circ} \mathrm{C}$, it takes only about 30 meters of flow up the fracture for the fluid to come to equilibrfum with the underground quartz. This rapid equilibration is due to the much more rapid kinetics of quartz dissolution at $300^{\circ} \mathrm{C}$. As more heat is extracted from the bottom of the reservoir, the fluid takes longer to reach equilibrium, but after 100 days the fluid is still reaching the equilibrium value at $300^{\circ} \mathrm{C}$. As significant thermal drawdown is experienced in later days, the outlet concentration declines, but at 300 days the fluid reaches the dissolved silica equilibrium dictated by the outlet temperature (signified by the dashed line). At 1000 days, the kinetics are slow enough that the fluid falls short of equilibrium during a fresh water flush, but would approach the dashed line in the recirculating mode.

The important result of this computer simulation is that in the beginning of the Phase II experiment, the outlet fluid silica concentration will reach equilibrium rapidly at $300^{\circ} \mathrm{C}$. Thus, a fluid with a concentration of $600 \mathrm{ppm}$ silica will be produced in this system. 76 


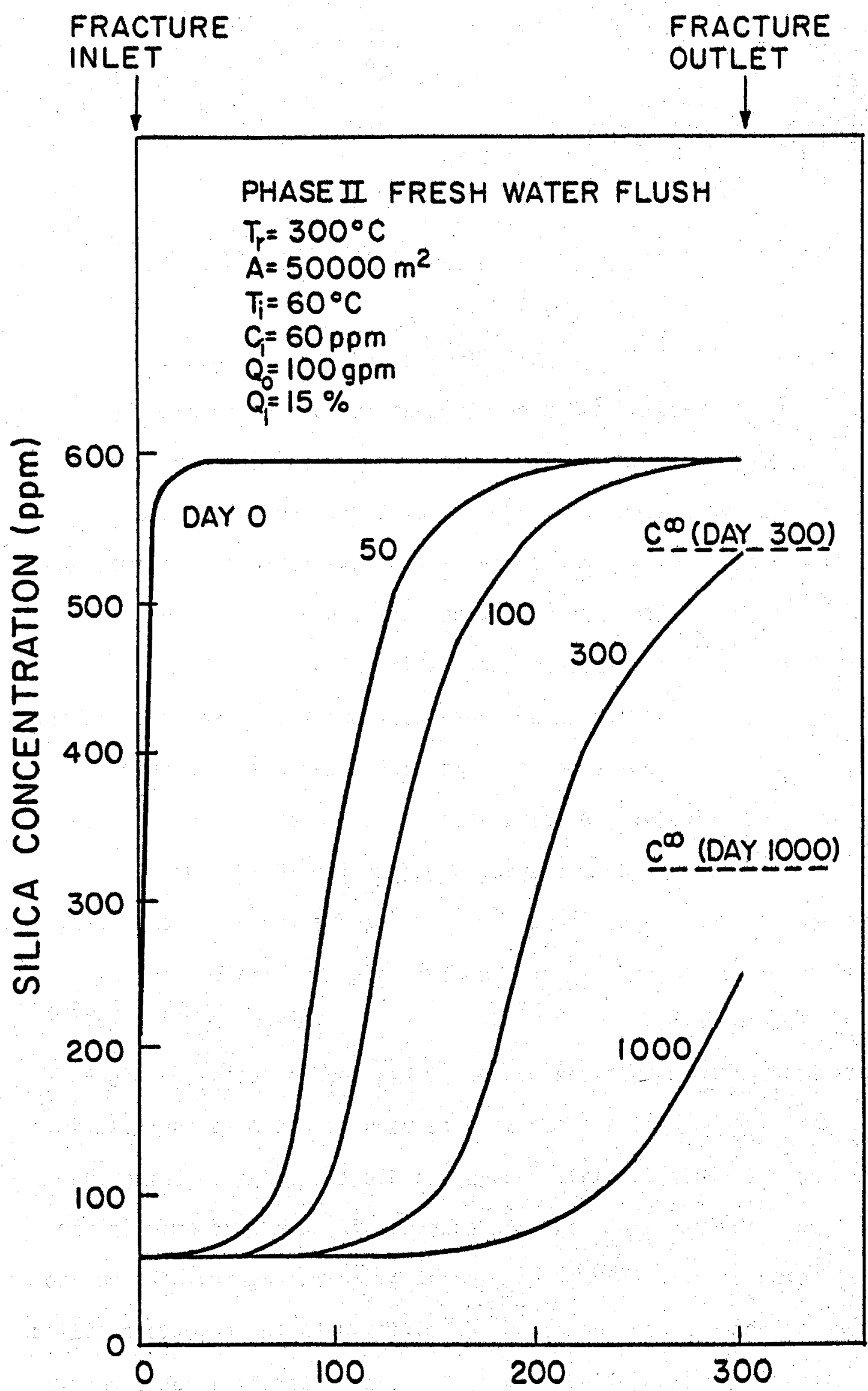

VERTICAL DISTANCE FROM BOTTOM OF FRACTURE (m)

Figure 29. Computer Simulated Phase II Fresh Mater Flush Dissolved Silica Concentration Profiles 
The effect-that this concentrated a fluid will have on silica scaling in heat exchange equipment and in the injection wellbore will be discussed in Chapter 5.

\subsection{Another Application of The Model: Chemically Reactive Tracers}

The successful fit of the Phase I dissolved silica data using the model outlined in Section 4.3 suggests that the use of chemically reactive tracers could be an effective method for sizing a HDR geothermal reservoir with only modest amounts of thermal drawdown. At the present time, the only conclusive method available for estimating the heat transfer surface area is to perform a heat extraction experiment and model temperature decline in the produced fluid. Ultimately, heat extraction experiments will be of limited value in the estimation of the surface area of commercial sized HDR reservoirs because the objective of the stimulation is to create a reservoir which will not exhibit significant thermal drawdown for 10-30 years. Thus, HDR researchers are faced with the dilema of striving to create larger reservoirs but having no accurate method for estimating the heat transfer surface area.

This study showed that the outlet silica concentration during a fresh water flush experiment can also be used to estimate the reservoir size if the reservoir is small enough and not so hot as to bring the fluid to equilibrium in one pass through the fracture system. In the Phase II computer simulations, commercial sized reservoirs will be too large and too hot to use the dissolved silica data for reservoir sizing. However, the Phase I modeling proves that the temperature sol ution may be coupled to a chemical reaction dependent mass bal ance equation to obtain important information on the reservoir size. The kinetics of 78 
granite dissolution were fortuitously in the correct range to make this modeling possible. In larger, hotter systems, a reaction with slower kinetics must be found so that chemical equilibrium is not reached in one pass through the system. A thorough engineering evaluation may identify the proper chemically reactive tracer for Phase II conditions.

Two types of chemical reactions could be used in a tracer experiment: those which involve reactions with the rock surface and those that do not. Quartz dissolution in the Phase I. system is an example of the former. In this case, if the initial rock temperature is known, then one tracer experiment is all that is required to obtain an estimate of the surface area, provided the reaction kinetics are in the correct range. However, even if a naturally occuring rock-fluid reaction with the proper kinetics exists, the uncertainty of the active dissolution surface area will limit the usefulhess: of this type of experiment.

The second type of chemically reactive tracer experiment, one which would not involve a reaction with the underground rock, is fundamentally different in that it would not contain the surface area in the reaction kinetic expression. Thus, a series of experiments would be required to show how rapidly the lower portion of the reservoir is cooling down. Alternatively, the total volume and residence time distribution of the system could first be obtained from a non-reactive tracer. Then a single measurement of temperature drawdown in the lower part of the fracture using the chemically reactive tracer would allow for an estimation of the effective heat transfer surface area. In either case, some decline in the temperature of the rock near the inlet is required, whereas in the case of a rock-fluid reaction it is not. A chemical reaction which does not involve the rock directly would provide surface area information only because the reaction kinetics are affected by temperature decline. This type of experiment is completely analogous to the temperature drawdown 
estimations of the surface area in the Phase I reservoir, except that the information will be obtained in the form of the extent of reaction, before the cold temperature wave reaches the top of the reservoir. One promising idea for a chemically reactive tracer experiment is the dissolution of small, hollow glass spheres filled with a radioactive tracer. The tracer would be emitted after the bead has dissolved away completely. These beads are presently manufactured to very precise specifications for use in laser fusion research. By using spheres of different wall thicknesses and observing the amount of tracer emitted after one pass through the reservoir, reservoir size information could be obtained. Using the best data available for the kinetics of amorphous silica dissolution (Rimstidt, 1979, and Holley, Jan. 1981), it can be shown that complete dissolution of the beads would take too long at normal reservoir conditions. Therefore, the chemistry of the geothermal fluid would have to be altered during the experiment to speed up the reaction rate. One way this could be accomplished is by temporarily raising the $\mathrm{pH}$ of the system. 


\section{Chapter 5}

\section{Silica Depostion In Geothermal Systems}

\subsection{Introduction}

One of the main reasons for studying quartz dissolution in hot dry rock geothermal systems is that it is necessary to know the concentration of dissolved silica in the produced fluid in order to evaluate the likel ihood of sflica scaling in the above ground equipment and the colder portions of the downhole system. One piece of equipment in which scaling is anticipated is the heat exchanger, where continued cooling of the liquid will eventually cause it to be supersaturated with respect to all of the solid silica phases. Even if the fluid makes it through the heat exchanger without significant deposition occuring, the problem of precipitation in the injection wellbore or, worse still, in the cooler regions of the reservoir, must be considered. White et al. (1956) showed that the deposition of silica is controlled by the solubility of amorphous silica rather than by quartz over temperatures of interest.

Figure 30 is a solubility plot which demonstrates the potential scaling problem in the heat exchanger and injection wellbore of the Fenton HIII HDR system under Phase II conditions. The outlet dissolved silica concentration approaches the quartz-controlled saturation value, as predicted by the model developed in Chapter 4. As the produced fluid is cooled from $300-40^{\circ} \mathrm{C}$ in the air-cooled heat exchanger, it will be greatly supersaturated with respect to amorphous silica. In contrast, the Phase I system, operating between $190-40^{\circ} \mathrm{C}$, shows only a mild supersaturation, too little to result in any silica scaling. Indeed, no 


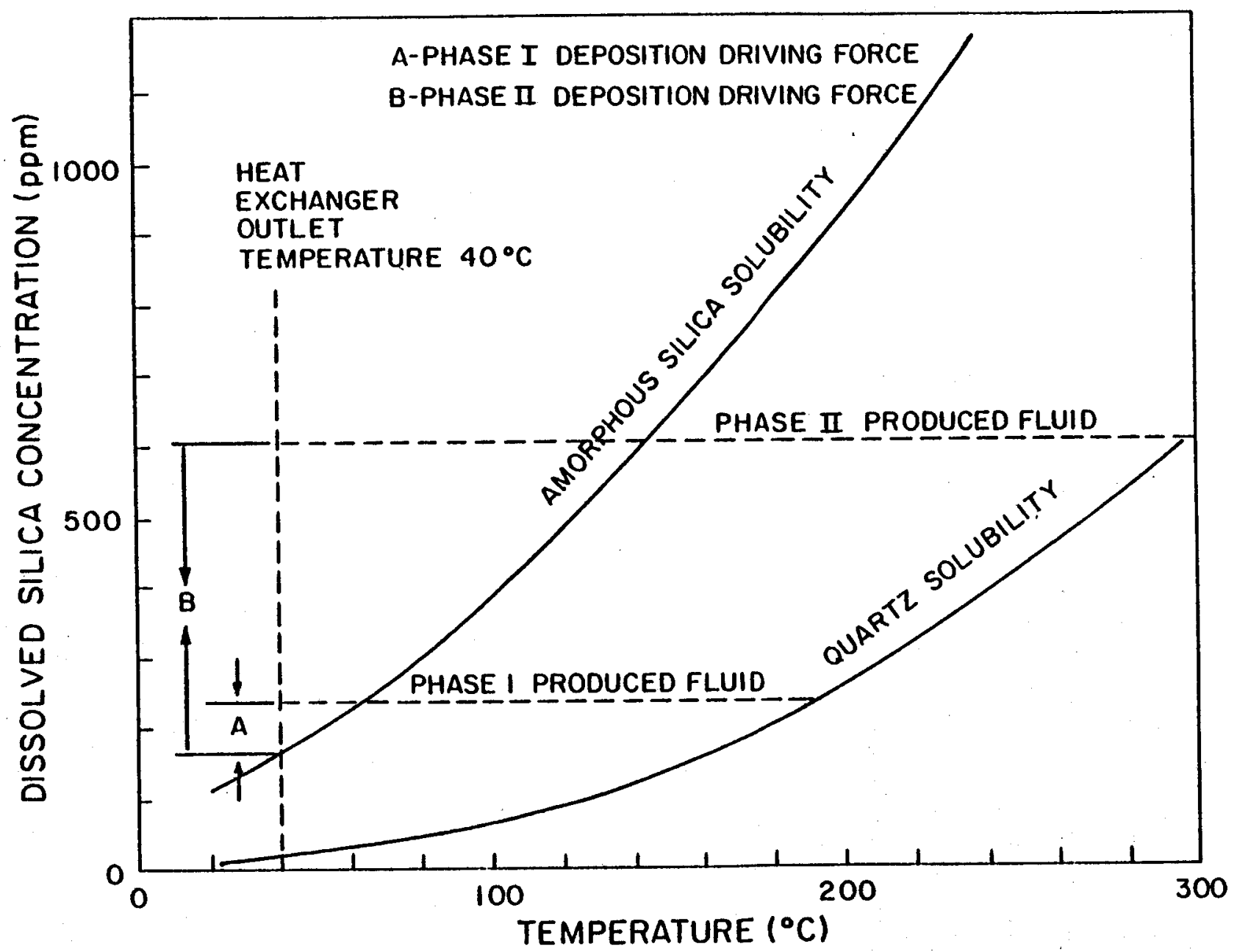

Figure 30. Comparison of the Driving Force for Silica Deposition: Phase I vs. Phase II 
evidence of scaling was found in the heat exchanger or any other part of the Phase I system during continuous recirculating operation.

The large supersaturation indicated by Figure 30 for the Phase II system suggests that closer attention must be paid to the kinetics of silica polymerization and deposition. According to Gudmundsson and Bott (1979), the rate of silica scaling is controlled by two distinct processes: 1iquid-phase polymerization followed by heterogeneous nucleation and deposition in solution competes with direct heterogeneous deposition of monomeric dissolved silica for the avaflable silficic acid molecules. Polymerization and subsequent deposition from solutions as colloids is known as homogeneous nucleation, which usually requires long induction periods. For instance, the time required for fluid to flow through a wellbore could be sufficiently long for homogeneous processes to become important. Empirical evidence from existing geothermal. systems suggests that heterogeneous nucleation, the direct deposition of $\mathrm{Si}(\mathrm{OH})_{4}$ molecules on a solid surface, is likely to be the dominant mechanism for scaling in a heat exchanger or on any surface with which the flufd comes in contact (Arnorsson, 1981).

There is a fundamental difference between the two mechanisms of silica deposition. The rate of heterogeneous deposition at any position in the heat exchanger or wellbore is dependent on the temperature, fluid geochemistry, and degree of amorphous silica supersaturation of the fluid at that position in the system. By contrast, homogeneous nucleation requires an induction time for a large number of critical size nuclei to form in solution. The rate of homgeneous nucleation in a volume element of fluid depends on the entire temperature and concentration history of that parcel of fluid as it passes through the geothermal system. Thus, long residence times in the injection wellbore may result in deposition via either the homogeneous or heterogeneous 
nucleation mechanism even if scaling in the heat exchanger is minimal.

The purpose of this chapter is to examine the literature data available on silica polymerization and deposition to evaluate the possibility of silica scaling in the Phase II system. The studies performed to date are of three types: laboratory studies designed to examine the kinetics of silica polymerization from supersaturated solutions, experimental heat exchanger studies, and empirical field data from existing geothermal systems. All of these types of studies are reviewed in this chapter and related to the Phase II system. Finally, an experimental apparatus, designed to simulate flow and concentration conditions anticipated at Fenton Hill, is discussed as a technique for examining silica scaling problems.

\subsection{Silica Polymerization Laboratory Studies}

Arnorsson (1981) observed that the heterogeneous nucleation process is the dominant mechanism for amorphous silica deposition, a contention which is borne out by evidence obtained from the operation of actual geothermal systems. These cases are described in Section 5.4. However, the residence times encountered in flow through an injection wellbore are likely to be long enough for polymerization to become a competing mechanism for the reaction of dissolved silica. Also, if retention tanks are used to allow precipitation to take place intentionally, then polymerization kinetics would be useful in sizing the tanks. Thus, determining the effect on polymerization of parameters such as $\mathrm{pH}$, temperature, dissolved ions, and silicic acid supersaturation would be helpful in predicting the chemical behavior of a geothermal system.

A comprehensive study of the kinetics of silica polymerization was carried out by Makrides et al. (1978). As previously noted by Iler 
(1955), the $\mathrm{pH}$ of the system is shown to have a large effect on the kinetics. Makrides et al. show that at low pH (below pH 3), hydrogen ions catalyze the reaction, with a minimum rate occuring at $\mathrm{pH} 3$. From $\mathrm{pH} 3$ to $6, \mathrm{OH}^{-}$ions influence the reaction, increasing the rate by a factor of 10 for each unit increase in $\mathrm{pH}$. Marsh et al. (1975) propose a mechanism to explain the hydroxyl ion behavior. They presume the polymerization rate to be controlled by the union of a silicic acid molecule with an ionized silicic acid molecule:

$$
\text { Rate }=k_{p}\left[\mathrm{Si}(\mathrm{OH})_{4}\right]\left[\mathrm{Si}(\mathrm{OH})_{3} \mathrm{O}^{-}\right] \text {. }
$$

where $k_{p}=$ silica polymerization rate constant.

Al though the rate of dissappearence of monomers is indicated by Equation

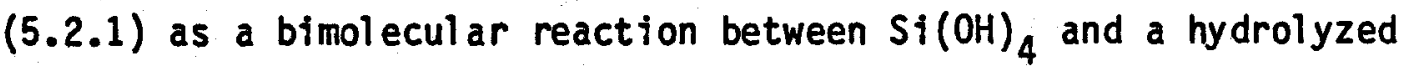
Si $(\mathrm{OH})_{3} \mathrm{O}^{-}$Ionic species, other reactants could be dimers, trimers, or longer chained polymers.

The concentration of ionized silicic acid molecules is governed by the following equation:

$$
\mathrm{Si}^{(\mathrm{OH})_{4}}=\mathrm{Si}(\mathrm{OH})_{3} \mathrm{O}^{-}+\mathrm{H}^{+} \text {. }
$$

An increase in $\mathrm{pH}$ will drive the reaction of Equation (5.2.2) to the right, increasing the concentration of $\mathrm{Si}(\mathrm{OH})_{3} \mathrm{O}^{-}$ions. Thus, by Equation (5.2.1), the polymerization rate increases with increasing $\mathrm{pH}$. Marsh et al. (1975) al so indicate that the maximum polymerization rate should occur at $\mathrm{pH} 9.8$, which is equivalent to the $\mathrm{pK}_{\mathrm{A}}$ of Equation (5.2.2). At this $\mathrm{pH}$, the fonized and undissociated $\mathrm{Si}(\mathrm{OH})_{4}$ molecules will be at equal concentration, a condition required for a maximum rate according to this mechanism. Experimentally, they show their contention to be basically valid, in spite of the complications of the reaction of longer chained molecules, each with their own $\mathrm{pK}_{A}$. Since the $\mathrm{pK}_{A}$ decreases as chain length increases, it is hypothesized that as the 
polymerization process proceeds, the $\mathrm{pH}$ of maximum rate should decrease. Carefully performed experiments verified this mechanism, and extrapolation of their data back to the start of the polymerization process (that is, the point where monomer-monomer reactions dominate) indicates that the initial rate of polymerization is a maximum at a $\mathrm{pH}$ of approximately 9.8, as predicted from the monomeric $\mathrm{pK}_{\mathrm{A}}$.

The preceeding discussion indicates that the concentration of monomeric silicic acid is one pertinent parameter in determining the kinetics of silica polymerization. However, since polymerization occurs only when the solution is supersaturated with respect to amorphous silica, rate laws are usually expressed as a function of the supersaturation, $\left(C-C^{\infty}\right)$, where $C^{\infty}$ is the equilibrium solubility of amorphous silica. Makrides et al. (1978) and Marsh et al. (1975) both cite literature studies which show a possible range of first to fifth order dependence of rate on supersaturation, depending on $\mathrm{pH}$ and the existence of other ions. The simple mechanism described above suggests a second order dependence, but the addition of certain ions complicates the picture considerably. Fluoride ion, for example, has been shown by Iler (1955) to catalyze the polymerization reactions. A possible mechanism proposed by Marsh et al. (1975) shows that $\mathrm{F}^{-}$ions could catalyze an overall reaction of three monomer units to form a trimer, resulting in an observed third order reaction at low $\mathrm{pH}$. At high $\mathrm{pH}$, polyvalent cations enhance the rate of formation of colloids, as is discussed in Section 5.4. Foreign ion effects are obviously important in many experimental studies and have added to the present confusion over what the true reaction order is for polymerization.

Makrides et al. (1978) al so studied the effect of temperature and found that at fixed initial silica concentrations it has little observable effect on polymerization rate. This result is attributed to 86 
the counterbalancing of two forces: the higher kinetic rate constants found at higher temperatures seem to be offset by the lower supersaturation driving force. Thus, the heat of polymerization of silicic acid must be of the same order as the activation energy to cancel out the temperature dependence on polymerization rate. The kinetic experiments which they performed at constant supersaturation did show an effect of temperature which corresponded to an activation energy of $17 \mathrm{kcal} / \mathrm{mol}$.

Weres et al. (1980) have attempted to account for all of the effects mentioned above by developing a single methodology designed to predict the extent of polymerization or homogeneous nucleation anticipated for a geothermal fluid of specified composition and temperature. They used fundamental nucleation theory as a basis for correlating their silica polymerization experiments. Plots of the decline in monomeric silica concentration versus time (i.e. polymerization rate) are given for different combinations of temperature and initial supersaturation. Salt concentration and $\mathrm{pH}$ effects were also examined experimentally. High salt concentration ( $1 \mathrm{~N}$ or higher) lowers the equilibrium solubility of amorphous silica by decreasing the activity of water. As mentioned above, the $\mathrm{pH}$ of a geothermal brine has a direct impact on the rate of silica polymerization, but Weres et al. found $\mathrm{pH}$ to have little effect on the shape of their concentration versus time curves. Thus, the rate curves are simply shifted along the time axis to account for pH. In Section 5.5, a sample calculation to estimate polymerization rate is performed for the Fenton Hill HDR geothermal reservoir under Phase II conditions. 


\subsection{Experimental Heat Exchanger Studies}

The heterogeneous nucleation of silica in a geothermal fluid as it passes through a heat exchanger has been examined experimentally for a number of specific brine compositions and heat exchanger designs. For example, Gudmundsson and Bott (1979) simulated a heat exchange system by using actual geothermal fluid in a scaled down countercurrent heat exchanger. The fluid was obtained by flashing the geothermal water at $100^{\circ} \mathrm{C}$. The liquid fraction was used, resulting in inlet conditions of $305 \mathrm{ppm} \mathrm{SiO} 2,777 \mathrm{ppm}$ TDS, and pH 9.46. Although the results varied with Reynolds number, in general it was found that silica scale deposited in the tubes in the form of small ripples which lie perpendicular to the direction of flow. During the initial stages of the experiment, the increase in flow turbulence caused by the ripples actually enhanced the heat transfer coefficient of the heat exchanger, but after 2000 hours of operation the scale had built up enough to result in a significant fouling resistance. Figure 31 shows one of Gudmundsson and Bott's plots of fouling resistance versus time. A simple calculation using this plot shows that after 1000 hours, the overall heat transfer coefficient for the pipe will be decreased to roughly $85 \%$ of its original value.

Bohlmann et al. (1981) al so studied the behavior of a simulated geothermal heat exchanger by flowing a synthetic brine through their experimental system. Their "geothermal fluids" contained controlled amounts of $\mathrm{NaCl}$ and dissolved silica, and the $\mathrm{pH}$ was variable. The heat exchanger cooled the fluid from about $200-40^{\circ} \mathrm{C}$ in five passes so that the phenomenon of silica scaling as a function of temperature could be examined. Salt concentration was found to have the largest influence on 88 


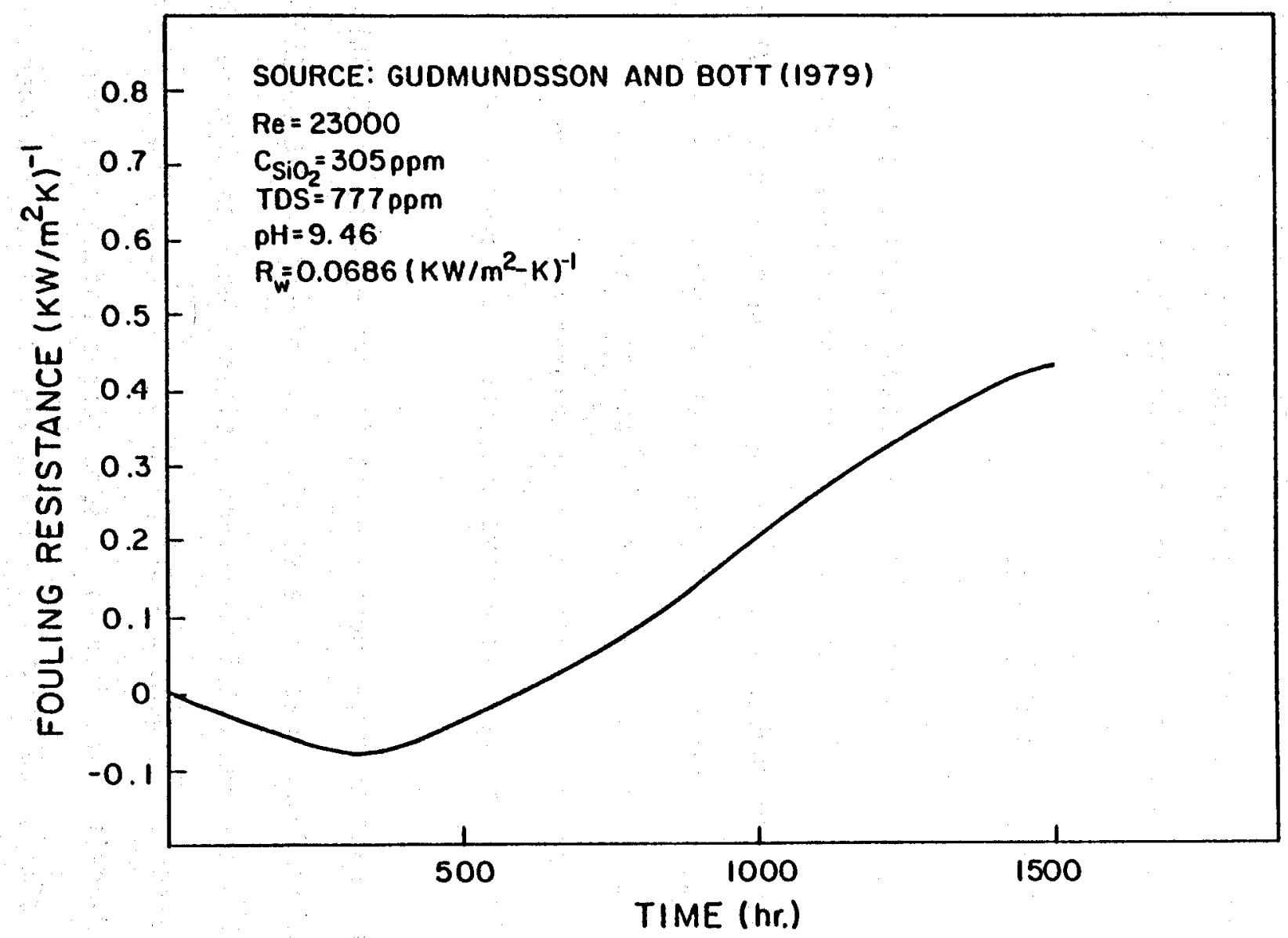

Figure 31. Silica Scale Induced Fouling Resistance in.a Heat Exchanger 
scaling rate. A significant decline of the heat transfer coefficient in the first two sections $\left(197-161^{\circ} \mathrm{C}\right.$ and $\left.160-126^{\circ} \mathrm{C}\right)$ was found after just 10 hours in the high $\mathrm{NaCl}$ concentration experiments. The solutions of lower salt concentration $(4600 \mathrm{ppm} \mathrm{NaCl})$ resulted in a much slower rate of molecular deposition on the walls of the heat exchanger. Figure 32 is a reproduction from the work of Bohlmann et al. (1981), showing the large effect of salt concentration on deposition rate. The plot also provides an order of magnitude estimate of silica scaling rates.

\subsection{Silica Scal ing Field Studies}

It is impossible to generalize the actual field experience of silica scaling in geothermal systems into one consistent theory because of the vast chemical and operational differences among the cases studied. Nevertheless, the characteristics and observed behavior of each system may be noted and the data extrapolated to the conditions of interest in the Phase II system. A number of case studies are reviewed in this section along with the silica removal methods employed in each of these systems.

In the Ahuachapan geothermal $\mathrm{pl}$ ant in the republic of El Salvador, investigators found that in passing a fluid of concentration $650 \mathrm{ppm}$ $\mathrm{SiO}_{2}$ at $95^{\circ} \mathrm{C}$ through a $1.5 \mathrm{~km}$ culvert, silica deposits of 6 to $10 \mathrm{~cm}$ thick resulted after 3 months of operation (Cuellar, 1975). The thickest deposits were found in a spot corresponding to a fluid residence time of 20 minutes after leaving the well. The concentration of dissolved ions, which were shown in Section 5.2 to play an important role in the kinetics of silica polymerization, was about ten times as great as in the Phase I system.

It was also found in the Ahuachapan system that if a retaining tank 


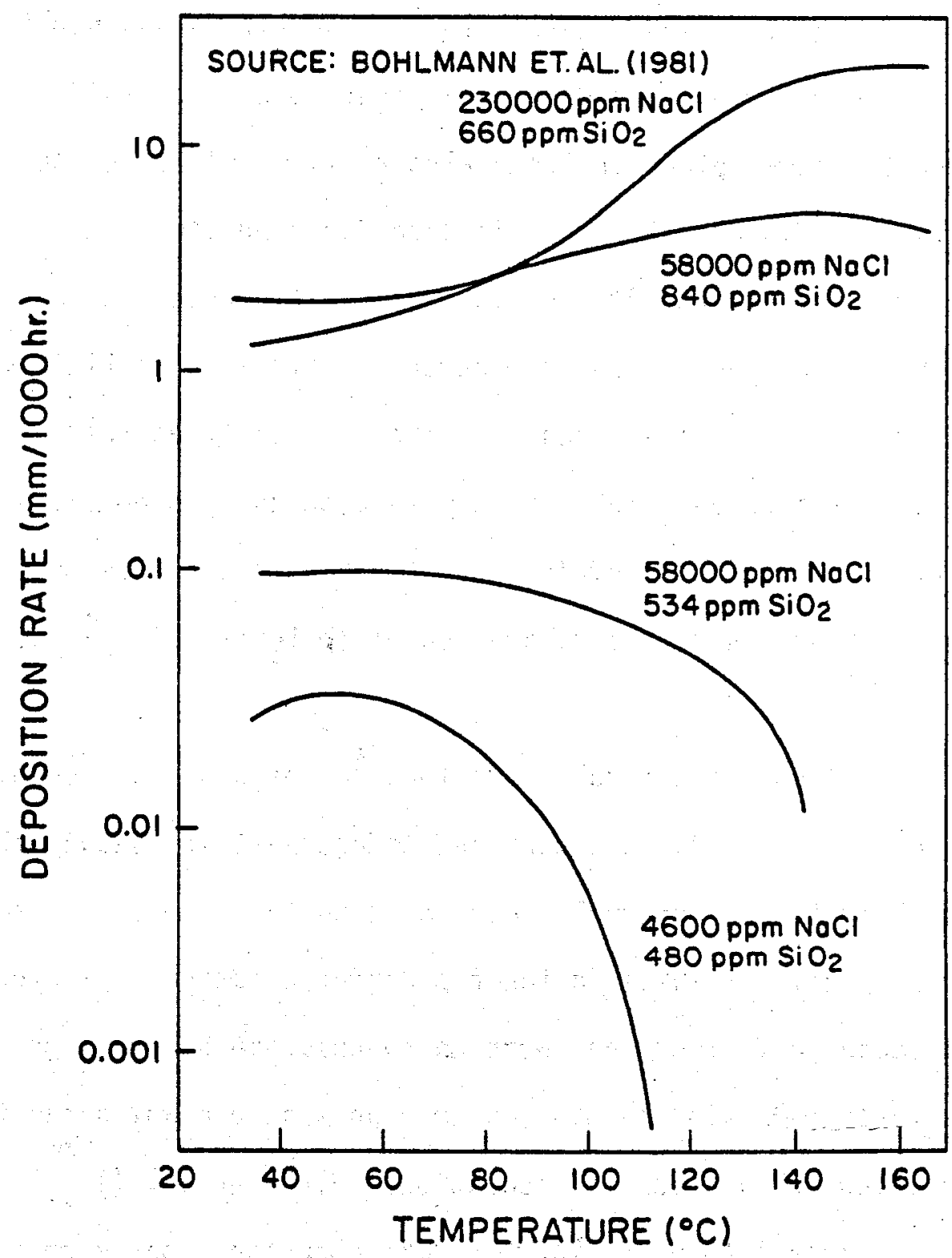

Figure 32. Silica Deposition Rate vs. Temperature for Different $\mathrm{SiO}_{2}$ and Salt Concentrations 
was used to allow the dissolved silica to polymerize before flowing into the culvert, the scale was reduced to an average thickness of 1 to $2 \mathrm{~mm}$ in the same 3 month period. Thus, the deposition must have been via the heterogeneous nucleation pathway--the retention tank allowed polymerization to take $\mathrm{place}$, decreasing the monomeric silica concentration to a level where heterogeneous nucleation was negligible.

The evidence of studies conducted by Yanagase et al $(1970)$ at the Otake geothermal power plant in Japan also confirm this theory of deposition. They found that for their specific conditions, a 1 hour residence time was required for polymerization to proceed to the degree where the subsequent deposition of monomeric silica was negl igible. Some of the colloidal silica deposited, but not nearly as fast as when the monomeric solution was sent directly through the piping system. Since the colloids did not exhibit a great tendency to plate out on solid sufaces, they found that filtration of colloidal silica was unnecessary.

The effect of pH and polyvalent cations on colloidal silica has also been studied in the field. Rothbaum and Anderton (1975) showed that the addition of lime to a geothermal fluid in which the silica has been allowed to polymerize results in the rapid precipitation of a hydrated calcium silicate gel. They then went on to describe how this gel may be easily separated and dried to give an amorphous powder which can be used in manufacturing wallboards and insulation. Weres et al. (1980) attribute this behavior to the large negative surface charge on colloidal particles in fluids of high pH. A polyvalent cation such as $\mathrm{Ca}^{2+}$ will form a bridge between the negatively charged colloids, resulting in rapid coagulation. Thus, in some cases it may be possible to pretreat a HDR geothermal fluid before reinjection to encourage silica polymerization rather than deposition of monomeric silicic acid, 92 
thus avoiding deposition problems in the cold regions of the injection wellibore and reservoir. Removal of silica from the recirculating fiuid could then be accomplished by precipitation as a silica gel or by a similar process.

\subsection{Silica Deposition In The Fenton Hill Phase II System}

The results of the last three sections may now be used to examine the potential problem of silfica deposition in the Fenton Hill system. As stated earlier, deposition is known to occur by two different mechanisms: heterogeneous nucleation (direct molecular deposition on a solid surface) and homogeneous nucleation (polymerization followed by colloidal deposition). This section will deal with both types of silica deposition, predicting, where possible, the extent of silica scaling under anticipated Phase II operating conditions.

One likely place for heterogeneous nucleation to occur is in the cold sections of the heat exchanger, where the fluid becomes greatly supersaturated with respect to amorphous silica. The two heat exchanger studies cited in Section 5.3 leave some doubt as to how much scal ing can be expected in the Fenton HIIl heat exchanger. The study of Gudmundsson and Bott (1979) examined a flufd with much lower silica and TOS content than can be expected under Phase II conditions (305 and 777 ppm versus 600 and $6000 \mathrm{ppm})$. However, the $\mathrm{pH}$ of 9.46 might be expected to have an accelerating effect on deposition--this effect will probably not be present in the Fenton $\mathrm{H} i 11$ system, where $\mathrm{pH}$ should be roughly 6.5-7. Direct application of this data to the Fenton Hill situation is not expected to be completely accurate, but figure 31 suggests the magnitude of the effect of scaling on heat exchanger performance. A possible $15 \%$ decl ine in the heat transfer coefficient after 1000 hours (41 days) is 
reason enough for further study of the problem.

The low salt concentration runs of Bohlmann et al. (1981) might be more representative of the Phase II system, except that the silica concentration is lower in Bohlmann's experiments. Thus, given this data, deposition rates in the Fenton Hill heat exchanger will definitely be higher than the lowest curve in Figure 32, possibly in the neighborhood of $0.1 \mathrm{~mm} / 1000 \mathrm{hr}$ or higher. These two studies indicate that silica scaling in the heat exchanger is likely, but it is difficult to pinpoint quantitatively. For this reason, it was decided that a bench scale experimental heat exchanger be designed and operated to examine the problem for the specific conditions of interest. This apparatus is described in Section 5.6 .

Heterogeneous nucleation is by no means 1 imited to just the heat exchanger and above ground piping. Section 5.4 shows that the field experience of geothermal plant operation leans toward the heterogeneous nucl eation mechanism even for flow in culverts or long piping systems. However, a simple calculation using the method described by Weres et al. (1980) shows that under Phase II conditions, homogeneous nucleation might also become an important silica precipitation mechanism in the injection wellbore. Figure 33 shows the results of such a calculation for the dissolved silica concentration range expected. The details of the calculation are presented in Appendix I. Figure 33 provides an estimate of the amount of time necessary for homogeneous nucleation to have an effect on the monomeric silica concentration. The residence time in the wellbore will be approximately 91 minutes, sufficient time for colloidal silica to form, at least at $700 \mathrm{ppm}$ initial silica concentration.

Figure 33 al so suggests that homogeneous nucleation could be used beneficially in the Phase II system, as it often is in the field. After 94 


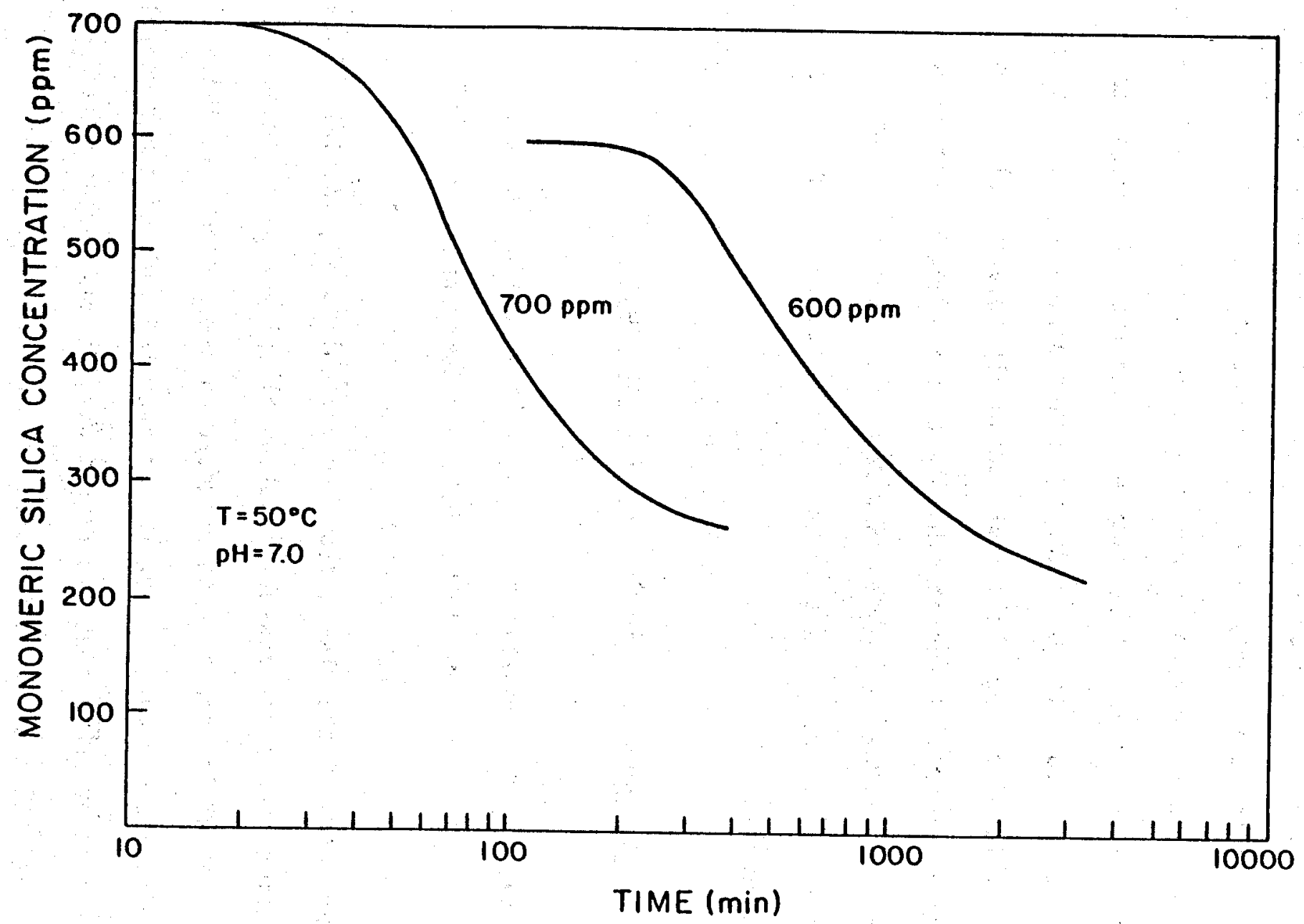

Figure 33. Estimated Phase II Monomeric Dissolved Silica Concentration vs. Time Based on Calculated Polymerization Rates 
the fluid passes through the heat exchanger, retention tanks could provide the brine with the necessary residence time to lower the monomeric silica concentration, thus slowing down the heterogeneous nucleation process. The plants described in Section 5.4 used this technique with great success. They also found that the colloidal silica did not even have to be removed from the fluid, since it did not adhere to the solid surfaces readily. However, since the HDR process calls for the reinjection into a low permeability reservoir, separation of the colloidal silica from the fluid would certainly be advisable. This precaution would prevent the possibility that silica deposition could raise the flow impedance in the reservoir intet region or cause undesirable flow short-circuiting through the path of least resistance in the reservoir.

\subsection{Experimental Apparatus For Silica Scaling Studies}

Two experimental programs examining silica scaling in heat exchangers (Gudmundsson and Bott, 1979, and Bohlmann et al., 1981) were cited in Section 5.3. These results showed that the conditions of temperature drop of the fluid, flow hydrodynamics, pH, initial silica concentration, and total dissolved solids all play a significant role in the amount of silica scale to be expected in the Fenton Hill Phase II system. Given the complexity of the problem and lack of experimental work performed at these specific conditions, it was decided that an apparatus be designed that could simulate the temperature and geochemical conditions of the outlet fluid and the behavior of the Fenton Hill heat exchanger.

A schematic diagram of the reaction system is shown in Figure 34. Flow is maintained using a Pulsafeeder pump which drives a high 96 


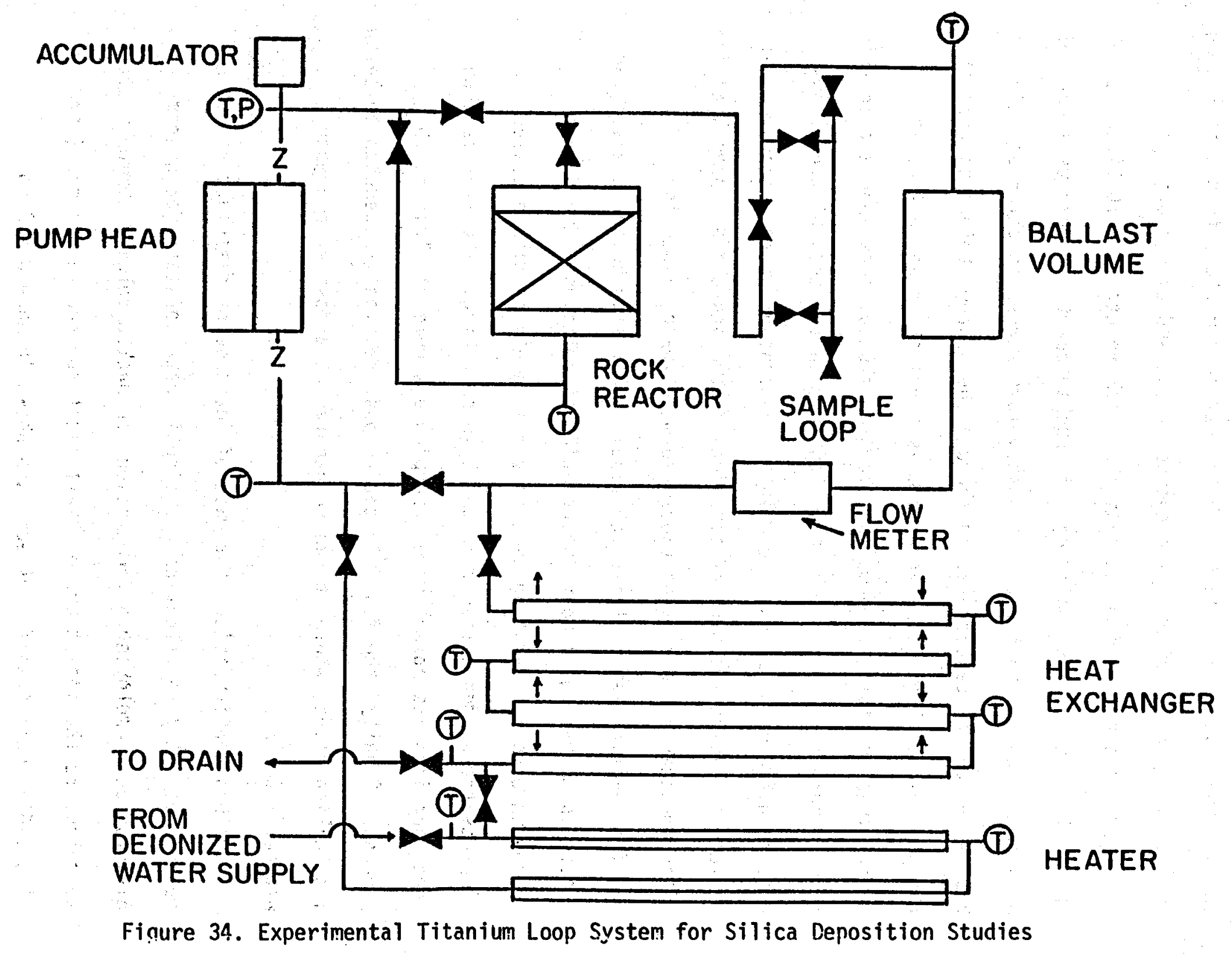


temperature oil into the remotely located diaphragm pump head. The motion of the oil pulses a diaphragm in the pump head, forcing the water on the other side of the diaphragm to pass through the pump head. One-way check valves in the pump head prevent the fluid from circulating in reverse when the diaphragm opens up at the end of a cycle.

Water is circulated up through the "rock reactor", a 10 liter vessel which will contain a known amount of crushed quartz or granite supported as a packed bed. The 5 liter ballast volume serves to catch any air bubbles which may be circulating through the system, before they reach the pump head. The accumulator tank is a vessel in which the water level rises and falls to damp out the flow fluctuations inherent in this type of pumping system. A rubber diaphragm in the accumulator allows bottled nitrogen to be used to maintain a constant system pressure. All val ves and piping are made of titanium and the vessels and pump head are titanium-sheathed to prevent undesired metal-water reactions.

The sampling setup allows for liquid samples to be taken while the system is operating without interrupting circulation. The flow is routed through the sampling by-pass for a length of time necessary to displace the stagnant liquid in the by-pass tubing. The flow is then sent back into its normal mode, trapping a sample of fluid in the process. Finally, the fluid in the by-pass section is quenched to below its boiling point, where it can be handled at atmospheric pressure without flashing.

In this configuration, the rate of increase of dissol ved silica may be used directly to calculate the kinetic rate constant for quartz dissolution. Employing a formulation for packed columns commonly used to calculate the mass transfer coefficient for such a reactor (Bird et al., 1960), mass transfer effects are shown in Appendix $J$ to be negligible for quartz dissolution at all anticipated flow rates. Thus, 98 
the observed rate will be controlled completely by the kinetics of quartz dissolution.

Having characterized fully the dissolution kinetics, the packed bed reactor-pump system will supply a simulated geothermal fluid to study silica scaling in a prototype heat exchanger. A titanium heat exchanger, shown schematically in Figure 34 , is presently being built. It will accept fluid up to $300^{\circ} \mathrm{C}$ supplied by the reactor and cool it to $50^{\circ} \mathrm{C}$ in four $10 \mathrm{ft}$ sections. The flurd will then be reheated using electric heaters strapped to the outside of two titanium pipes. The fluid temperature at the end of each section of the heat exchanger will be measured using immersed thermocouple wells. In each section, a separate source of cooling water will flow countercurrently to the geothermal fluid flow, thus providing the ability for independent flow rates and inlet and outlet temperatures to be maintained. The cooling water will be regenerated to a usable temperature using an evaporative cooling tower to minimize make-up water requirements.

By controlling the cooling water flow rates, the outlet geothermal fluid temperature from each section can be controlled. The heat transfer performance is then quantified by defining the overall heat transfer coefficient for that section as

$$
U_{0}=\frac{q}{A \Delta T_{1 m}}
$$

where

$q=$ heat flux from brine to cooling water $(W)$

$A=$ heat transfer surface area $\left(\mathrm{m}^{2}\right)$

$\Delta T_{1 \mathrm{~m}}=\log$ mean temperature difference between brine and cooling water $(K)$.

As silica scale builds up, the overall heat transfer coefficient will decline due to the added resistance of an amorphous silica scale layer. Observation of $U_{0}$ in each section will determine the temperature range 
where silica scaling will be a problem in the Fenton Hill heat exchanger. The laboratory heat exchanger is designed to be easily assembled and disassembled, allowing not only for rapid cleaning but also for visual and analytical observation of the scale. Once the scaling rate and locations have been identified, preventative measures could be studied further. For example, it would be possible to test for the effect of different heat exchanger materials on scale adherence by inserting coupons or a small section of tubing coated with different metals. 


\section{Appendix A}

Explanation of Calculations Required to Obtain Quartz Dissolution Rate Constants From the Literature Data

Van Lier et al. (1960)

Van Lier et al. correlated their initial rate data on the basis of the following equation:

$$
\left.\frac{d C}{d t}\right)_{t=0}=k_{1} \frac{S}{V}
$$

Comparing Equation $(A-1)$ to Equation $(2.3 .3)$ and setting $C_{0}=0$,

$$
k_{1}=k C^{\infty} \text {. }
$$

Since Van Lier et al. 1 isted their experimentally determined values of $k_{1}$. Equation $(A-2)$ was used to convert this rate constant data to the rate constant $k$ of the present study.

Kitahara (1960)

Kitahara plotted his data in the form of $\ln \left(\left(C^{\infty}-C\right) / C^{\infty}\right)$ vs. t. Thus, the slopes of these straight lines equal $-k^{*}$. The value of $a^{*}$ was given, so $k$ may be calculated directly.

Weill and Fyfe (1960)

Weill and Fyfe plotted $C$ vs. $t$, so the data analysis in this case followed the method outlined in Section 2.3. 
Siebert et al. plotted their experimental data in the form of C vs. t. Their experiments measured only the initial rate of dissolution, so Equation (2.3.3) was used to calculate the rate constant in each case.

Rimstidt (1979)

Rimstidt correlated his rate data using an equation derived on the basis of absolute rate theory. Assuming unit activity of the water and an activity coefficient of unity for $\mathrm{Si}(\mathrm{OH})_{4}$, his rate equation may be simplified to

$$
\frac{d C}{d t}=\frac{A}{M} k_{-}\left(C^{\infty}-C\right) \text {, }
$$

where

$$
\begin{aligned}
& A=\text { surface area } \\
& M=\text { mass of water } \\
& k_{-}=\text {Rimstidt's silica precipitation rate constant. }
\end{aligned}
$$

Since Rimstidt assumed absolute rate theory, he then proceeded to evaluate both quartz dissolution and silica precipitation experiments using the integrated form of Equation $(A-3)$. However, in analyzing Rimstidt's data in the present study, only his quartz dissolution experiments were considered.

Rimstidt used $\mathrm{Ar}$ or $\mathrm{N}_{2}$ BET as his method of surface area determination for most experiments. This type of measurement is not applicable to a liquid-solid reaction because the amount of surface area accessible to a gas (argon or nitrogen) is much greater than the surface area available to a liquid. Fortunately, he al so listed the amount and particle size distribution of quartz used in each experiment. Thus, the rate constant values listed in the present study are Rimstidt's k. 102 
values (from dissolution experiments only) recalculated using a surface area based on the particle size distribution. The surface area calculation assumed perfect spheres of one characteristic radius. 


\section{Appendix B}

Quartz Dissolution Concentration Versus Time Data

All times are in hours, all concentrations in $\mathrm{ppm} \mathrm{Si}(\mathrm{OH})_{4}$. Stirred autoclave runs are signified by an "A" followed by the experiment number. Runs A25-A31 are quartz dissolution experiments using crushed granite. Rocking arm runs are signified by an " $R$ " followed by the experiment number. An asterisk denotes that the data point was not used in the analysis.

\begin{tabular}{c|c}
\multicolumn{2}{c}{ Run A10 } \\
Time & Concentration \\
\hline 0 & $0.0^{\star}$ \\
1.98 & 8.8 \\
6.40 & 19.6 \\
12.20 & 29.4 \\
22.58 & 43.7 \\
27.65 & 45.6
\end{tabular}

\begin{tabular}{c|c}
\multicolumn{2}{c}{ Run All } \\
Time & Concentration \\
\hline 0 & $4.8^{\star}$ \\
2.87 & $10.1^{\star}$ \\
5.25 & $16.8^{\star}$ \\
16.17 & 40.4 \\
27.00 & 49.4 \\
40.02 & 58.4 \\
49.10 & 61.7 \\
64.02 & 67.5
\end{tabular}

\begin{tabular}{c|c}
\multicolumn{2}{c}{ Run A12 } \\
Time & Concentration \\
\hline 0 & $1.8^{*}$ \\
2.22 & $11.2^{\star}$ \\
7.50 & $30.3^{*}$ \\
17.75 & 55.4 \\
21.25 & 59.4 \\
25.20 & 65.6 \\
30.57 & 69.4 \\
41.40 & 75.0
\end{tabular}

\begin{tabular}{|c|c|}
\hline \multicolumn{2}{|c|}{ Run A13 } \\
\hline Time & Concentration \\
\hline $\begin{array}{l}0 \\
0.97 \\
1.88 \\
3.15 \\
4.13 \\
5.28 \\
7.00 \\
11.27\end{array}$ & $\begin{array}{c}64.6 \\
181.0 \\
218.7 \\
249.6 \\
269.7^{\star} \\
282.2^{\star} \\
274.7^{\star} \\
228.5^{\star}\end{array}$ \\
\hline
\end{tabular}


Run A14

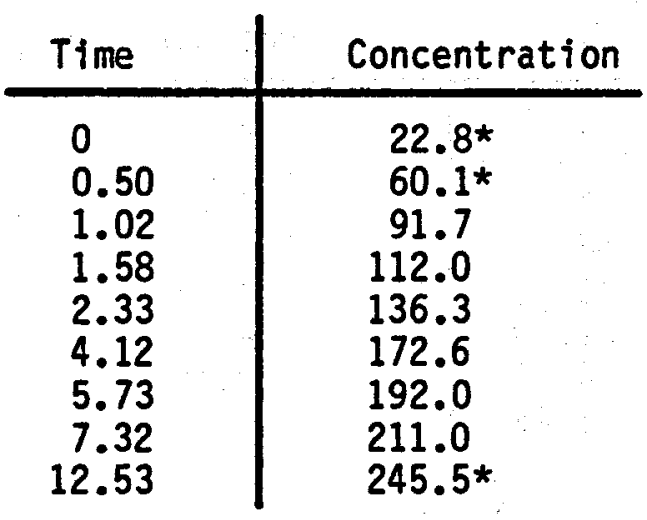

Run A16

\begin{tabular}{l|c} 
Time & Concentration \\
\hline 0 & $23.1^{\star}$ \\
0.52 & $71.7^{\star}$ \\
1.02 & $97.2^{\star}$ \\
1.52 & 121.8 \\
2.02 & 131.8 \\
3.55 & 171.1 \\
6.43 & 208.8 \\
10.62 & 237.1
\end{tabular}

Run A19

\begin{tabular}{l|r} 
Time & Concentration \\
\hline 0 & 38.4 \\
0.38 & 71.0 \\
0.82 & 104.9 \\
1.17 & 117.7 \\
1.50 & 130.3 \\
2.57 & 146.8
\end{tabular}

Run A22

\begin{tabular}{c|c} 
Time & Concentration \\
\hline 0 & 74.4 \\
0.28 & 129.8 \\
0.55 & 165.9 \\
0.80 & 196.0 \\
1.05 & 219.0 \\
3.28 & $337.1^{\star}$ \\
3.90 & $330.7^{\star}$
\end{tabular}

Run A15

\begin{tabular}{l|c} 
Time & Concentration \\
\hline 0 & $16.5^{\star}$ \\
0.52 & $47.8^{\star}$ \\
1.10 & 71.7 \\
1.63 & 84.4 \\
3.10 & 118.9 \\
4.80 & 142.8 \\
6.30 & 158.2 \\
11.37 & $190.5^{\star}$
\end{tabular}

Run A18

\begin{tabular}{l|c} 
Time & Concentration \\
\hline 0 & $65.5^{\star}$ \\
0.45 & 121.9 \\
0.85 & 157.3 \\
1.42 & 196.6 \\
1.98 & 212.5 \\
3.27 & 242.4 \\
4.47 & 231.8
\end{tabular}

Run A20

\begin{tabular}{l|r} 
Time & Concentration \\
\hline 0 & 39.0 \\
0.53 & 74.3 \\
1.00 & 101.4 \\
1.50 & 131.3 \\
1.95 & 140.1 \\
3.23 & 173.5 \\
4.28 & 197.2 \\
5.22 & 220.2
\end{tabular}

Run A23

\begin{tabular}{l|l} 
Time & Concentration \\
\hline 0 & 130.9 \\
0.25 & 163.6 \\
0.50 & 190.9 \\
0.75 & 215.4 \\
1.00 & 229.1 \\
1.25 & 247.3 \\
1.50 & 261.6 \\
1.75 & $269.8^{\star}$
\end{tabular}


Run A24

\begin{tabular}{l|c} 
Time & Concentration \\
\hline 0 & 33.8 \\
0.28 & 40.0 \\
0.50 & 47.8 \\
0.75 & 53.0 \\
1.08 & 60.1 \\
1.42 & 65.9 \\
1.75 & 71.8 \\
2.15 & 80.4
\end{tabular}

Run A26

\begin{tabular}{l|l} 
Time & Concentration \\
\hline 0 & 107.1 \\
0.77 & 123.5 \\
1.45 & 146.2 \\
2.20 & 131.5 \\
3.20 & 159.0 \\
4.70 & $289.3^{*}$
\end{tabular}

Run A28

\begin{tabular}{c|c} 
Time & Concentration \\
\hline 0 & $85.1^{\star}$ \\
1.08 & $92.1^{\star}$ \\
2.92 & $65.9^{\star}$ \\
4.95 & $66.6^{\star}$ \\
10.23 & 106.7 \\
22.46 & 120.7 \\
30.10 & 127.0 \\
33.83 & 128.0
\end{tabular}

\begin{tabular}{c|c}
\multicolumn{2}{c}{ Run A30 } \\
Time & Concentration \\
\hline 0 & 109.3 \\
1.03 & 109.8 \\
2.65 & 167.7 \\
4.33 & 168.6 \\
6.27 & 182.3 \\
9.30 & $131.7^{\star}$ \\
10.97 & $143.8^{\star}$ \\
22.48 & $157.8^{\star}$
\end{tabular}

Run A25

\begin{tabular}{l|l} 
Time & Concentration \\
\hline 0 & $93.2^{\star}$ \\
1.43 & 124.5 \\
3.30 & 153.1 \\
6.42 & 173.8 \\
19.32 & $217.7^{\star}$ \\
22.08 & 234.9 \\
24.13 & $260.7^{\star}$ \\
25.46 & $257.1^{\star}$
\end{tabular}

Run A27

\begin{tabular}{l|l} 
Time & Concentration \\
\hline 0 & 118.6 \\
0.50 & 127.6 \\
1.00 & $185.7^{\star}$ \\
1.55 & 161.7 \\
2.00 & 158.9 \\
2.50 & 148.9 \\
3.00 & $69.3 \star$ \\
3.50 & 171.1
\end{tabular}

Run A29

\begin{tabular}{l|c} 
Time & Concentration \\
\hline 0 & 73.2 \\
0.88 & 77.5 \\
2.03 & 81.0 \\
3.25 & 128.3 \\
4.45 & 132.2 \\
9.18 & 161.2
\end{tabular}

Run A31

\begin{tabular}{l|l} 
Time & Concentration \\
\hline 0 & 84.3 \\
0.48 & 114.6 \\
1.55 & 103.8 \\
2.37 & 141.5 \\
3.78 & 155.4 \\
5.48 & $222.7^{\star}$ \\
7.92 & 195.6 \\
10.28 & $210.2^{\star}$
\end{tabular}


Run R1

\begin{tabular}{c|c} 
Time & Concentration \\
\hline 4.0 & 16 \\
6.0 & 28 \\
48.0 & 83 \\
96.0 & 191
\end{tabular}

Run R3

\begin{tabular}{c|c} 
Time & Concentration \\
\hline 2.0 & 16 \\
4.0 & 18 \\
24.0 & 47 \\
96.0 & 154
\end{tabular}

Run R2

\begin{tabular}{r|c} 
Time & Concentration \\
\hline 4.0 & $105^{\star}$ \\
6.0 & 106 \\
24.0 & 281 \\
96.0 & 377 \\
192.2 & $342 \star$
\end{tabular}

Run R4

\begin{tabular}{c|c} 
Time & Concentration \\
\hline 6.0 & 23 \\
24.0 & 59 \\
96.0 & 159 \\
192.0 & 187
\end{tabular}




\section{Appendix C}

Sample Calculation For Stirred Autoclave Run A14

The analysis of the concentration versus time data from a stirred autoclave reactor is complicated by three effects: thermal expansion and a small amount of vaporization of the liquid, the decrease in liquid vol ume due to sampling, and the initial rapid rate of dissolution of the small fines. This appendix is a sample calculation demonstrating how all of these considerations were taken into account.

The stirred autoclave used in this study contained a total usable volume of $1000 \mathrm{ml}$, but the amount of water charged to the reactor was usually $500 \mathrm{ml}$. This water was often preheated somewhat to shorten the time necessary for heatup in the reactor. Let

$$
\begin{aligned}
& V=\text { initial vol ume of } 1 \text { iquid }(\mathrm{ml}) \\
& \rho=\text { density }\left(\mathrm{g} / \mathrm{cm}^{3}\right) \\
& V=\text { volume of reactor }=1000 \mathrm{ml} \\
& \underline{V}_{g}=\text { volume of vapor }(\mathrm{ml}) \\
& T_{i}=\text { initial water temperature }\left({ }^{\circ} \mathrm{C}\right) \\
& T=\text { final water temperature }\left({ }^{\circ} \mathrm{C}\right) .
\end{aligned}
$$

A mass balance before and after heatup gives

$$
\rho\left(1, T_{i}\right) V=\underline{V}_{g} \rho(g, T)+\left(\underline{V}-\underline{V}_{g}\right) \rho(1, T),
$$

or

$$
\underline{v}_{-g}=\frac{\rho\left(1, T_{i}\right) V-\rho(1, T) \underline{V}}{\rho(g, T)-\rho(T, T)}
$$

Thus, the amount of fluid vaporized is

$$
\rho(g, T) \underline{V}_{g}=\frac{\rho(g, T)\left[\rho\left(1, T_{j}\right) V-\rho(1, T) \underline{V}\right]}{\rho(g, T)-\rho(T, T)}
$$

Since at room temperature the density of water is $1.00 \mathrm{~g} / \mathrm{ml}$, Equation (C-3) gives the room temperature volume of water evaporated.

For Run A14, 


$$
\begin{aligned}
& T=202^{\circ} \mathrm{C} \\
& T_{i}=55^{\circ} \mathrm{C} \\
& \rho(g, T)=8.187 \times 10^{-3} \mathrm{~g} / \mathrm{cm}^{3} \\
& \rho(1, T)=0.862 \mathrm{~g} / \mathrm{cm}^{3} \\
& \rho\left(1, T_{i}\right)=0.963 \mathrm{~g} / \mathrm{cm}^{3} .
\end{aligned}
$$

Equation (C-3) yields

$$
\begin{aligned}
& \rho(g, T) \underline{V}_{g}=\frac{8.187 \times 10^{-3}(500(0.986)-1000(0.862))}{\left(8.187 \times 10^{-3}-0.862\right)}, \\
& \rho(g, t) \underline{V}_{g}=3.54 \mathrm{~g} \mathrm{H}_{2} 0 \text { vaporized }=3.54 \mathrm{mT} \text { at room temperature. }
\end{aligned}
$$

Thus, the amount of liquid water remaining, when converted to a volume at room temperature, is

$$
500.0\left(\rho\left(1, \mathrm{~T}_{j}\right) / \rho\left(1,20^{\circ} \mathrm{C}\right)\right)-3.54=490.2 \mathrm{ml} \text {. }
$$

This value is the initial fluid volume used in all future calculations.

Next, to account for the decrease in fluid volume due to sampling, Equation (3.5.1) is used. Due to the simple nature of the function $V(t), \int_{0}^{t} d t / V$ may be easily cal cul ated.

The following table lists the data for Run A14:

\begin{tabular}{l|c|c|c|c}
$t(h r)$ & $V(m l)$ & $\int_{0}^{t} d t / V\left(h r / m l \times 10^{3}\right)$ & $c$ & $\Phi$ \\
\hline 0 & 482.7 & 0 & 22.8 & 1 \\
0.5 & 475.2 & 1.04 & 60.1 & 0.850 \\
1.02 & 467.2 & 2.13 & 91.7 & 0.724 \\
1.58 & 459.7 & 3.33 & 112.0 & 0.642 \\
2.33 & 451.7 & 4.96 & 136.3 & 0.545 \\
4.12 & 443.7 & 8.92 & 172.6 & 0.399 \\
5.73 & 435.2 & 12.55 & 192.0 & 0.321 \\
7.32 & 428.2 & 16.20 & 211.0 & 0.245 \\
12.53 & & 28.37 & 245.5 & 0.106
\end{tabular}

The volume represents the volume after that particular sample was taken, and remains constant until the next sample.

The plot of $\ln \Phi v s . \int_{0}^{t} d t / V$ shown in Figure 35 demonstrates the same two-slope behavior that was seen by Rimstidt (1979). Small fine dissolution was responsible for the initial rapid dissolution rate, and 


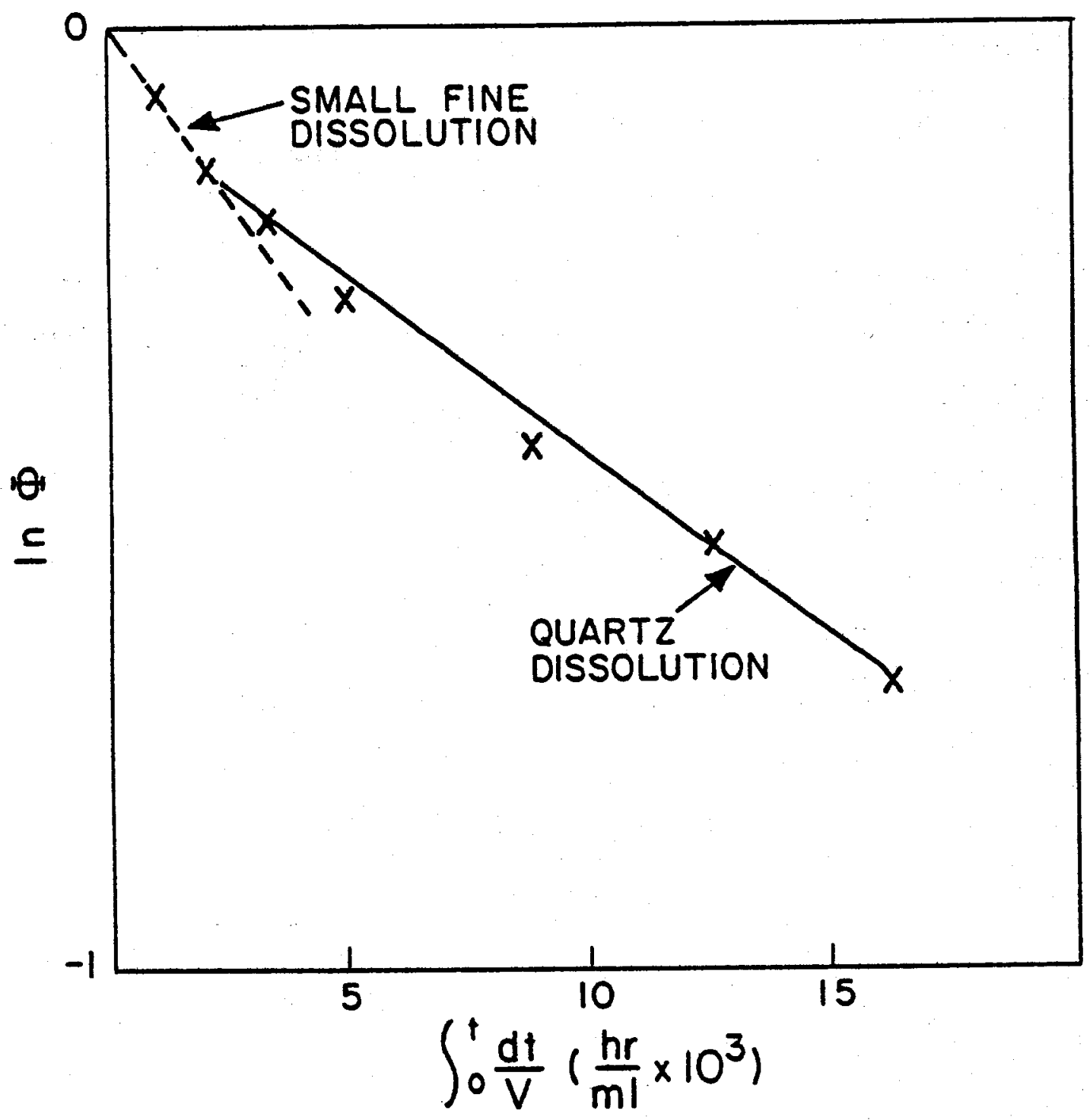

Fioure 35. In vs. $\int_{0}^{t} d t / V$ for Run A14. Initial Rapid Rate of Dissolution (Dotted Line) is Caused by Small Fines of Silica. 
the slope of the solid line was used to determine -kS. The final data point was also omitted from the analysis.

Using the rate constant obtained from the analys is presented above, the concentration versus time response was calculated and plotted in Figure 36. 


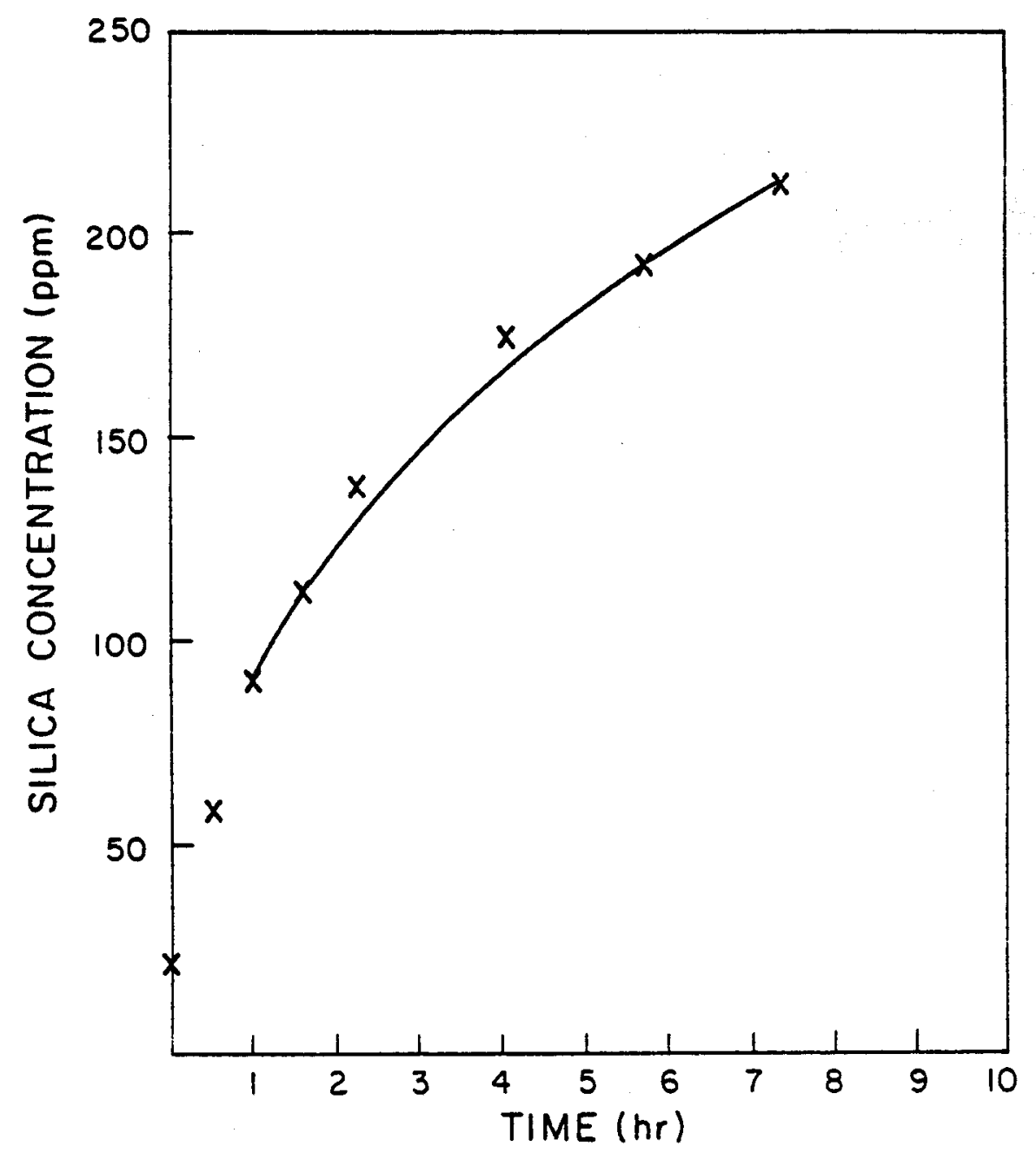

Fiqure 36. Concentration vs. Time Best Fit for Run Al4 


\section{Appendix D \\ Calculation of the Mass Transfer Coefficient In the Stirred}

\section{Autocl ave Reactor}

Source: Sherwood et al. (1975)

This sample calculation is carried out for 200-270 mesh particles $(0.0313 \mathrm{~mm})$ at $250^{\circ} \mathrm{C}$. The stokes' law terminal velocity is given by Equation (3.6.1). Let

$$
\begin{aligned}
& d_{p}=0.00313 \mathrm{~cm} \\
& \rho_{s}=2.65 \mathrm{~g} / \mathrm{cm}^{3} \\
& \rho_{7}=0.8008 \mathrm{~g} / \mathrm{cm}^{3} \\
& \mu_{7}=1.12 \times 10^{-3} \mathrm{~g} / \mathrm{cm}-\mathrm{sec} . \\
& \quad U_{T S}=\frac{(0.00313)^{2}|2.65-0.8008|(981)}{18\left(1.12 \times 10^{-3}\right)}=0.8816 \mathrm{~cm} / \mathrm{sec} .
\end{aligned}
$$

The Reynolds number based on the Stokes' law velocity is calculated from Equation $(3.6 .2)$ :

$$
\operatorname{Re}_{T S}=\frac{(0.00313)^{3}(0.8008)|2.65-0.8008|(981)}{18\left(1.12 \times 10^{-3}\right)^{2}}=1.97 .
$$

From the table of $U_{T} / U_{T S}$ versus $R e_{T S}$ in Sherwood et al . (1975),

$$
U_{T} / U_{T S}=0.825 \text {, }
$$

or

$$
U_{T}=0.7273 \mathrm{~cm} / \mathrm{sec} .
$$

The new Reynolds number based on $U_{T}$ is

$$
\operatorname{Re}=\frac{(0.7273)(0.00313)(0.8008)}{\left(1.12 \times 10^{-3}\right)}=1.627 .
$$

A method for estimating $D_{A B}$ for monomeric silicic acid in water is outl ined in Appendix J. Thus, from Equation (3.6.3), with $\mathrm{Sc}=14.18$ at 
this temperature,

$$
\begin{aligned}
& S h=\frac{k_{m} d_{p}}{D_{A B}}=2+0.6(1.627)^{1 / 2}(14.18)^{1 / 3}=3.852 \\
& k_{m}=0.1215 \mathrm{~cm} / \mathrm{sec}=1.215 \times 10^{-3} \mathrm{~m} / \mathrm{sec} .
\end{aligned}
$$

This value must be compared to the value of the rate constant at $250^{\circ} \mathrm{C}$. From the Arrhenius plot in Figure $11, k=4.76 \times 10^{-8} \mathrm{~m} / \mathrm{sec}$ at $250^{\circ} \mathrm{C}$. The mass transfer coefficient $k_{m}$ is 5 orders of magnitude larger than $k$, indicating that if the particles are suspended, mass transfer limitations will be negligible. 


\section{Appendix E}

Calculation of the Minimum Rotation Speed For Complete

Particle Suspension

Source: Zwietering (1958)

Zwietering correlated the minimum rotation speed necessary for suspension of the particles in a stirred reactor as a function of fluid properties, particle size, and total weight of the particles. He then obtained dimensionless number $s$, which he correlated for different reactor dimensions and types of stirrers. The final result is

$$
s=\frac{n D^{0.85}}{v^{0.1} d_{p}^{0.2}\left(\frac{g \Delta \rho}{\rho_{1}}\right)^{0.45}{ }_{B}^{0.13}}
$$

where

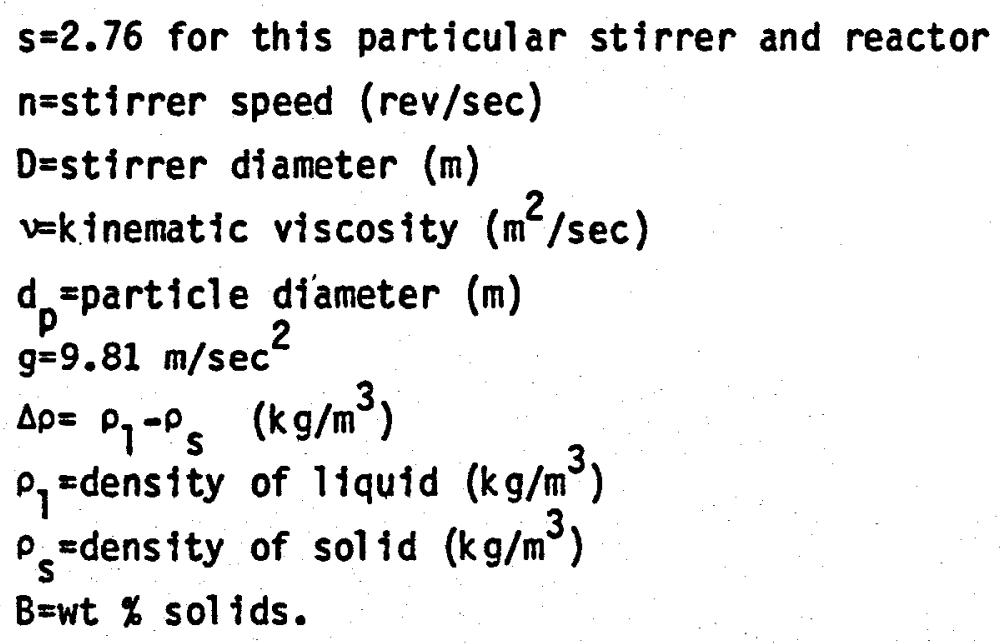

The temperature will influence the results only by changing the liquid properties, but this effect will be small for water at these conditions. For this sample calculation, let

$$
\begin{aligned}
& T=200^{\circ} \mathrm{C} \\
& D_{p}=8.33 \times 10^{-4} \mathrm{~m}(18-24 \text { mesh }) \\
& B=10 \% .
\end{aligned}
$$


Then,

$$
\begin{aligned}
& \nu=1.6 \times 10^{-7} \mathrm{~m}^{2} / \mathrm{sec} \\
& \rho_{\mathrm{s}}=2723 \mathrm{~kg} / \mathrm{m}^{3} \\
& \rho_{1}=866.8 \mathrm{~kg} / \mathrm{m}^{3} \\
& D=5.4 \times 10^{-2} \mathrm{~m} \\
& 2.76=\frac{n\left(5.4 \times 10^{-2}\right)^{0.85}}{\left(1.6 \times 10^{-7}\right)^{0.7}\left(8.33 \times 10^{-4}\right)^{0.2}\left[\frac{9.81(2723-866.8)}{866.8}\right]^{0.45} 10^{0.13}} \\
& n=8.87 \mathrm{rev} / \mathrm{sec}=532 \mathrm{rpm}
\end{aligned}
$$




\section{Appendix F \\ Calculation of the Time Required to Dissolve \\ the Damaged Silica In a HOR Reservoir}

This calculation will establish an upper bound on the number of small fines on the granite and apply that result to the Fenton Hill Phase I reservoir to determine whether the small fines contributed significantly to the dissolution mechanism. This analysis assumes that the granite crushing process used in the stirred autoclave experiments creates roughly the same amount of damaged material per unit area as reservoir fracturing.

\section{Run A25}

$$
\begin{aligned}
& M=73.25 \mathrm{~g} \text { granite, } 18-24 \text { mesh }\left(26.45 \mathrm{~cm}^{2} / \mathrm{g}\right) \\
& V=500.0 \mathrm{ml} \mathrm{H} \mathrm{H}^{0} \\
& T=201^{\circ} \mathrm{C} \\
& C\left(200^{\circ} \mathrm{C}\right)=257 \mathrm{ppm} \\
& C_{\text {final }}=261 \mathrm{ppm} \approx \mathrm{C}^{\infty} .
\end{aligned}
$$

Since the final concentration is governed by the quartz solubility equilibrium curve, the small fines must have been very nearly dissolved away at the end of the experiment. Thus, an upper bound on the number of fines per unit area is obtained by assuming that the entire $257 \mathrm{ppm}$ dissolved sillica were contributed from small fine dissolution.

$$
\frac{(257 \mathrm{mg} / \mathrm{kg})\left(500 \times 10^{-3} \mathrm{~kg}\right)}{(73.25 \mathrm{~g})\left(26.45 \mathrm{~cm}^{2} / \mathrm{g}\right)}=6.63 \times 10^{-2} \frac{\mathrm{mg} \text { fines }}{\mathrm{sq} . \mathrm{cm} \mathrm{rock}}
$$


$\left(50000 \mathrm{~m}^{2}\right)(2$ faces $)\left(10^{4} \mathrm{~cm}^{2} / \mathrm{m}^{2}\right)\left(6.63 \times 10^{-2} \mathrm{mg}\right.$ fines $\left./ \mathrm{cm}^{2}\right)=$ $6.63 \times 10^{7} \mathrm{mg}$ fines initiall $\mathrm{y}=66.3 \mathrm{~kg}$.

Under recirculation, a mass balance shows that the net rate at which silica is extracted from the reservoir is approximately equal to the make-up water flow rate times the dissolved silica concentration difference between the make-up fluid and the produced fluid.

$(10 \mathrm{gpm})(220-60 \mathrm{mg} / \mathrm{kg})(3.785 \mathrm{~kg} \mathrm{H} 20 / \mathrm{gal})=6.06 \times 10^{-3} \mathrm{~kg} / \mathrm{min}$ $(66.3 \mathrm{~kg})\left(6.06 \times 10^{-3} \mathrm{~kg} / \mathrm{min}\right)^{-1}(1$ day $/ 1440 \mathrm{~min})=7.5$ days.

Thus, it would take 7.5 days to dissolve away $66.3 \mathrm{~kg}$ of fines. Since the initial water loss was much higher than $10 \%, 7.5$ days represents the maximum amount of time for the fines to be dissolved away in the reservoir. It appears that some other mechanism must be found to account for the rapid rate of granite dissolution in the Fenton Hill reservoir. 


\section{Appendix G}

\section{Analytical Solution For Reservoir Temperature Field}

Source: Arpact (1966)

Arpaci solved a variation of the heat transfer problem outlined in Section 4.3. The heat transfer assumptions are one-dimensional heat conduction in the rock (in the x-direction), thermal equilibrium between the fluid and the rock at $x=0$, and a flat fluid temperature profile across the fracture. The fluid flow assumptions are plug flow in the z-direction in a rectangular fracture, an infinitely wide fracture in the y-direction, and no fluid loss. Mathematically, this problem is stated as

$$
\begin{aligned}
& \frac{\partial \theta}{\partial t}=\alpha \frac{\partial^{2} \theta}{\partial x^{2}} \\
& \theta(x, z, 0)=1 \\
& \theta(\infty, z, t)=1 \\
& \left(\frac{\partial \theta}{\partial t}+u \frac{\partial \theta}{\partial z}=\varepsilon \frac{\partial \theta}{\partial x}\right)_{x=0} \\
& \theta(0,0, t)=0
\end{aligned}
$$

where

$$
\begin{aligned}
& \theta=\left(T-T_{f}\right) /\left(T_{r}-T_{f}\right) \\
& u=\text { average fiuid velocity } \\
& \varepsilon=\left(2 \lambda_{r}\right) /\left(\overline{w p C_{p}}\right) .
\end{aligned}
$$

Taking the Laplace transform of Equations (G-1) and (G-2):

$$
\begin{aligned}
& \frac{d^{2} \bar{\theta}}{d x^{2}}-q^{2} \bar{\theta}=-1 / \alpha \\
& \bar{\theta}(\infty, z, p)=1 / p \\
& \left(p \bar{\theta}-1+u \frac{d \bar{\theta}}{d z}=\varepsilon \frac{d \bar{\theta}}{d x}\right) x=0 \\
& \bar{\theta}(0,0, p)=0
\end{aligned}
$$

where $p$ is the transformed time variable and $q^{2}=p / \alpha$. Solving Equation (G-3) with the first boundary condition of Equation (G-4), 


$$
\bar{\theta}=\left(\frac{1}{p}+\bar{\theta}(0, z, p)\right) e^{-q x}+\frac{1}{p}
$$

Differentiating Equation (G-5) and setting $x=0$,

$$
\left.\frac{d \bar{\theta}}{d x}\right|_{x=0}=\left(\frac{1}{(\alpha p)^{1 / 2}}-q \bar{\theta}\right) x=0
$$

Equation (G-6) may now be combined with the $x=0$ boundary condition of Equation (G-4):

$$
\left(\frac{d \bar{\theta}}{d z}+\frac{1}{u}(p+\varepsilon q) \bar{\theta}\right)_{x=0}=\frac{1+\varepsilon /(\alpha p)^{1 / 2}}{u}
$$

Equation (G-7) can now be solved with the third boundary condition of Equation (G-4) to obtain $\bar{\theta}(0, z, p)$ :

$$
\bar{\theta}(0, z, p)=\frac{1+\varepsilon /(\alpha p)^{1 / 2}}{p+\varepsilon q}\left(1-\exp \left(\frac{(p+\varepsilon q) z}{u}\right)\right)
$$

Combining Equations (G-8) and (G-5):

$$
\bar{\theta}=\left[-\frac{1}{p}+\frac{1+\varepsilon /(\alpha p)^{1 / 2}}{p+\varepsilon q}\left(1-\exp \left(-\frac{(p+\varepsilon q) z}{u}\right)\right)\right] e^{-q x}+\frac{1}{p}
$$

To take the inverse Laplace transform of this function, the following identity must be used (Beyer, 1976):

$$
L^{-1}\left(e^{-b p_{f}}(p)\right)=\left\{\begin{array}{l}
0, t<b \\
F(t-b), t>b
\end{array}\right.
$$

In this case, rearrangement of Equation (G-9) results in a form of the argument of Equation (G-10), where $b=z / u$. In other words, at any vertical position $z$, the temperature starts changing only after the "new" fluid has pushed the original fluid past that point in the fracture. The inverse transform of Equation (G-9) is

$$
\theta=\operatorname{erf}\left[\frac{\varepsilon z / u+x}{2(\alpha t)^{1 / 2}}\right]
$$

where $\theta$ is defined for all $z$ only after-the time of operation has exceeded one residence time for the fracture. 
The time $t$ in Equation (G-11) is actually $t-z / u$, but for practical cases of interest, the residence time in the fracture is much shorter than the overall time of operation. Equation (G-11) expresses the temperature of the rock at any position. The fluid temperature is obtained by setting $x=0$ and simplifying to the result shown in Equation (4.3.1). 


\section{Appendix H}

\section{HDR Reservoir Computer Model}

Equation (4.3.8) is a mass balance on the dissolved silica in a volume element of fluid. The model assumes plug flow up a rectangular fracture (see Figure 17). Choosing a finite vertical spacing $\Delta z$, the concentration increase in a volume element of fluid can be calculated using the trapezoid rule on Equation (4.3.8):

Solving for $C_{i}$,

$$
c_{i}-c_{i-1}=\frac{0.6 A \Delta z}{2 L}\left[\frac{k_{i}\left(c_{i}^{\infty}-c_{i}\right)}{Q_{i}}+\frac{k_{i-1}\left(c_{i-1}^{\infty}-c_{i-1}\right)}{Q_{i-1}}\right] \text {. }
$$

$$
C_{i}=\frac{C_{i-1}\left(1-\beta_{i-1}\right)+\beta_{i} C_{i}^{\infty}+\beta_{i-1} C_{i-1}^{\infty}}{1+\beta_{i}},
$$

where

$$
B_{i}=\frac{0.3 A \Delta z k_{i}}{L Q_{i}} \text {. }
$$

Thus, the program calculates $c_{i}$ on the basis of $C_{i-1}$ and the reaction kinetics. If the fluid happens to be at a low enough temperature such that $c^{\infty}<C$, then the rate constant is set to zero and $C_{i}=C_{i-1}$.

The parameters with subscripts are calculated at each position. The flow rate $Q$ is found using Equation (4.3.2). Equation (4.3.1) describes the temperature at each position, which is necessary for determining $k_{i}$ and $c_{i}^{\infty}$. Finally, the program uses Rimstidt's correlation for the equilibrium solubility of quartz (Table 1 ) to calculate $c^{\infty}$ at any position. The rate constant $k$ is estimated using the correlation found for granite dissolution in the present study. A further increase in the pre-exponential factor of 2.5 was necessary to fit the Phase I data. This adjustment seems justified, given the fact that the flat fracture assumption provides a lower bound on the active area of dissolution. 
$10 \operatorname{DIM} C(501), T(501), B B(501), A A(501), A 1(501), U(501), E R(501)$

15 REM RATE CONSTANT, EQUIL. SOLUBILITY DEFINITION

16 REM COEFF. IN MASS BALANCE DEFINED

20 DEF FN $K(T)=\operatorname{EXP}((-3994 / T+2: 369) * \operatorname{LOG}(10))$

25 DEF FN CF $(T)=60000 * \star E X P((1.881-2.028 E-3 * T-1560 / T) * \operatorname{LOG}(10))$

30 DEF FN KP(J)=AK $\star A 1(J) / U(J)$

$40 \mathrm{JS}=100$

45 REM SYSTEM PARAMETERS AND PROPERTIES INITIALIZED

$50 \mathrm{TI}=333.2: \mathrm{TR}=465.2: R C=4.013 \mathrm{E} 6: A F=1.074 E-6: L A=2.9: A R=55000$

$60 \mathrm{EL}=300: D Z=E L / J S: V=185: P F=.05: M M=143: T M=M M * 86400$

$65 N M=0: C(0)=60: C I=C(0): C S=F N \quad C F(T R): X Y=0$

70 Q1 $=100: 02=15:$ GOSUB 640

71 REM SUROUTINE AT 640 ALLOWS FOR CHANGE OF PARAMETERS

72 IF $T(1)=0$ THEN 80

73 REM "IF" STATEMENTS WILL BY-PASS TEMPERATURE SOLUTION IF DESIRED

75 PRINT "DO YOU WANT TO RECALCULATE. TEMPERATURE FIELD": INPUT $Z \$$

76 IF $Z \$=" N O "$ THEN 180

77 PRINT "IS IT NECESSARY TO RECALCULATE ERF(T(J))": INPUT Z\$.

78 IF $Z \$=$ "NO" THEN 1500

$80 Z=-D Z$

85 REM LOOP CALCULATES FLUID VELOCITY, TEMPERATURE,

86 REM $K$, AND EQUIL. SOLUBILITY AS A FUNCTION OF $Z$

90 FOR $J=0$. TO. JS

94 REM NM=1 IF ERF $(X)$ IS NOT BEING RECALCULATED

95 IF NM=1 THEN 140

$100 Z=Z+0 Z$

105 IF $X Y=1$ THEN 120

$110 U(J)=6.308 E-5 *(Q 1-Q 1 * Q 2 * Z /(100 * E L)) * E L / N$

115 REM $X$ IS THE ARGUMENT IN THE. ERROR FUNCTION

116 REM TEMPERATURE SOLUTION

$120 X=A R * L A * Z /(R C * V * U(J) * S Q R(A F * T M))$

130 GOSUB 1000

140 IF $J>0$ THEN 150

$145 \mathrm{~T}(\mathrm{~J})=\mathrm{TI}:$ :GOTO 160

$150 T(J)=E R(J) *(T R-T I)+T I$

$160 A A(J)=F N \quad K(T(J)): B B(J)=F N \quad C F(T(J))$

170 NEXT $J$

173 REM $X Y=1$ IF RECIRCULATION CALCULATION IS IN PROGRESS AND

174 REM TEMPERATURE FIELD IS BEING RECALCULATED:

175 IF $X Y=1$ THEN 525

180 PRINT "DO YOU WANT"

190 PRINT "1. FRESH WATER FLUSH".

200 PRINT "2. RECIRCULATION": INPUT Q3.

210 IF $Q 3=1$ THEN 240

220 IF $Q 3=2$ THEN 410

230 GOTO 180

235 REM FRESH WATER FLUSH

240 GOSUB 1410: GOSUB 1300:GOSUB 1550

300 GOTO 50

400 REM RECIRCULATION

410 GOSUB 1410 
450 PRINT "INPUT TIME STEP, \# OF INTERVALS": INPUT HR,QD

$460 T E=0: T A=0$

465 REM OUTLET CONC. VS. TIME FOUND FROM

466 REM RESIDENCE TIME AND DISSOLUTION SUBROUTINES

470 PRINT "TIME(HR.) OUTLET CONC."

480 FOR I $=1$ TO QD

$490 T A=T A+H R$

$500 T E=T E+H R$

510 IF TE $<T T+17$ THEN 560

515 IF TA $<$ TE THEN 520

516 GOSUB 1300:GOTO 530

517 REM INLET CONC. CALCULATED FROM OUTLET OF

518 PREVIOUS PASS AND MAKE-UP FLUID DILUTION

$519 C(0)=(Q 2-100 * P F) * C I / 100+P F *(F N \quad C F(T R))$

$520 \mathrm{C}(0)=\mathrm{C}(0)+(100-Q 2) * \mathrm{C}(\mathrm{JS}) / 100$

$521 T M=M M * 86400+T A * 3600: X Y=1$

522 GOTO 80

525 GOSUB 1300

530 TE $=0: C S=C$ (JS)

$555 C X=(100 * P F *(F N \quad C F(T R))+(100-Q 2) * C(J S)) /(100-Q 2+100 * P F)$

560 PRINT MM+TA/24;" ";CX

570 NEXT I

580 GOTO 50

630 REM SUBROUTINE ASKS FOR PARAMETER CHANGES AND MAKES THEM

632 REM INTERRELATED PARAMETERS ARE AUTOMATICALLY CHANGED

$640 \mathrm{~B} \$=$ "YES"

645 PRINT "1.DAY EXPT. BEGINS= ";MM

650 PRINT "2.INLET H2O TEMP. $="$; TI -273.2

655 PRINT "3.INIT. ROCK TEMP. $="$;TR-273.2

660 PRINT "4.AREA $=$ ";AR

665 PRINT "5.HEIGHT=";EL

670 PRINT "6.VOLUME =";V

680 PRINT "7.FLOW RATE = ";Q1:PRINT "8.LOSS = ";Q2; "\%"

685 PRINT "9. INLET CONC. $=" ; C(0)$

690 IF $B \$=" N O "$ THEN 990

700 PRINT "DO YOU WISH TO CHANGE ANY OF THESE":INPUT A\$

710 IF A\$= "NO" THEN 990

720 PRINT "WHICH ONE": INPUT VA

730 PRINT "INPUT NEW VALUE"

732 IF $V A=1$ THEN 813

735 IF $V A=2$ THEN 820

740 IF $V A=3$ THEN 840

750 IF $V A=4$ THEN 860

760 IF $V A=5$ THEN 880

770 IF $V A=6$ THEN 900

790 IF $V A=7$ THEN 930

800 IF $V A=8$ THEN 940

805 IF $V A=9$ THEN 950

810 GOTO 720

813 INPUT MM: TM $=M M * 86400$

814 GOTO 960

820 INPUT $T I: T I=T I+273.2$

830 GOTO 960

840 INPUT TR:TR=TR+273.2: CS=FN CF (TR)

850 GOTO 960

860 INPUT AR

870 GOTO 960

124 


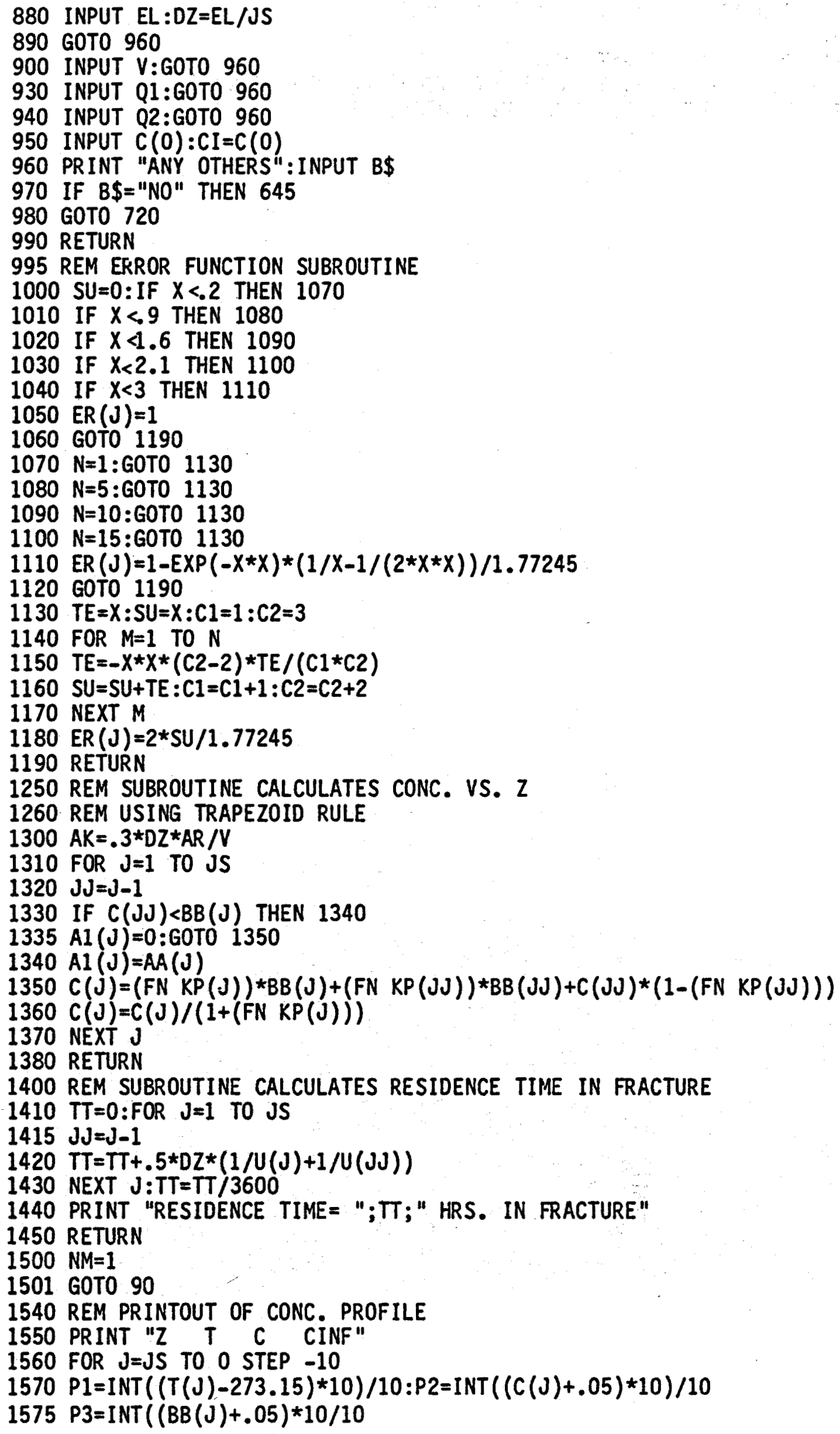


1580 PRINT J*DZ;" ";P1;" ";P2;" ";P3

1590 NEXT $J$

1594 REM PORE FLUID CORRECTION

$1595 C P=(100 * P F *(F N C F(T R))+(100-Q 2) * C(J S)) /(100-Q 2+100 * P F)$

1596 PRINT "OUTLET CONC. WITH PORE FLUID $=$ ";CP

1600 RETURN 


\section{Appendix I}

Calculation of the Rate of Homogeneous Nucleation of Coll oidal Silica Under Phase II Conditions

Source: Weres et al. (1980)

Weres et al. (1980) provided curves for the concentration of monomeric dissolved silfica versus time for various temperatures and initial silica concentrations (see figure 37 ). This calculation uses the combination of $600 \mathrm{ppm}$ and $50^{\circ} \mathrm{C}$ to estimate the extent of homogeneous nucleation in the injection wellbore of the Phase II system. In general, the equilibrium silica concentration should be corrected for the effects of salt concentration and $\mathrm{pH}$, but for the values expected in the Phase II system (appoximately $6000 \mathrm{ppm}$ TDS and $\mathrm{pH}=7$ ), these variables will have a negligible effect on the equilibrium solubility of quartz.

To correct for the effect of $\mathrm{pH}$ on polymerization rate, the time axis is shifted using the following equation:

$$
\log t=-1-\log \left(\mathrm{pH}_{,} \mathrm{pH}_{\mathrm{nom}}\right)+1412(\sigma / T)^{3}\left(1 n s^{\infty}\right)^{-2}-\mathrm{F}_{\text {ref }} \text {, }
$$

where $F=a$ tabulated function given in Weres et al. (1980)

$\sigma=$ surface tension $\left(\mathrm{erg} / \mathrm{cm}^{2}\right)$

$S^{\infty}=C / C^{\infty}=$ supersaturation ratio based on amorphous silica

$\mathrm{pH}_{\text {nom }}=\mathrm{a}$ "corrected" $\mathrm{pH}$.

The reason that $\mathrm{pH}_{\text {nom }}$ appears in this work follows as a result of the way Weres et al. chose to fit their polymerization data, and is not based on any physical considerations. They define $\mathrm{pH}_{\text {nom }}$ as

$$
\left.\mathrm{pH}_{\text {nom }}=\mathrm{pH}+\log \left(\mathrm{ENa}^{+}\right] / 0.069\right) \text {. }
$$

The salt concentration to be expected under Phase II conditions is not 
$\vec{\infty}$

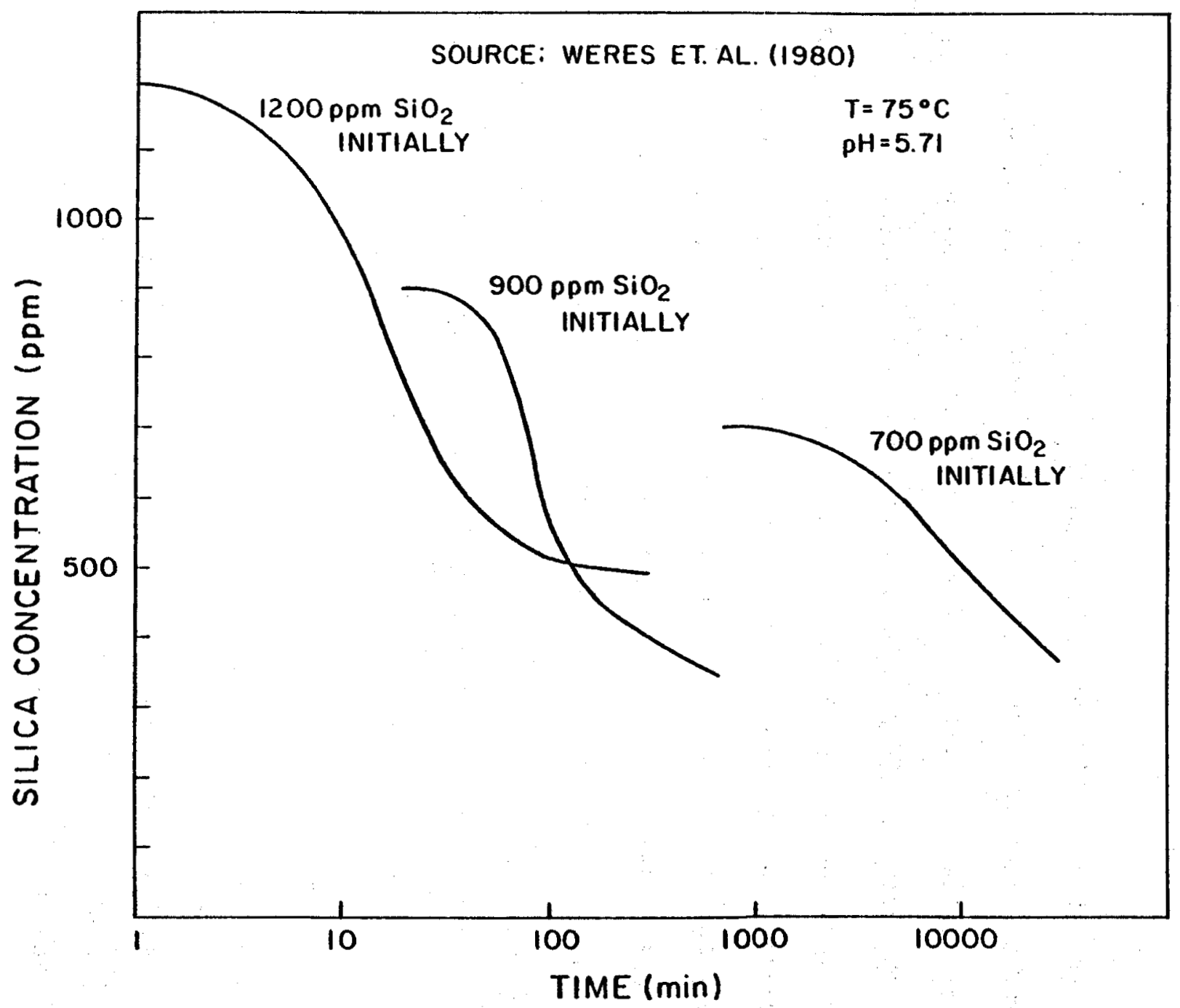

Figure 37. Predicted Monomeric Dissolved Silica Concentration vs. Time Based on Calculated Polymerization Rates 
known precisely, but it should be fairly close to $0.069 \mathrm{~N}(1578 \mathrm{ppm})$, in which case $\mathrm{pH}_{\text {nom }}=\mathrm{pH}$. It follows from Weres, et al. that $\mathrm{F}\left(\mathrm{pH}, \mathrm{pH}_{\text {nom }}\right)=$ 2.11 , so using Equation (I-2),

$$
\begin{aligned}
& \log t=-1-\log (2.11)+1412\left(\frac{47.47}{323.15}\right)^{3}(\ln 3.31)^{-2}-3.12 \\
& \log t=-1.32 .
\end{aligned}
$$

Thus, the concentration versus time curve of Weres et al. should be shifted 1.32 orders of magnitude to the left. This result is not surprising, since curves such as those in Figure 37 were obtained from experiments at a lower $\mathrm{pH}$ (5.71 in this case). In fact, Section 5.2 showed that in this $\mathrm{pH}$ range, polymerization rates should increase by a factor of 10 for each unit increase in pH. This calculation agrees al most exactly with that finding, indicating that $\mathrm{pH}$ is the important parameter for this system, while corrections for salt concentration are negligible. Figure 33 represents silica concentration versus time for the Phase II system using 600 and 700 ppm dissol ved silica.

To calculate the well bore residence time, the following parameters will be used:

$$
\begin{aligned}
& D=0.219 \mathrm{~m} \\
& L=4572 \mathrm{~m} \\
& Q=0.03154 \mathrm{~m}^{3} / \mathrm{sec} .
\end{aligned}
$$

Thus,

$$
\begin{aligned}
& V=(\pi / 4)(0.219)^{2}(4572)=172.2 \mathrm{~m}^{3} \\
& \tau_{w}=\text { wel 1 bore residence time }=\frac{172.2}{.03154}=5460 \mathrm{sec}=91 \mathrm{~min} .
\end{aligned}
$$

This value is used in the discussion of the possibility of homogeneous nucleation in the injection wellbore of the Phase II system (Section 5.6). 


\section{Appendix J}

Calculation of the Mass Transfer Coefficient in the

\section{Rock Reactor}

In a fixed bed reactor, the possibility of mass transfer limitations. exists. Mass transfer could possibly mask the true kinetic data. To calculate the mass transfer coefficient in a packed bed, the following relations can be used (Bird et al., 1960):

$$
\begin{aligned}
& j_{H}=j_{D}=0.91 \operatorname{Re}^{-0.51} \quad(\operatorname{Re}<50), \\
& j_{H}=j_{D}=0.61 \operatorname{Re}^{-0.41} \quad(\operatorname{Re}>50) .
\end{aligned}
$$

The Chilton-Colburn analogy equating the molecular mechanisms of heat and mass transfer has been employed. The mass transfer coefficient $k_{m}$ is found from Equation (J-1) or (J-2) using

$$
j_{D}=\frac{k_{m} \rho_{f} M_{s} S c^{2 / 3}}{G_{0}}-
$$

where

$\rho_{\mathrm{f}}=$ density of water $\left(\mathrm{kg} / \mathrm{m}^{3}\right)$

$M_{s}=$ mol ecular weight of $\mathrm{Si}(\mathrm{OH})_{4}=100 \mathrm{~g} / \mathrm{mol}$

$G_{0}=$ superficial mass velocity $\left(\mathrm{kg} / \mathrm{m}^{2}-\mathrm{sec}\right)$.

Iregui et al. (1978) describe a method to calculate an effective particle radius for a distribution of particles of various sizes and shapes. The result is

$$
R_{e}=\frac{\sum-P_{k}\left(R_{k}\right) R_{k}^{3}-}{\sum P_{k}\left(R_{k}\right) R_{k}^{2} / \Psi_{k}}
$$

where

$P_{k}=\%$ of particles in a given size range

$R_{k}=$ equivalent sphere radius

$\Psi_{k}=$ shape correction factor (assumed to be unity for this calculation). 
The summations are performed over the number of different size fractions assumed. A prel iminary run performed in this reactor system used the following size distribution:

\begin{tabular}{c|c} 
Wt \% & $R(\mathrm{~m})$ \\
\hline 11 & $4.53 \times 10^{-3}$ \\
21 & $3.62 \times 10^{-3}$ \\
68 & $1.35 \times 10^{-3}$
\end{tabular}

Using Equation $(J-4), R_{e}=1.70 \times 10^{-3} \mathrm{~m}$. Typical reactor conditions are:

$\mathrm{T}=200^{\circ} \mathrm{C}$ (used to obtain water properties)

$G_{0}=2.363 \mathrm{~kg} / \mathrm{m}^{2}-\sec (2.51 / \mathrm{min}$ in this reactor)

$\varepsilon_{v}=$ void fraction $=0.408$ (determined experimentally for this size

distribution)

$a=$ ratio of rock surface area to bed volume $=3\left(1-\varepsilon_{v}\right) / R_{e}=2651 \mathrm{~m}^{-1}$. Thus,

$$
\operatorname{Re}=\frac{G_{0}}{a_{\mu}}=\frac{2.363}{(2651)\left(1.387 \times 10^{-4}\right)}=6.426<50 .
$$

Equation $(\mathrm{J}-1)$ is used to obtain $j_{D}$ :

$$
j_{D}=0.91(6.426)^{-0.51}=0.3542 \text {. }
$$

All quantities in Equation (J-3) are easily obtained except the diffusivity of $\mathrm{Si}(\mathrm{OH})_{4}$ in water, which is contained in SC. Jander and Jahr (1934) reported a value of $6.15 \times 10^{-10} \mathrm{~m} / \mathrm{sec}$ at $20^{\circ} \mathrm{C}$. The Wilke-Chang correlation (Treybal, 1968) for estimating liquid diffusivities shows that $D_{A B}$ is proportional to temperature to the first power and liquid viscosity to the -1 power. Using this fact to correct Jander and Jahr's value for temperature:

$$
\begin{aligned}
& D_{A B}\left(200^{\circ} \mathrm{C}\right)=\frac{473}{293} \stackrel{\mu(293 \mathrm{~K})}{\mu(473 \mathrm{~K})} \mathrm{D}_{A B}\left(20^{\circ} \mathrm{C}\right) \\
& D_{A B}\left(200^{\circ} \mathrm{C}\right)=\frac{(473)\left(1.007 \times 10^{-3}\right)\left(6.15 \times 10^{-10}\right)}{(293)\left(1.387 \times 10^{-4}\right)} \\
& D_{A B}\left(200^{\circ} \mathrm{C}\right)=7.205 \times 10^{-9} \mathrm{~m}^{2} / \mathrm{sec} .
\end{aligned}
$$

All parameters in Equation $(\mathrm{J}-3)$ are now known, so $k_{m}$ may be calculated: 


$$
k_{m}=2.19 \times 10^{-5} \mathrm{~m} / \mathrm{sec}>k\left(200^{\circ} \mathrm{C}\right)=6.39 \times 10^{-9} \mathrm{~m} / \mathrm{sec} .
$$

Thus, for these conditions $\left(2.51 / \mathrm{min}, 200^{\circ} \mathrm{C}\right)$, the reaction rate will be kinetically controlled. For different flow rates and temperatures, $k_{m}$ was calculated and plotted alongside the rate constant $k$ for quartz dissolution in Figure 38. The graph shows that mass transfer limitations in this system should be negligible even at $300^{\circ} \mathrm{C}$ and the slowest flow rates. 


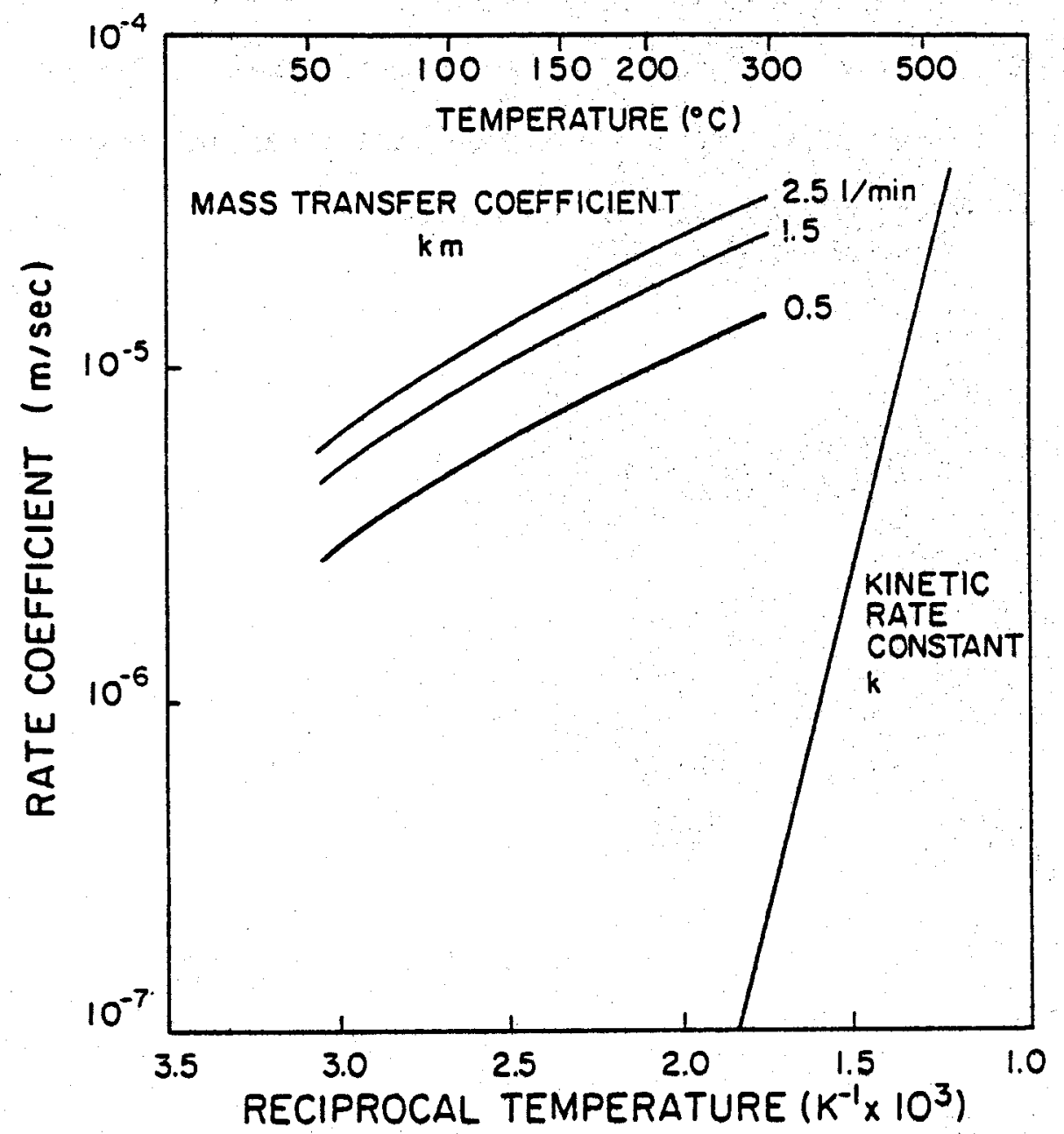

Figure 38. Comparison of the Calculated Mass Transfer Coefficient to the Experimentally Determined Rate Constant in the Titanium Loop Packed Bed Rock Reactor for Different Volumetric Flow Rates 


\section{Acknowledgements}

I would like to thank Jefferson Tester for his invaluable guidance and support during the research and writing of this thesis. I also owe a debt of graditude to Charles Grigsby, who provided many useful coments and suggestions throughout the course of this work. Able technical assistance was provided by Ron Aguilar. Finally, the experimental work published in this thesis would have been impossible without the financial support of the ESS-4 group of LoS Alamos National Laboratory. 
Al exander, G.B., Heston, W.M., and Iler, R.K., "The Solubil ity of Amorphous Silica In Water," J. Phys. Chem., 58 (1954).

Arnorsson, S., "Mineral Deposition From Icel andic Geothermal Waters: Environmental and Utilization Problems," J. Petrol. Tech., 33 (1981).

Arpaci, V.S., Conduction Heat Transfer, Addison-Wesley (1966).

Beyer, W.H. (ed.), CRC Standard Mathematical Tables, CRC Press (1976).

Bird, R.B., Stewart, W.E., and Lightfoot, E.N., Transport Phenomena, John Wiley and Sons (1960).

Bohlmann, E.G., Shor, A.J., Berlinski, P., and Mesmer, R.E., "Silica Scal ing in Simulated Geothermal Brines," Oak Ridge National Laboratory Report Number TM-7681 (1981).

Blatz, L.A., Holley, C.E., Grigsby, C.O., and Tester, J.W., Los Al amos Scientific Laboratory Unpubl ished Memorandum (1977).

Charles, R.W., "Experimental Geothermal Loop: I, $295^{\circ} \mathrm{C}$ Study," Los Al amos Sctentific Laboratory Report LA-7334-MS (1978).

Charles, R.W., "Experimental Geothermal Loop: II, $200^{\circ} \mathrm{C}$ Study," Los Al amos Scientific Laboratory Report LA-7735-MS (1979).

Charles, R.W., Holley, C.E., Tester, J.W., Bl atz, L.A., and Grigsby, C.0., "Experimentally Determined Rock-Fluid Interactions Appl icable To A Natural Hot Dry Rock Geothermal System," TMS Paper Sel ection Report A80-8, The Metallurgical Society of AIME, Warrendale, Pa. (1979).

Crerar, D.A., and Anderson, G.M., "Solubility and Solution Reactions of Quartz in Dilute Hydrothermal Solutions," Chem. Geol., 8 (1971). 
Cuellar, G., "Behavior of Silica in Geothermal Waste Waters," $2^{\text {nd }}$ U.N. Symposium on the Development and Use of Geothermal Resources, San

Francisco, Ca. (1975).

Cummings, R.G., Morris, G.E., Tester, J.W., and Bivens, R.L., "Mining Earth's Heat: Hot Dry Rock Geothermal Energy, "Tech. Rev., 81 (1979).

Dash, Z.V., Murphy, H.D., and Cremer, G.M. (eds.), "Hot Dry Rock Geothermal Testing: 1978 to 1980," Los Al amos National Laboratory Report LA-9080-SR (1981).

Demuth, R.B., and Harlow, F.H., "Geothermal Energy Enhancement By Thermal Fracture," Los Al amos Scientific Laboratory Report LA-8428 (1980).

Fournier, R.0., and Rowe, J.J., "Estimation of Underground Temperature From the Silica Content of Water From Hot Springs and Wet-Steam Wells," Am. J. Sci., 264 (1966).

Fritz, J.S., and Schenk, G.H., Quantitative Analytical Chemistry, Allyn and Bacon, Inc. (1974).

Grigsby, C.0., M.1.T., Personal Communication (1981).

Gudmundsson, J.S., and Bott, T.R., "Deposition of Silica From Geothermal Waters on Heat Transfer Surfaces," Desalination, 28 (1979).

Harriott, P., "Mass Transfer to Particles: Part 1. Suspended in Agitated Tanks," AIChE J., 8 (1962).

Holley, C.E., Los Alamos National Laboratory, Personal Communication (Jan. 1981).

Holley, C.E., Los Alamos National Laboratory, Personal Communication (Sept. 1981).

Iler, R.K., The Colloid Chemistry of Silica and the Silicates, Cornell University Press (1955). 
Iler, R.K., The Chemistry of Silica, John Wiley and Sons (1979).

Iregui, R., Hunsbedt, A., Kruger, P., and London, A.L., "Analys is of Heat Transfer and Energy Recovery in Fractured Geothermal Reservoirs," NSF Report Number SGP-TR-31, Stanford Geothermal Program (1978).

Jander, G., and Jahr, K.F. "Neuere Anschauungen uber die Hydrolyse anorganischer Salze und die Chemie der hochmol ekul aren Hydrolyseprodukte (einschl ie lich der Iso- und Heteropolyverbindungen);" Kolloid-Beihefte, 41 (1934).

Kennedy, G.C., "A Portion of the System Silica-Water," Econ. Geol., 45 (1950).

Kitahara, S., "The Solubility Equilibrium and the Rate of Solution of Quartz in Water at High Temperatures and High Pressures," Rev. Phys. Chem. Japan, 30 (1960).

Laughl in, A.W., and Eddy, A., "Petrography and Geochemistry of Precambrian Rocks From GT-2 and EE-1," Los Al amos Scientific Laboratory Report LA-6930-MS, (1977).

Levich, V.G., Phystcochemical Hydrodynamics, Prentice-Hall, (1962).

Mackenzie, F.T., and Gees, R., "Quartz: Synthesis at Earth-Surface Conditions," Science, 173 (1971).

Makrides, A.C., Turner, M.J., Harvey, W.W., Slaughter, J., Brummer, S.B., Offenhartz, P.O'D., and Pearson, G.F., "Study of Silica Scaling From Geothermal Brines," U.S. Dept, of Energy, Report Number C00-2607-5 (1978).

Marsh, A.R., Klein, G., and Vermeulen, T., "Polymerization Kinetics and Equilibria of Silicic Acid in Aqueous Systems, "Lawerence Berkeley Laboratory Report Number LBL-4415 (1975). 
Model1, M., and Reid, R.C., Thermodynamics and Its Applications, Prentice-Hall (1974).

Morey, G.W., Fournier, R.O., and Rowe, J.J., "The Solubility of Quartz in Water in the Temperature Interval From $25^{\circ} \mathrm{C}$ to $300^{\circ} \mathrm{C}$, "Geochim. et Cosmochim. Acta, 26 (1962).

Mull in, J.B, and Riley, J.P., "Colorimetric Determination of Silicate With Special Reference to Sea and Natural Waters," Anal. Chim. Acta, 12 (1955).

Murphy, H.D. (ed.), "Prel iminary Evaluation of the Second Hot Dry Rock Geothermal Energy Reservoir: Results of Phase I, Run Segment 4," Los Al amos Scientific Laboratory Report LA-8354-MS (1980).

Murphy, H.D., Tester, J.W., Grigsby, C.O., and Potter, R.M., "Energy Extraction From Fractured Geothermal Reservoirs in Low-Permeability Crystall ine Rock," J. Geophys. Res., 86 (1981).

Rimstidt, J.D., "Kinetics of Silica-Water Reactions," PhD Thesis, The Pennsyl vania State University Department of Geosciences (1979).

Rothbaum, H.P., and Anderton, B.H., "Removal of Silica and Arsenic from Geothermal Discharge Waters by Precipitation of Useful Calcium Silicates," $2^{\text {nd }}$ U.N. Symposium on the Devel opment and Use of Geothermal Resources, San Francisco, Ca. (1975).

Sherwood, T.K., Pigford, R.L., and Wiike, C.R., Mass Transfer, McGraw-Hill (1975).

Siebert, H., Youdel is, W.V., Leja, J., and Lilge, E.O., "The Kinetics of the Dissolution of Crystalline Quartz in Water at High Temperatures and High Pressures," Unit Processes in Hydrometallurgy, The Metallurgical Society of A.I.M.E. Conference, 24 (1963).

Siever, R., "Silica Solubility $0^{\circ}-200^{\circ} \mathrm{C}$ and the Diagenesis of Siliceous Sediments," J. Geol., 70 (1962). 138 
Smith, M.C., Aamodt, R.L., Potter, R.M., and Brown, D.W., "Man-Made Geothermal Reservoirs," $2^{\text {nd }} U . N$. Symposium on the Devel opment and Use of Geothermal Resources, San Francisco, California (1975).

Stober, W., "Formation of Silicic Acid in Aqueous Suspensions of Different Silica Modifications," Equil ibrium Concepts in Natural Water Systems, American Chemical Society, 67 (1967).

Tester, J.W., and Albright, J.N. (eds.), "Hot Dry Rock Energy Extraction Field Test: 75 Days of Operation of a Prototype Reservoir at Fenton Hi11," Los Al amos Scientific Laboratory Report LA-7771-MS (1979).

Treybal, R.E., Mass-Transfer Operations, McGraw-Hill (1968).

Van Lier, J.A., de Bruyn, P.L., and Overbeek, J.Th.G., "The Solubil ity of Quartz," J. Phys. Chem., 64 (1960).

Voloson, A.G., Khodakovskiy, I.G., and Ryzhenko, B.N., "Equilibria in the System $\mathrm{SiO}_{2}-\mathrm{H}_{2} \mathrm{O}$ at Elevated Temperatures Along the Lower Three-Phase Curve," Geochim. Int., 9 (1972).

Weill, D.F., and Fyfe, W.S., "The Solubility of Quartz in $\mathrm{H}_{2} \mathrm{O}$ in the Range 1000-4000 Bars and $400-550^{\circ} \mathrm{C}, "$ Geochim. et Cosmochim. Acta, 28 (1960).

Weres, 0., Yee, A., and Tsao, L., "Kinetics of Silica Polymerization," Lawerence Berkeley Laboratory Report Number LBL-7033 (1980).

White, D.E., Brannock, W.W., and Murata, K.J., "Silica in Hot-Spring Waters," Geochim. et Cosmochim. Acta, 10 (1956).

Yanagase, T., Suginohara, $Y_{.}$, and Yanagase, $K_{.}$, "The Properties of Scales and Methods to Prevent Them," Geothermics, (1970).

Zwietering, Th.N., "Suspending of Solid Particles in Liquid by Agitators," Chem. Eng. Sci., 8 (1958). 